Argonne

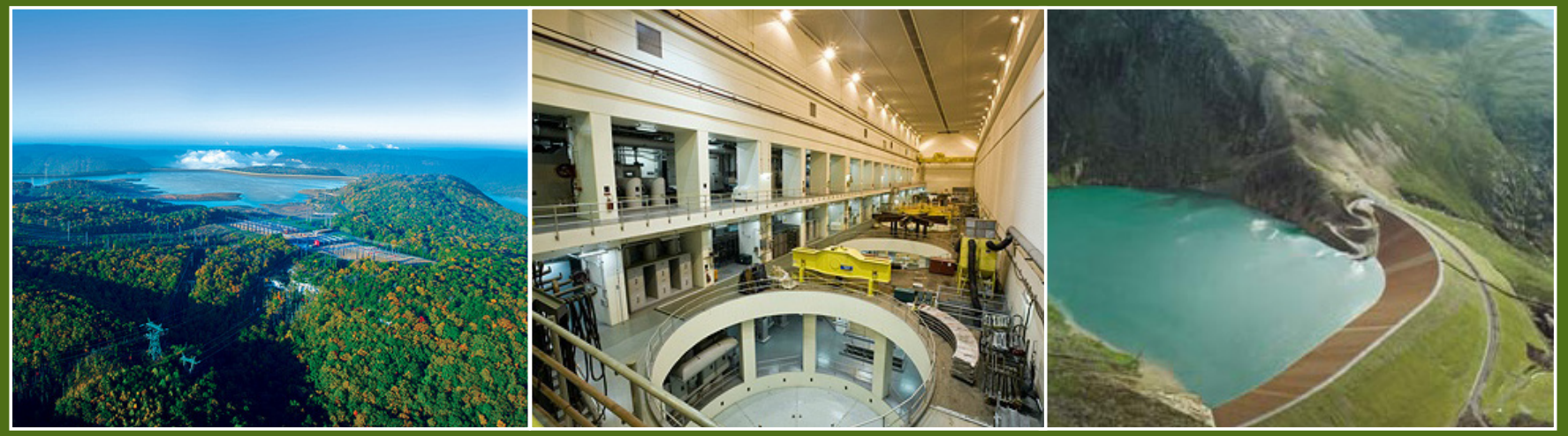

\title{
Review of Existing Hydroelectric Turbine-Governor Simulation Models
}

Decision and Information Sciences 


\begin{abstract}
About Argonne National Laboratory
Argonne is a U.S. Department of Energy laboratory managed by UChicago Argonne, LLC under contract DE-AC02-06CH11357. The Laboratory's main facility is outside Chicago, at 9700 South Cass Avenue, Argonne, Illinois 60439. For information about Argonne and its pioneering science and technology programs, see www.anl.gov.
\end{abstract}

\title{
Availability of This Report
}

This report is available, at no cost, at http://www.osti.gov/bridge. It is also available on paper to the U.S. Department of Energy and its contractors, for a processing fee, from:

U.S. Department of Energy

Office of Scientific and Technical Information

P.O. Box 62

Oak Ridge, TN 37831-0062

phone (865) 576-8401

fax (865) 576-5728

reports@adonis.osti.gov

\section{Disclaimer}

This report was prepared as an account of work sponsored by an agency of the United States Government. Neither the United States Government nor any agency thereof, nor UChicago Argonne, LLC, nor any of their employees or officers, makes any warranty, express or implied, or assumes any legal liability or responsibility for the accuracy, completeness, or usefulness of any information, apparatus, product, or process disclosed, or represents that its use would not infringe privately owned rights. Reference herein to any specific commercial product, process, or service by trade name, trademark, manufacturer, or otherwise, does not necessarily constitute or imply its endorsement, recommendation, or favoring by the United States Government or any agency thereof. The views and opinions of document authors expressed herein do not necessarily state or reflect those of the United States Government or any agency thereof, Argonne National Laboratory, or UChicago Argonne, LLC.

This report is being disseminated by the Department of Energy. As such, this document was prepared in compliance with Section 515 of the Treasury and General Government Appropriations Act for Fiscal Year 2001 (Public Law 106-554) and Information Quality Guidelines issued by the Department of Energy. Although this report does not constitute "influential" information, as that term is defined in DOE's Information Quality Guidelines or the Office of Management and Budget's Information Quality Bulletin for Peer Review, the study was reviewed both internally and externally prior to publication. For purposes of external review, the study benefited from the advice and comments of an advisory working group consisting of more than 30 experts from the industry, government, and research institutions. 


\section{Review of Existing Hydroelectric Turbine-Governor Simulation Models}

prepared for

U.S. Department of Energy - Wind and Water Power Technologies Office

prepared by

Vladimir Koritarov and Leah Guzowski

Decision and Information Sciences, Argonne National Laboratory

James Feltes, Yuriy Kazachkov, Baldwin Lam, Carlos Grande-Moran,

Gary Thomann and Larry Eng

Siemens PTI

Bruno Trouille and Peter Donalek

MWH Americas

August 2013 
This page intentionally left blank. 


\section{Preface}

This report is one of several reports developed during the U.S. Department of Energy (DOE) study on the Modeling and Analysis of Value of Advanced Pumped Storage Hydropower in the United States. The study was led by Argonne National Laboratory in collaboration with Siemens PTI, Energy Exemplar, MWH Americas, and the National Renewable Energy Laboratory. Funding for the study was provided by DOE's Office of Energy Efficiency and Renewable Energy (EERE) through a program managed by the EERE's Wind and Water Power Technologies Office (WWPTO).

The scope of work for the study has two main components: (1) development of vendorneutral dynamic simulation models for advanced pumped storage hydro (PSH) technologies, and (2) production cost and revenue analyses to assess the value of PSH in the power system. Throughout the study, the project team was supported and guided by an Advisory Working Group (AWG) consisting of more than 30 experts from a diverse group of organizations including the hydropower industry and equipment manufacturers, electric power utilities and regional electricity market operators, hydro engineering and consulting companies, national laboratories, universities and research institutions, hydropower industry associations, and government and regulatory agencies.

The development of vendor-neutral models was carried out by the Advanced Technology Modeling Task Force Group (TFG) and was led by experts from Siemens PTI with the participation of experts from other project team members. First, the Advanced Technology Modeling TFG reviewed and prepared a summary of the existing dynamic models of hydro and PSH plants that are currently in use in the United States. This is published in the report Review of Existing Hydroelectric Turbine-Governor Simulation Models. The review served to determine the needs for improvements of existing models and for the development of new ones.

While it was found that the existing dynamic models for conventional hydro and PSH plants allow for accurate representation and modeling of these technologies, it was concluded that there is a need for the development of dynamic models for two PSH technologies for which there were no existing models available in the United States at the time of the study. Those two technologies are (1) adjustable speed PSH plants employing doubly-fed induction machines (DFIM), and (2) ternary PSH units. The Advanced Technology Modeling TFG developed vendor-neutral models of these two PSH technologies, which are published in two reports: (1) Modeling Adjustable Speed Pumped Storage Hydro Units Employing Doubly-Fed Induction Machines, and (2) Modeling Ternary Pumped Storage Units.

Extensive testing of newly developed models was performed using the Siemens PTI's standard test cases for the Power System Simulator for Engineering (PSS ${ }^{\circledR} E$ ) model as well as the Western Electricity Coordinating Council's (WECC's) modeling cases for Western Interconnection that were provided in $\mathrm{PSS}^{\circledR} \mathrm{E}$ format. The results of model 
testing are presented in the report Testing Dynamic Simulation Models for Different Types of Advanced Pumped Storage Hydro Units.

In addition to review by the project team members and the DOE, all these reports have been reviewed by members of the AWG, and their comments and suggestions have been incorporated into the final versions of the reports. Parts of these reports will also be included in the final report for the entire study to illustrate the model development component of the work. 


\section{Acknowledgements}

The authors would like to acknowledge the support and guidance provided to the project team by the staff and contractors of the DOE/EERE's Wind and Water Power Technologies Office (WWPTO), including Michael Reed, Rajesh Dham, Charlton Clark, Rob Hovsapian, Patrick O'Connor, Richard Gilker, and others. The authors are also grateful to the members of the Advisory Working Group for their excellent collaboration and efforts in advising the project team and guiding the study. The Advisory Working Group included a broad spectrum of global pumped storage hydropower specialists including:

\begin{tabular}{|c|c|}
\hline $\begin{array}{l}\text { Rajesh Dham, Charlton Clark, Rob } \\
\text { Hovsapian, Patrick O'Connor, } \\
\text { Richard Gilker }\end{array}$ & $\begin{array}{l}\text { DOE/EERE - Wind and Water Power Technologies } \\
\text { Office (WWPTO) }\end{array}$ \\
\hline Rachna Handa & $\begin{array}{l}\text { DOE - Office of Electricity Delivery and Energy } \\
\text { Reliability (OE) }\end{array}$ \\
\hline Rahim Amerkhail & Federal Energy Regulatory Commission (FERC) \\
\hline Michael Manwaring, Douglas Divine & National Hydropower Association (NHA) \\
\hline Mark Jones, Elliot Mainzer & Bonneville Power Administration (BPA) \\
\hline Xiaobo Wang & California Independent System Operator (CAISO) \\
\hline Zheng Zhou & Midwest Independent System Operator (MISO) \\
\hline Matt Hunsaker & Western Electricity Coordinating Council (WECC) \\
\hline Tuan Bui & California Department of Water Resources (CDWR) \\
\hline David Harpman & Bureau of Reclamation (Reclamation) \\
\hline Kyle L. Jones & U.S. Army Corps of Engineers (USACE) \\
\hline Scott Flake, Greg Brownell & Sacramento Municipal Utility District (SMUD) \\
\hline Paul Jacobson, Stan Rosinski & Electric Power Research Institute (EPRI) \\
\hline Alan Soneda & Pacific Gas and Electric Co. (PG\&E) \\
\hline Osamu Nagura & Hitachi Mitsubishi Hydro \\
\hline Teruyuki Ishizuki & Toshiba Corp. \\
\hline Rick Miller. Rick Jones & HDR Engineering Inc. (HDR|DTA) \\
\hline Jiri Koutnik, Maximilian Manderla & Voith Hydro \\
\hline Christophe Nicolet & Power Vision Engineering (PVE) \\
\hline Peter McLaren & Center for Advanced Power System (CAPS) \\
\hline Landis Kannberg & Pacific Northwest National Laboratory (PNNL) \\
\hline Klaus Engels & E.ON Wasserkraft GmbH \\
\hline Kim Johnson & Riverbank Power \\
\hline Steve Aubert, Le Tang & ABB Switzerland Ltd. \\
\hline Ali Nourai & DNV KEMA \\
\hline
\end{tabular}


This page intentionally left blank. 


\section{Contents}

Preface

Acknowledgements

iii

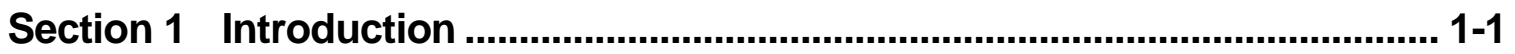

Section 2 Power System Dynamic Overview .................................................. 2-1

2.1 Interaction between Main Elements of Power Systems and their

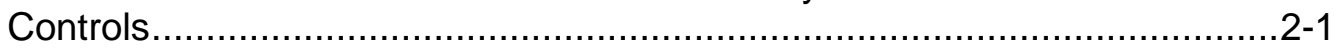

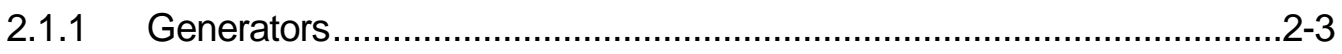

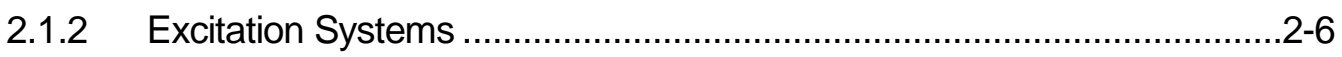

2.1.3 Governor and Prime Mover Controls...................................................2-8

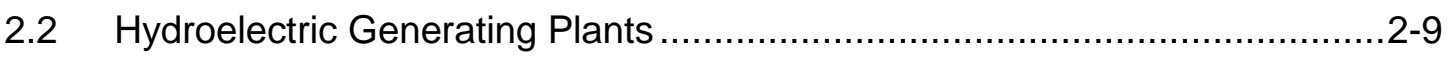

Section 3 Hydro Turbine-Governor ……..................................................... 3-1

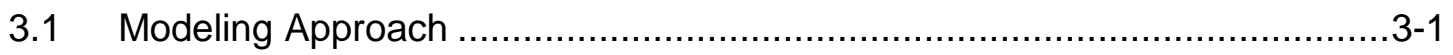

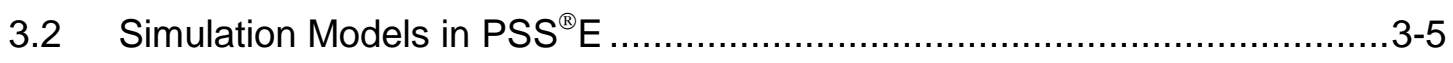

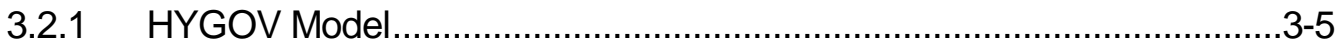

3.2.2 HYGOV2 Model........................................................................

3.2.3 HYGOVM Model.......................................................................

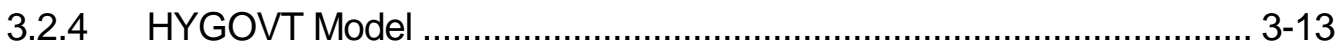

3.2.5 IEEEG2 Model........................................................................ 3-16

3.2.6 IEEEG3 Model....................................................................... 3-17

3.2.7 PIDGOV Model..................................................................... 3-18

3.2.8 TURCZT Model ..................................................................... 3-20

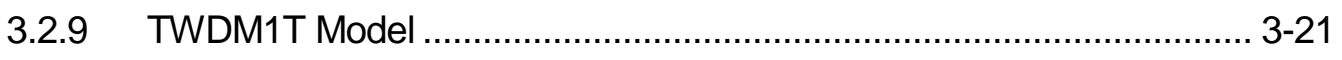

3.2.10 TWDM2T Model ........................................................................ 3-23

3.2.11 WEHGOV Model ....................................................................... 3-25

3.2.12 WPIDHY Model ..................................................................... 3-27

3.2.13 WSHYDD Model..................................................................... 3-28

3.2.14 WSHYPG Model..................................................................... 3-30

3.3 An Example of the Prevalence of the Hydro Models in a Large U.S.

Simulation Database Using the PSS ${ }^{\circledR}$ E Software .....................................3-32

Section 4 PSLF Hydro Turbine-Governor Simulation Models ......................... 4-1 
4.1 Simulation Models in PSLF Version 18 ......................................................4-1

4.1.1 GPWSCC Model .................................................................... 4

4.1.2 G2WSCC Model.......................................................................4-4

4.1.3 HYG3 Model .......................................................................... $4-6$

4.1.4 HYGOV Model...........................................................................4-8

4.1.5 HYGOV4 Model....................................................................... 4-10

4.1.6 HYGOVR Model ......................................................................... 4-12

4.1.7 IEEEG3 Model............................................................................ 44

4.1.8 PIDGOV Model........................................................................ 4-16

4.1.9 HYPID Model........................................................................ 4-18

4.1.10 HYST1 Model ........................................................................ 4-20

4.1.11 W2301 Model .......................................................................... 4-22

4.1.12 HYGOV8 Model....................................................................... 4-24

4.2 An Example of the Prevalence of the Hydro Models in a WECC

Region Database Using the PSLF Software ...................................... 4-29

Section 5 Modeling of Conventional Pumped Storage Hydro Plants............. 5-1

Section 6 Bibliography ........................................... 6-Error! Bookmark not defined. 


\section{Section \\ 1}

\section{Introduction}

This report is the first in a series of documents to be issued in the course of a DOE project titled "Modeling and Analysis of Value of Advanced Pumped Storage Hydropower in the U.S."

We are all intimately familiar with small energy storage devices; we use batteries of various types in our cell phones and other electronic devices as well as the more traditional batterypowered devices such as flashlights and radios. However, storing large amounts of energy, on the scale that would be useful for a utility-scale power system, has been a much more challenging task. While several new technologies are being developed, pumped storage hydro is the most widely employed method available for storing large amounts of energy to supply electricity. The basic concept of pumped storage is quite simple: electricity is used to pump water up to an elevated reservoir, where the energy can be stored as potential energy until it is needed; then electricity is generated by letting the water flow back down thorough a turbine/generator. Of course, since there is a loss of energy due to the pumping and generating cycle (as low as 10\% for some new plants), there must be an economic incentive for the storage, such as a variation in electricity prices between times of pumping and generating.

Energy usage is greatly influenced by the normal schedule of people (high during the day when people are most active and low at night) and weather (high when the temperature is very hot or cold and lower when the temperature is moderate), and, of course, many other factors also influence usage. Most electricity is generated at large power stations powered by the combustion of fossil fuels, by the use of nuclear energy, and by hydroelectric plants. There is a growing, but still small in most locations, contribution from wind- and solar-based generation. While the use of electricity varies throughout the day, large generation plants run most efficiently at a constant output. Thus, it would be advantageous to run these large generators during periods of lower electricity usage and store the energy to supply electricity at periods of higher demand. An additional benefit is that these large generating stations are very capital intensive; thus, being able to store and deliver some of the energy needed at times of peak demand reduces the number of large generating stations required to supply the peak period. Therefore, there are savings in both energy costs and the capital costs of the generating stations.

The growth in the amount of energy supplied by renewable generation has increased the need for energy storage. Renewable energy sources generally are not well correlated with electricity usage. Wind energy, for example, tends to be unavailable during periods of high energy usage (e.g., there is little wind during a hot summer day when air conditioning demand is high) and to be high during periods of low electric usage (e.g., winds pick up in the 
evening as electricity demand falls). Energy storage thus allows the renewable energy to be generated when it is available (e.g., when the wind is blowing at night) and stored until it is needed (e.g., during periods of high demand the next day).

A third benefit is regulation. The supply and usage of electricity must be carefully balanced to maintain a frequency of $60 \mathrm{~Hz}$ and voltage within a narrow range. The mechanisms for this regulation are explained briefly in this report and in more detail in other reports from this project. Here we simply state that the advanced pump storage technologies that are the focus of this project have significant advantages over conventional pumped storage due to their fast controllability in both generating and pumping modes.

The benefits just described were recognized early in the development of the electric power grids, especially as systems became larger and more interconnected. The first pumped storage plant in the United States was the Rocky River Pumped Storage Station located near Milton, Connecticut, which started operation in 1929. The use of reversible pump-turbines in pumped storage plants began in the 1950s in the United States. While the design and engineering of more recent plants in the United States have improved efficiency and reduced environmental impacts, the basic design of the modern pumped storage plants in the United States is similar to that used in those earlier plants.

The objective of this overall effort is to investigate the advantages of recent advances in the design of pumped storage hydro plants. The objective of the first task of this project, "Develop Prototype Models of Advanced Pumped Storage Hydro (PSH) and Conventional Hydro $(\mathrm{CH})$ Plants," is to develop vendor-neutral dynamic simulation models for both fixed- and adjustable-speed PSH plants.

These models are a critical component of the analysis needed to plan, design, and operate the power system. Power system studies that use such models are performed to:

- Determine operating strategies and power transfer limits

- $\quad$ Study the impact of new generator additions

- Determine the need for new transmission lines and substations

- Investigate the stability of the system following large disturbances (transient stability) or incremental impacts (small signal stability)

- Analyze the control of frequency and/or system voltages

Thus it is very important that the models used in the above analysis be accurate. If the models are overly optimistic, the system could be operated in a manner that leads to severe consequences, including widespread disturbances or blackouts. On the other hand, if the models are overly conservative, the system could be operated uneconomically, or unnecessary system additions could be built. 
It is logical to start this work with a review of the status of hydro unit modeling in the commercially available software packages used by utilities and system operators in the planning and operation of the U.S. power grid. The two software packages that dominate this market are Siemens PTI's PSS ${ }^{\circledR} E$ and GE's PSLF programs; nearly all major U.S. utilities and system operators use one of these two programs. This report summarizes the turbinegovernor models for hydroelectric units present in these two software packages.

To put this modeling in perspective, this report begins with a general overview of the approach to power system stability studies in Section 1. It includes a brief description of the modeling of generators, excitation systems, and turbine-governors. This overview is followed by a description of the specific models extracted from the standard libraries of both software platforms in Section 2 and Section 3.

The report also includes a discussion on the approach to modeling conventional (fixedspeed) PSH units in Section 4.

Section 5 discusses Modeling of Conventional Pumped Storage Hydro Plants.

Section 6 contains the Bibliography. 
This page intentionally left blank. 


\section{Section}

2

\section{Power System Dynamic Overview}

This section provides a brief overview of the control systems and strategies employed to operate the power system. It also briefly describes the models used to simulate the major equipment in the generating stations. While this section is by necessity brief, there are many excellent references that give further details on these topics.

\subsection{Interaction between Main Elements of Power Systems and their Controls}

A power system is designed to provide adequate capability and transmission capacity to meet system demand and maintain generation reserve. Standards regarding frequency, the voltage profile, and reliability are enforced to meet required system energy quality and performance standards. Numerous power system components and associated controls are involved in maintaining constant frequency, a normal voltage profile, and desired levels of security and reliability.

Figure 2-1 shows the various systems/subsystems, their associated controls, and their functional relationships as found in typical power systems. Controls at the plant and system level are used to ensure not only local but also global regulation of the frequency and voltage or active and reactive power flows throughout the power system.

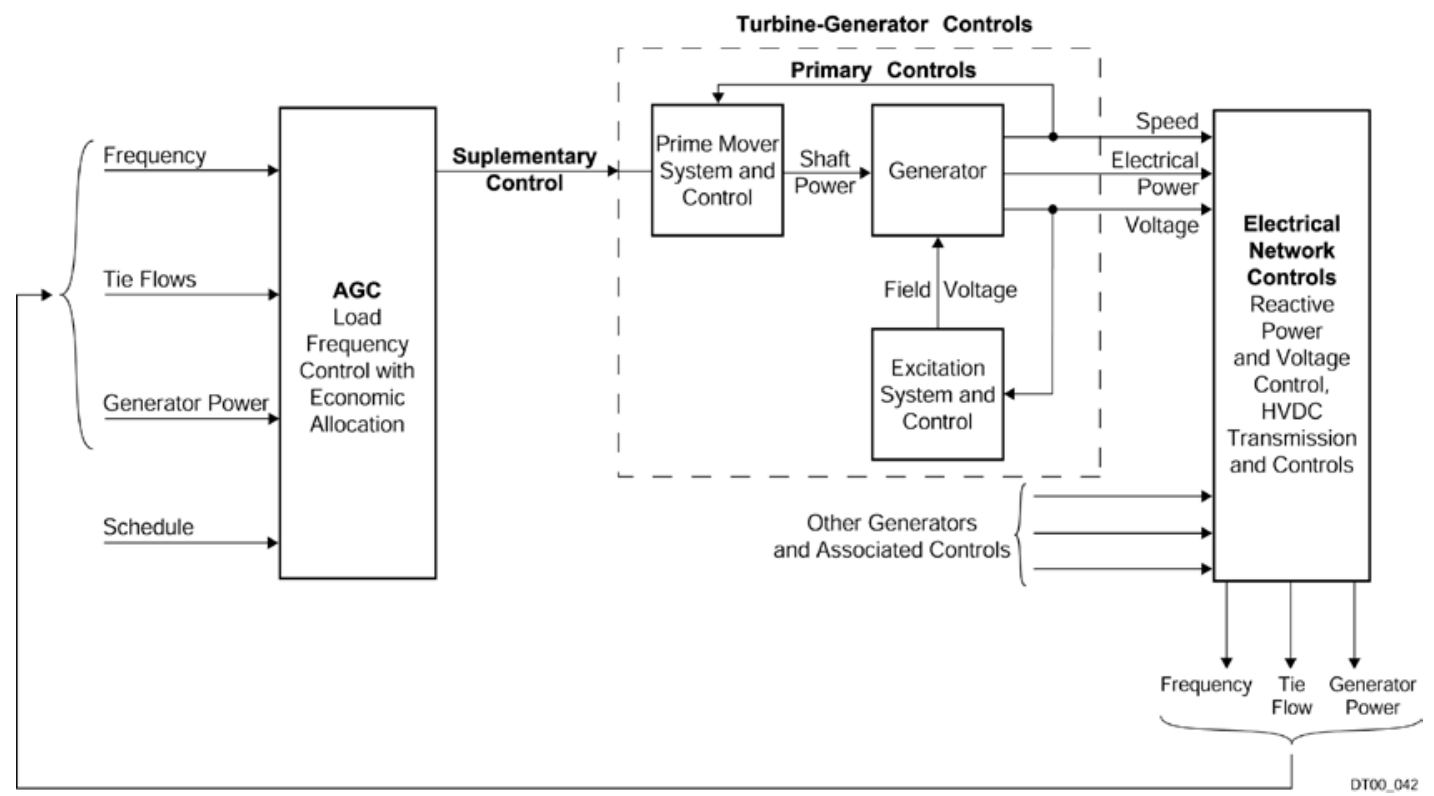

Figure 2-1 Power Plant and Network Primary and Supplementary Power System Controls 
The system load frequency control (LFC) is concerned with scheduling the active power output for generating units under automatic generation control (AGC) so that system frequency and net megawatt (MW) interchange across tie-lines in the interconnected power system are maintained to comply with scheduled values. This is accomplished by matching the total active power generation to the total system MW load and active power losses.

Generator controls are concerned with voltage regulation and reactive power control. The main objective of the excitation system, automatic voltage regulator (AVR), and exciter is to regulate the generator terminal voltage by controlling field voltage. The excitation system may include a load compensator that allows regulation of voltage at a different point, such as inside the generator windings or the windings of the main step-up transformer unit. The voltage regulator provides the regulating and stabilizing function in the excitation system, while the exciter is the power source supplying the direct current (DC) or variable-frequency power used in the generator field windings.

Power plant and network components and their controls contribute to the proper operation of a power system by maintaining a desired frequency and voltage profile and defining the performance of the system during small and large disturbances. The control objectives are closely related to the operating states of the power system. Control objectives under normal (steady-state) conditions are to operate the system efficiently, adequately, and reliably and to keep frequency and voltage within established limits, close to nominal values. When an abnormal operating condition develops, the power system should prevent major system failures and be restored to normal operation as soon as possible.

The primary objective of the power system generation control is to balance the total generation with system demand and losses, so that frequency, active net power interchange across tie-lines, and required voltage support are maintained. Generation controls consist of the prime mover controls (governing system) and the generator controls (excitation systems).

Figure 2-2 is a schematic diagram describing the functional relationships of the synchronous generator, excitation system, and prime mover and their associated controls that are used in assessing small and large signal stability in power systems.

The modeling of each of the pieces of power plant equipment shown in Figure 2-2 is described briefly in the three subsections that follow. 
Individual machine reference frame: $d-q$

Common reference frame: R-I

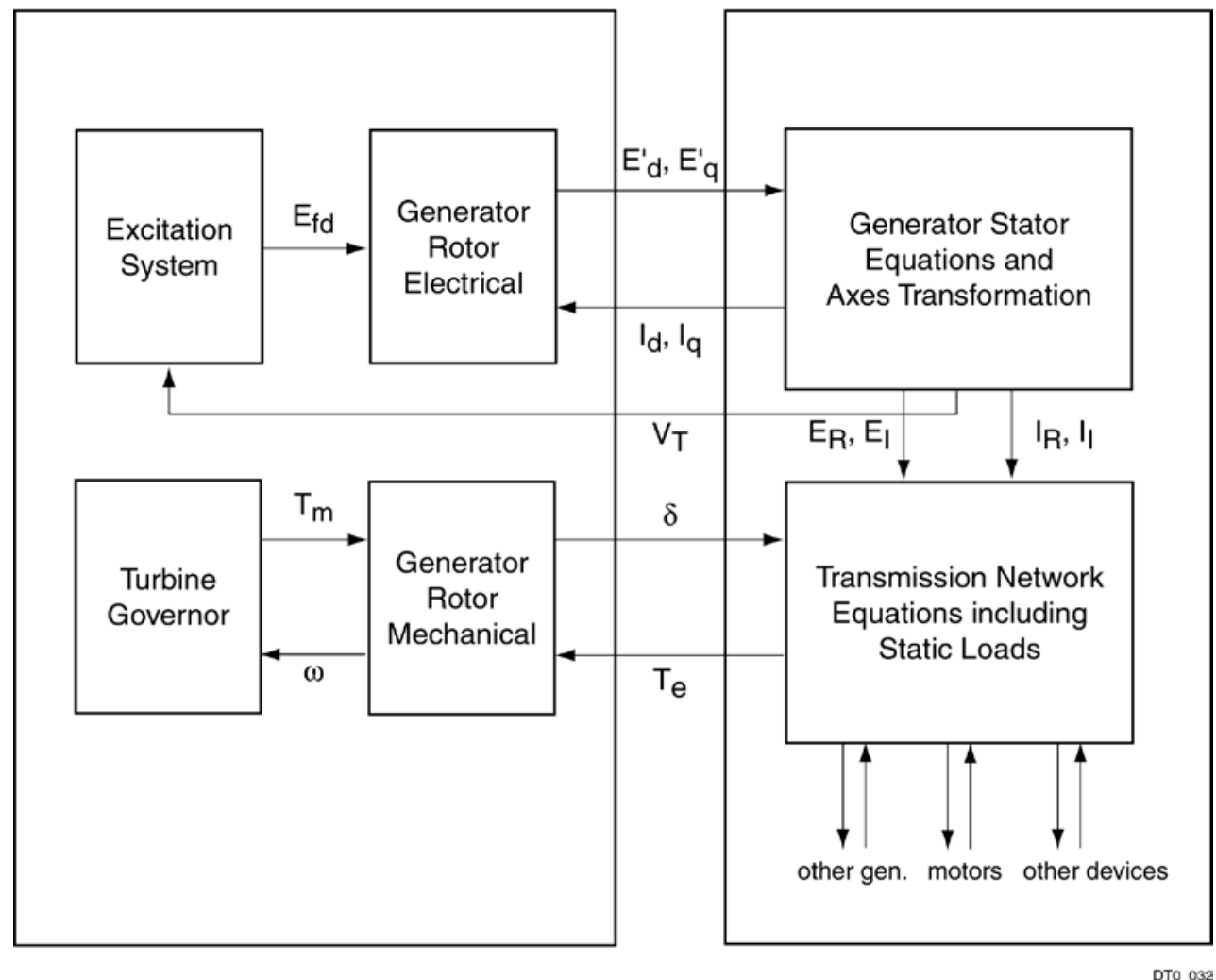

Figure 2-2 Functional Relationships among Generator, Prime Mover, and Associated Controls

\subsubsection{Generators}

Conventional generating units are furnished with synchronous generators driven by either high-speed turbines (gas and steam turbines) or low-speed prime movers (hydraulic and internal combustion engines). High-speed synchronous generators are designed with two or four magnetic poles and cylindrical rotors with a long axial length and small diameter. Lowspeed synchronous generators (those used in hydro and pumped storage plants) are designed with rotors having a large number of salient pole pairs, a short axial length, and a large diameter. Models for synchronous generators used for large and small signal stability studies include both inertial and rotor circuits flux dynamics.

Power system simulation commercial software (PSS ${ }^{\circledR}$ E, PSLF, and others) use a fifth-order dynamic model for salient pole rotor generators, with three state variables related to rotor circuits flux dynamics (field and damper windings) and two-state variables related to the mechanics of rotating motion. For the round rotor (high-speed) generator, the model uses sixstate variables, with four for the electromagnetic dynamics (fluxes linkages and induced voltages associated with the main field winding and damper windings) and two for the rotor mechanical motion (rotor speed and angle). The name given to the most commonly used dynamic model for synchronous generators with a salient rotor design is GENSAL, and that used for round rotor design is GENROU. The magnetic saturation of the stator and rotor iron used with these models is described by a quadratic function (an exponential function is also 
used in other similar models). In addition, the combined inertia of all equipment mounted on the unit shaft system (generator, turbine, and exciter, if it is of the rotating type) is used in these models.

The data sheet for the salient pole generator model GENSAL is shown in Figure 2-3, and the data sheet for the round rotor generator model GENROU is shown in Figure 2-4.

Both models use standard circuit parameters, reactances, and time constants that describe the rotor circuits flux dynamics seen during the subtransient, transient, and steady-state periods following a disturbance of the power system.

GENSAL

Sallent Pole Generator Model (Quadratic Saturation on d-Axds)

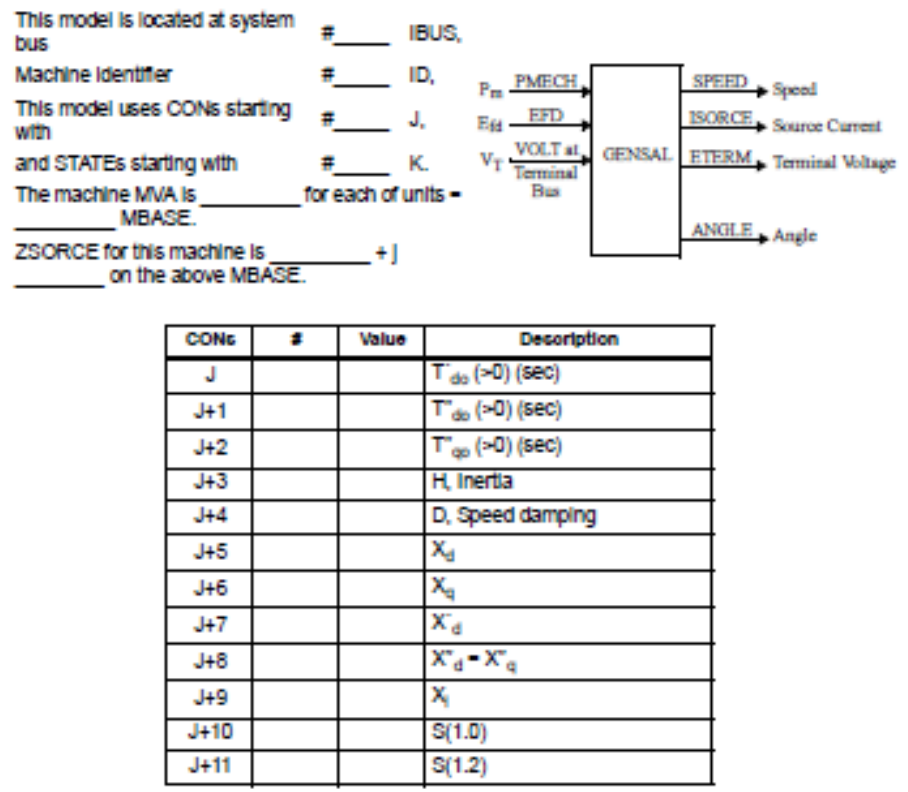

\begin{tabular}{|c|c|l|}
\hline 3TATEc & $\boldsymbol{z}$ & \multicolumn{1}{|c|}{ Decoription } \\
\hline \hline$K$ & & $E_{q}$ \\
\hline$K+1$ & & $\psi^{k} d$ \\
\hline$K+2$ & & $\psi^{\prime \prime q}$ \\
\hline$K+3$ & & $\Delta$ speed (pu) \\
\hline$K+4$ & & Angle (radlans) \\
\hline
\end{tabular}

IBUS, 'GENSAL', ID, CON(J) to CON(J+11) $f$

Note: $X_{\triangleleft} X_{\phi}, X_{d} X_{G}, X_{\Phi}, X_{1}, H$, and $D$ are in pu, machine Mna base.

$x_{q}$ must be equal to $x_{d}$.

Figure 2-3 Datasheet of the Salient Pole Generator Model 


\section{GENROU}

Round Rotor Generator Model (Quadratic Saturation)
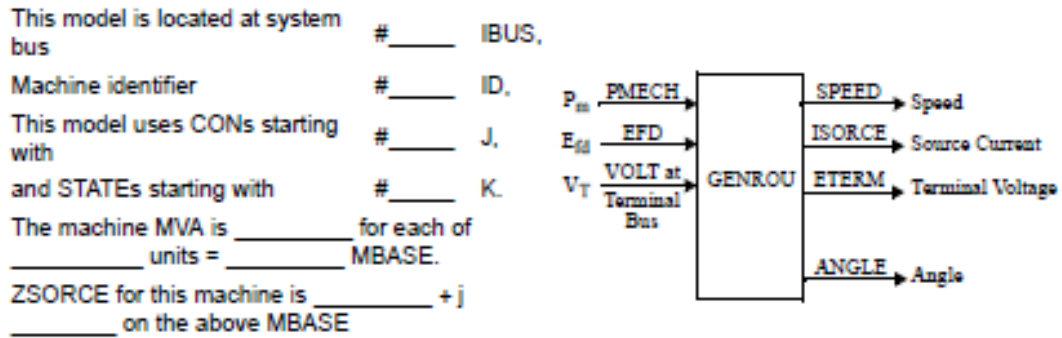

\begin{tabular}{|c|c|c|c|}
\hline CON8 & $=$ & Value & Description \\
\hline $\bar{J}$ & & & $\mathrm{~T}^{\prime}$ do $(>0)(\mathrm{sec})$ \\
\hline $\mathrm{J}+1$ & & & $\mathrm{~T}^{\prime \prime}{ }_{\text {do }}(>0)(\mathrm{sec})$ \\
\hline $\mathrm{J}+2$ & & & $\mathrm{~T}_{\text {qo }}^{\prime}(>0)(\mathrm{sec})$ \\
\hline $\mathrm{J}+3$ & & & $\mathrm{~T}^{\prime} \mathrm{qO}(>0)(\mathrm{sec})$ \\
\hline $\mathrm{J}+4$ & & & H, Inertia \\
\hline$J+5$ & & & D. Speed damping \\
\hline $\mathrm{J}+6$ & & & $x_{d}$ \\
\hline $\mathrm{J}+7$ & & & $x_{a}$ \\
\hline $\mathrm{J}+8$ & & & $X_{d}^{\prime}$ \\
\hline $\mathrm{J}+9$ & & & $X_{a}^{\prime}$ \\
\hline$J+10$ & & & $X_{d}^{n}=X_{q}^{n}$ \\
\hline$J+11$ & & & $x_{1}$ \\
\hline $\mathrm{J}+12$ & & & $S(1.0)$ \\
\hline$J+13$ & & & $S(1.2)$ \\
\hline
\end{tabular}

Note: $\mathrm{X}_{\mathrm{d}}, \mathrm{X}_{\mathrm{q}}, \mathrm{X}_{\mathrm{d},}^{\prime} \mathrm{X}_{\mathrm{q},}^{\prime} \mathrm{X}_{\mathrm{d},}, \mathrm{X}_{\mathrm{q},}, \mathrm{X}_{\mathrm{f}}, \mathrm{H}$, and $\mathrm{D}$ are in pu, machine MVA base.

$\mathrm{X}^{n} \mathrm{q}$ must be equal to $\mathrm{X}^{n}$.

\begin{tabular}{|c|l|l|}
\hline STATEs & $\#$ & \multicolumn{1}{|c|}{ Description } \\
\hline \hline $\mathrm{K}$ & & $\mathrm{E}_{\text {'q }}$ \\
\hline $\mathrm{K}+1$ & & $\mathrm{E}_{\mathrm{d}}$ \\
\hline $\mathrm{K}+2$ & & $\psi \mathrm{kd}$ \\
\hline $\mathrm{K}+3$ & & $\psi \mathrm{kq}$ \\
\hline $\mathrm{K}+4$ & & $\Delta$ speed (pu) \\
\hline $\mathrm{K}+5$ & & Angle (radians) \\
\hline
\end{tabular}

IBUS, 'GENROU", ID, $\operatorname{CON}(J)$ to $\operatorname{CON}(J+13) /$

Figure 2-4 Datasheet of the Round Rotor Generator Model GENROU

Because the fluxes, and thus the mutual inductances, between the stator and rotor windings change with rotor position, a set of orthogonal axes ascribed to the rotor is used to make the time-varying inductances time invariant. One axis is aligned with the machine main field flux; this is the direct axis or d-axis. The second axis is set leading this axis by $90^{\circ}$; this is the quadrature axis or q-axis. Each generating unit rotor is thus assigned a pair of $d-q$ axes. The angular speed associated with these axes is the rotor speed. The rotor angle associated with each generating unit is measured with respect to a common synchronously rotating pair of orthogonal axes, $\mathrm{R}$ and I, associated with the electrical network. These axes will thus rotate 
at a constant angular speed equal to $2 \pi f_{0}$ electrical radians/s, where $f_{0}$ is the system base frequency (60 Hz for U.S. power grids).

\subsubsection{Excitation Systems}

The functional relationships among the fundamental components associated with the generator and its excitation system in a conventional (synchronous) generating unit are shown in Figure 2-5.

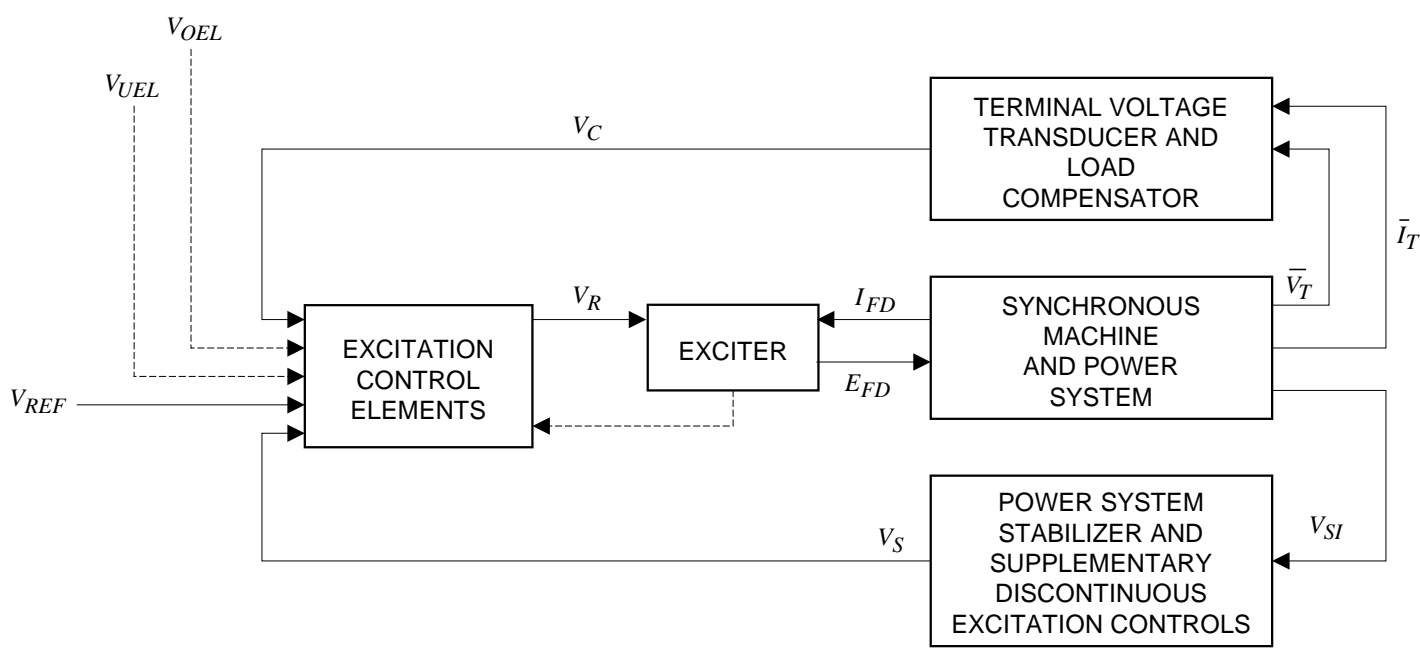

Figure 2-5 Generator and Excitation System Functional Relationships

Excitation systems found in "old" hydro power plants were usually powered with DC rotating exciters. However, static excitation systems are often being used in upgrading old facilities and in modern power plants. Excitation systems of the static type do not use rotating exciters and thus have a much faster dynamic response and a larger field forcing capability to respond to large disturbances without exceeding generator field current limits. However, because of the high initial response, they require voltage regulators with high gains that may have an adverse impact on the damping of electromechanical oscillatory modes in power systems. Power system stabilizers are often used as supplementary controls to add positive damping to the affected oscillatory modes through the excitation system by adding an electric torque in phase with the generator rotor speed. Additional control and protection systems used in excitation systems include field current limiters, terminal voltage limiters, underexcitation and over-excitation limiters (UELs and OELs), and flux $(\mathrm{V} / \mathrm{Hz})$ limiters and relays.

There are more than 50 excitation system models in the PSS ${ }^{\circledR} E$ and PSLF libraries that cover the spectrum of devices, starting from the oldest DC excitation systems to modern systems based on power electronics. These models have been defined and refined by a series of the Institute of Electrical and Electronic Engineers (IEEE) working groups over the last 40 years. The most recent models are described in IEEE Standard 421.5-2005. 
As noted above, static excitation systems are commonly used for modern hydro units. In static excitation systems, the DC source is a rectifier bridge (controlled or uncontrolled), and all components are stationary. The excitation current is fed directly to the generator through collector rings. The supply of power to the rectifier bridge can be from the main generator (through a transformer) or from auxiliary generator windings.

One example of a static excitation system, the ESST1A model, is shown in Figure 2-6. This model includes a simplified representation of the AVR and the rectifier bridge controls.

ESST1A

IEEE Type ST1A Excitation System

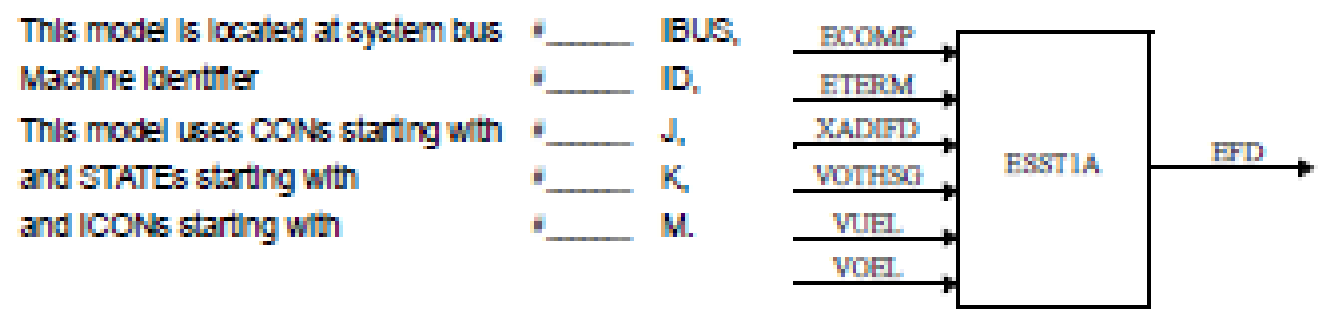

\begin{tabular}{|c|c|c|c|}
\hline CONE & $z$ & Value & Decoription \\
\hline $\bar{J}$ & & & $T_{R}(\mathrm{sec})$ \\
\hline$J+1$ & & & VIMAXX \\
\hline$J+2$ & & & $\mathrm{~V}_{\text {IMN }}$ \\
\hline$J+3$ & & & $\mathrm{~T}_{\mathrm{C}}(\mathrm{sec})$ \\
\hline$J+4$ & & & $T_{\mathrm{g}}(\mathrm{sec})$ \\
\hline$J+5$ & & & $\mathrm{~T}_{\mathrm{C1}}(\mathrm{sec})$ \\
\hline$J+6$ & & & $T_{\mathrm{B} 1}(\mathrm{sec})$ \\
\hline$J+7$ & & & $\mathrm{~K}_{\mathrm{A}}$ \\
\hline$J+8$ & & & $T_{A}(\mathrm{sec})$ \\
\hline$J+9$ & & & $V_{\text {AMAX }}$ \\
\hline $\mathrm{J}+10$ & & & VAMIN $_{\text {AM }}$ \\
\hline$J+11$ & & & VRMAX $_{\text {RM }}$ \\
\hline$\sqrt{ }+12$ & & & $\mathrm{~V}_{\text {RMIN }}$ \\
\hline $\mathrm{J}+13$ & & & $\mathrm{~K}_{\mathrm{c}}$ \\
\hline$\sqrt{J+14}$ & & & $K_{f}$ \\
\hline$J+15$ & & & $T_{F}>0(\sec )$ \\
\hline$J+16$ & & & $K_{L R}$ \\
\hline$\sqrt[J]{ }+17$ & & & $\overline{\text { ILR }}$ \\
\hline
\end{tabular}

Figure 2-6 Excitation System Model ESST1A 


\begin{tabular}{|c|c|l|}
\hline sTATEc & $\boldsymbol{*}$ & \multicolumn{1}{|c|}{ Deconiption } \\
\hline \hline $\mathrm{K}$ & & $\mathrm{V}_{\text {measured }}$ \\
\hline $\mathrm{K}+1$ & & Flrst lead lag \\
\hline $\mathrm{K}+2$ & & Second lead lag \\
\hline $\mathrm{K}+3$ & & $\mathrm{~V}_{\mathrm{A}}$ \\
\hline $\mathrm{K}+4$ & & Feecback \\
\hline
\end{tabular}

\begin{tabular}{|c|c|c|c|}
\hline ICONc & $\boldsymbol{z}$ & Value & \multicolumn{1}{|c|}{ Docoription } \\
\hline \hline$M$ & & & UEL $(1,2$, or 3$)$ \\
\hline$M+1$ & & & $\operatorname{VOS}(1$ or 2$)$ \\
\hline
\end{tabular}

IEUS, 'ESST1A', ID, ICON(M), ICON(M+1), $\operatorname{CON}(J)$ to $\operatorname{CON}(\mathrm{J}+17) /$

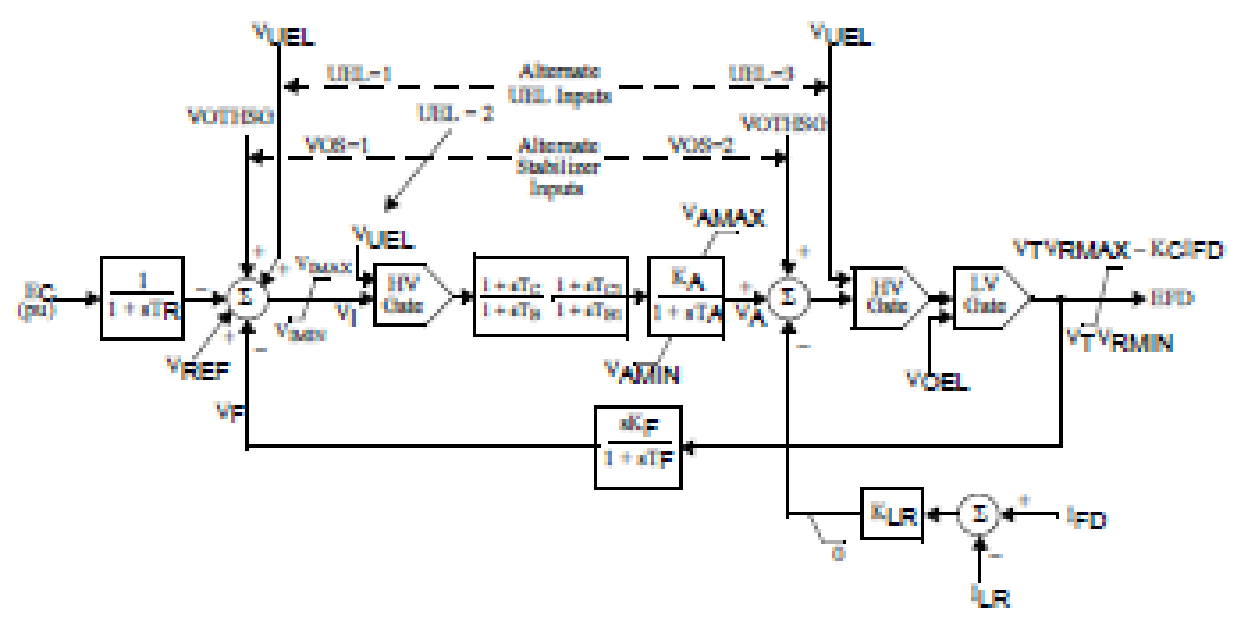

Figure 2-6 Excitation System Model ESST1A (Cont.)

\subsubsection{Governor and Prime Mover Controls}

Prime mover controls are concerned with regulating speed and controlling the energy supply system variables. For hydro turbine generators, the variables include head and flow. For thermal units, variables may include boiler pressure, temperature, and flow. The main function of the governing system is to regulate system frequency by controlling the prime mover's mechanical power output. Thus, its controlling input signal is shaft speed, and the controlled output variable is mechanical power output, which is converted into electrical power by the generator unit. Energy systems often used in conventional power plants are based on fossil fuels, such as natural gas, oil, coal, and water. The thermal energy available in fossil fuels is transformed into high-pressure and high-temperature steam or gas, which expands in the prime mover. The resulting kinetic energy is then converted to mechanical power available on the shaft of the prime mover. Conventional and pumped storage hydro plants employing water as a working fluid use the potential energy available in the hydraulic head at the prime mover wicket gates, so the resulting kinetic energy in the turbine's runner is converted to mechanical power available on the shaft of the prime mover. 
The functional relationships among the fundamental components associated with the turbine, its governing system, and the generator in a conventional generating unit are shown in Figure 2-7.

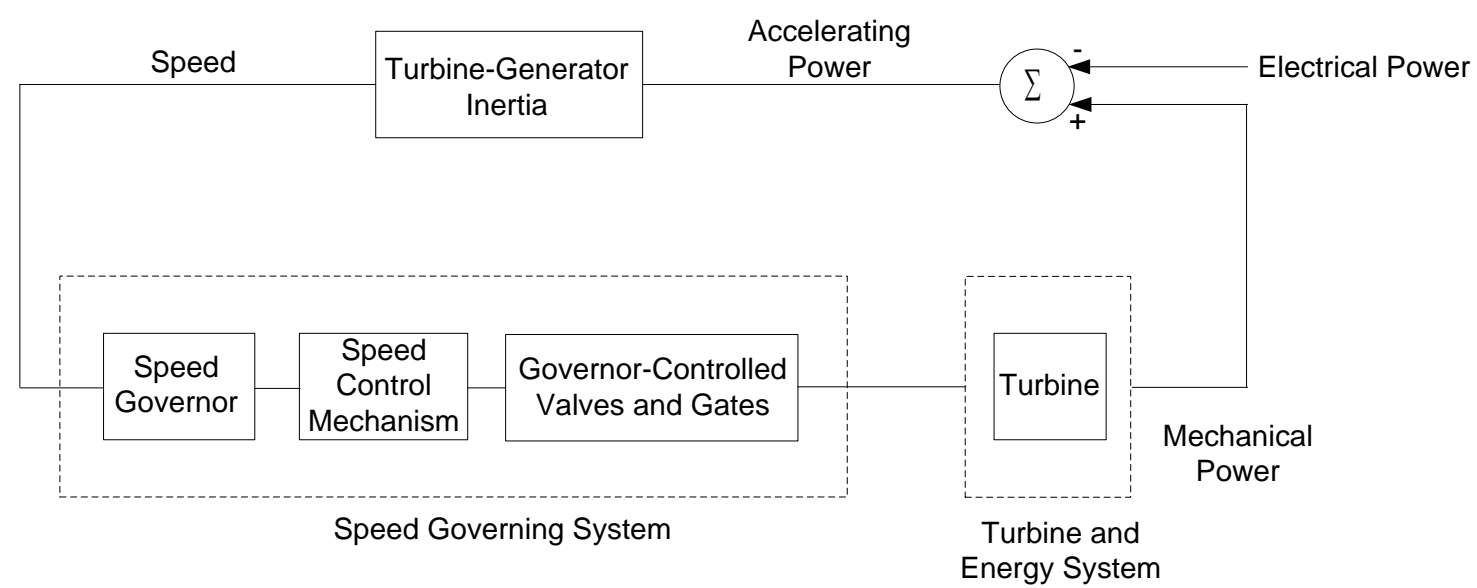

Figure 2-7 Turbine, Governor System, and Generator Functional Relationships

Because of the wide variety of designs found in turbine controls, the turbine-governor models are not designed to provide a high degree of accuracy with regard to any particular plant; rather, they represent the principal dynamic effects of the energy source and prime mover, with its associated controls, in power plants.

Section 2.2 describes the models used to represent hydroelectric governors.

\subsection{Hydroelectric Generating Plants}

Since the focus of this project is hydroelectric power plants, it is appropriate to give a general overview of the different types of hydroelectric units employed. There are two basic types of hydroelectric turbines: impulse turbines and reaction turbines.

Impulse turbines are generally used for installations where there is high head (head is the effective height between the water source and the turbine) and where the flow is relatively low (compared to that of the other turbine types described below). The water is focused and directed though a nozzle, and the water stream impacts the turbine blades, thereby forcing the turbine to spin. Generally the water leaves the nozzle at a high velocity and at atmospheric pressure, and two to six nozzles are distributed uniformly around the turbine circumference. The most commonly used impulse turbine design is the Pelton turbine.

Reaction turbines are generally used for installations where the head is relatively low and the flow is relatively high. The transfer of energy from the water to the turbine does not occur at atmospheric pressure, as it does in the Pelton turbine. The water changes pressure as it moves through the turbine and gives up its energy. Thus, reaction turbines are either encased to contain the water pressure or submerged in the water flow. Energy from the pressure drop is transferred to the turbine through both the fixed guide vanes and the rotating runner blades. The most common reaction turbine types are the Kaplan and Francis turbines. 
The Kaplan turbine is a propeller-like water turbine with adjustable blades. The combination of adjustable propeller blade angle and adjustable wicket gates enables high efficiency to be achieved over a wider range of head and flow.

The Francis turbine uses a spiral-shaped inlet and guide vanes to direct the water tangentially to the turbine runner. This radial water flow transfers the energy to the runner vanes. Adjustable guide vanes allow higher efficiency over a wider range of head and flow.

The technologies associated with the turbines just described are well known and documented in many references. These technologies are not new, as evidenced by their dates of invention (Francis in 1848, Pelton in the 1870s, and Kaplan in 1913). Of course, the actual design and physics of hydraulic turbines are much more complex than the few sentences above convey. Much effort has been put into research and design to improve the efficiency and reliability of these basic designs, as well as to reduce adverse environmental impacts, such as the impacts on erosion and fish populations.

The general head-versus-flow relationships just described affect which type of turbine is selected for a particular site. This report focuses on pump storage hydro plants. Since the amount of energy stored is proportional to the volume of water and the head at which it is stored, in order to be economical, such plants generally require a reasonably high head so that a large amount of energy can be stored without a very large reservoir being required. In addition, since these plants must have relatively large power outputs to have a significant impact on power system operation, relatively high flow rates are required.

Figure 2-8 and Figure 2-9 show application ranges for the different hydro turbine types taken from two publicly available U.S. government references. Note that the axes for Figure 2-8 are head versus power, while those for Figure 2-9 are head versus flow. Both of these indicate the suitability of Francis turbines for applications that have a relatively high head (ranging from 100 to 2,000 feet) and that allow large turbines/generators (currently up to about $700 \mathrm{MW}$ ). Francis turbines can also be designed to be suitable for pumping operation. Hence, the vast majority of the large pumped storage plants built in the United States employ Francis turbines. 


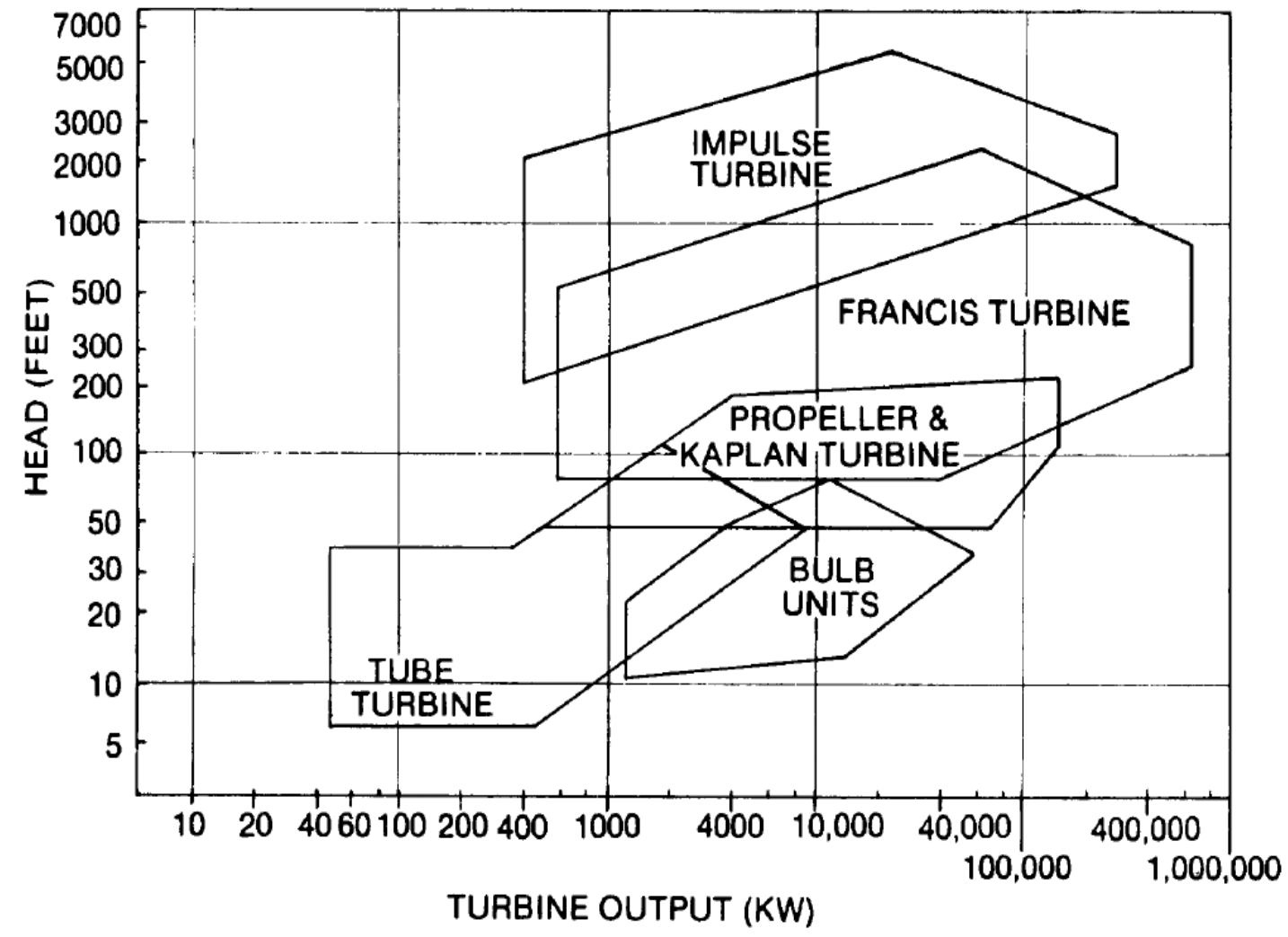

Figure 2-8 Hydro Turbine Application Ranges (From "Engineering and Design - Hydropower," U.S. Corp of Engineers Engineering Manual EM-1110-2-1701, December 1985) 


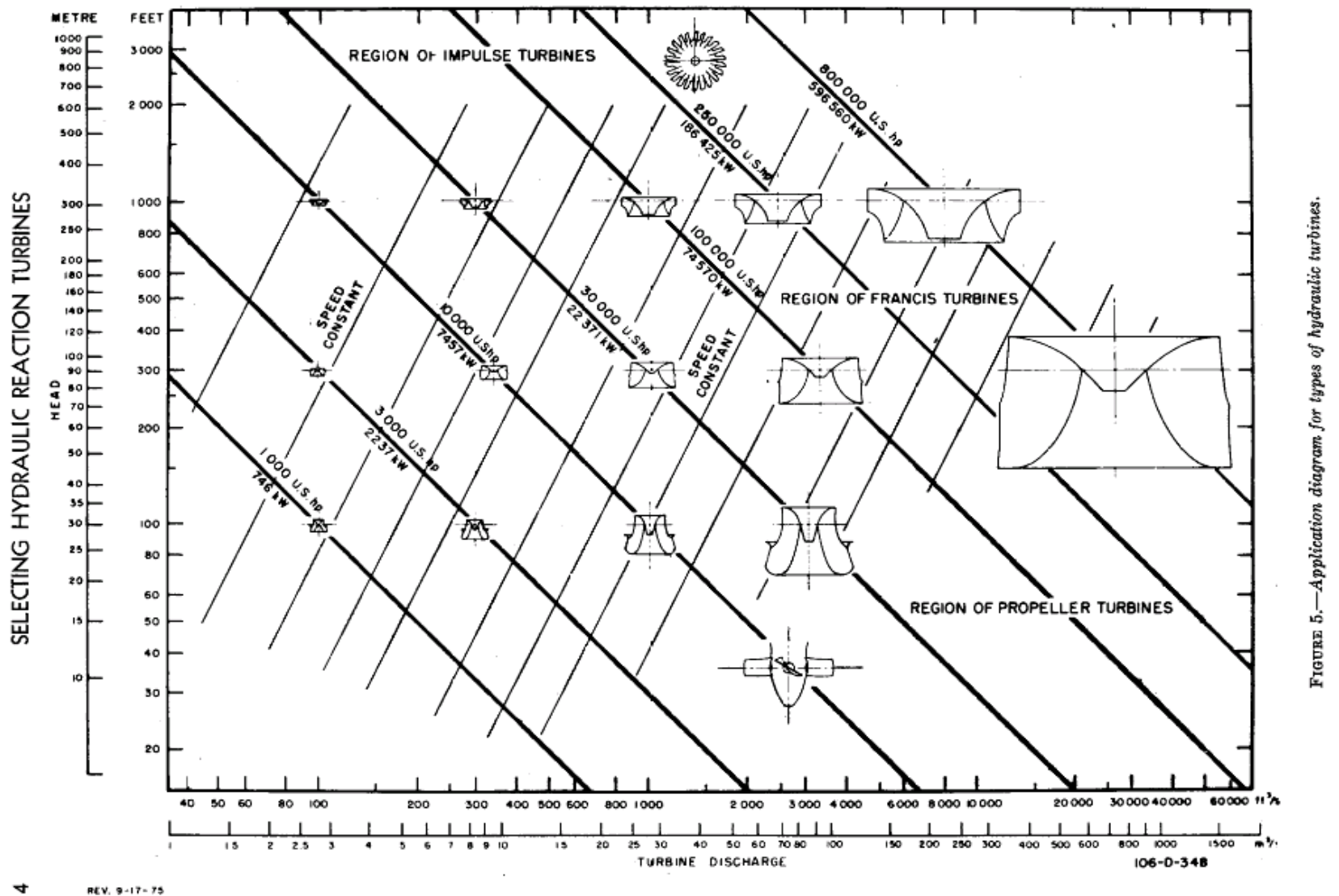

Figure 2-9 Hydro Turbine Application Ranges (From "Selecting Hydraulic Reaction Turbines," U.S. Bureau of Reclamation Engineering Monograph EM20, 1976) 


\section{Section

\section{Hydro Turbine-Governor Simulation}

\section{Models in PSS ${ }^{\circledR} \mathrm{E}$}

\subsection{Modeling Approach}

This section provides a summary of the hydro governor models that can be found in commercial software packages that are commonly in use in North America as well as on other continents. Table 3-1 lists the models in the PSS ${ }^{\circledR} E$ software, while Table 3-2 lists the models in the PSLF software.

The models vary in their complexity, and hence, in their data requirements. In general, they differ in hydraulic system representation and can be grouped under "linear models" or "nonlinear models."

Linear models assume the following penstock/turbine transfer function:

$$
\left.\Delta p(s) / \Delta g(s)=\left(1-T_{W} \times s\right) /\left(1+T_{W} \times s / 2\right) \quad \text { (p.u. }\right)
$$

where $\Delta \mathrm{p}$ and $\Delta \mathrm{g}$ are $\mathrm{p} . u$. incremental changes in mechanical power and gate position around a steady-state operating point, respectively.

The water column time constant, $\mathrm{T}_{\mathrm{W}}$, is associated with the acceleration time for the water in the penstock between the turbine inlet and the forebay (or surge tank if present) and is given, approximately, by:

$$
T_{W}=(L \times Q) /\left(g_{v} \times A \times H\right)
$$

where:

$$
\begin{aligned}
& Q=\text { water flow rate at initial loading level }\left(\mathrm{m}^{3} / \mathrm{s}\right) \\
& H=\text { net hydraulic head at initial loading level }(\mathrm{m}) \\
& \mathrm{L}=\text { centerline length of penstock conduit plus scroll case plus draft tube }(\mathrm{m}) \\
& g_{\mathrm{v}}=\text { gravitational acceleration }\left(\mathrm{m} / \mathrm{s}^{2}\right) \\
& A=\text { penstock cross-sectional area }\left(\mathrm{m}^{2}\right)
\end{aligned}
$$


Table 3-1 Hydro Governor Models in the PSS ${ }^{\circledR}$ E Software

\begin{tabular}{|c|c|}
\hline Model Name & Description \\
\hline HYGOV & Standard hydro turbine governor model \\
\hline HYGOV2 & Linearized hydro turbine governor model \\
\hline HYGOVM & Hydro turbine governor model with lumped parameters \\
\hline HYGOVT & Hydro turbine governor model with traveling wave \\
\hline HYGOVRU & Fourth order lead-lag hydro turbine governor model \\
\hline IEEEG2 & General-purpose linearized turbine governor model \\
\hline IEEEG3 & General-purpose linearized turbine governor model \\
\hline PIDGOV & $\begin{array}{l}\text { Hydro turbine governor model for plants with straightforward penstock } \\
\text { configurations and three-term electro-hydraulic governors }\end{array}$ \\
\hline TURCZT & General-purpose turbine governor model \\
\hline TWDM1T & Hydro turbine governor model with tail water depression \\
\hline TWDM2T & $\begin{array}{l}\text { Hydro turbine governor model with proportional, integral, and derivative (PID) } \\
\text { controller and tail water depression }\end{array}$ \\
\hline WEHGOV & Woodward electro-hydraulic hydro turbine governor model \\
\hline WPIDHY & Woodward PID hydro turbine governor model \\
\hline WSHYDD & WECC double derivative hydro turbine governor model \\
\hline WSHYPG & WECC type GP hydro turbine governor model \\
\hline HYGOV4 & Hydro turbine governor model \\
\hline
\end{tabular}


Table 3-2 Hydro Governor Models in the PSLF Software

\begin{tabular}{|c|c|}
\hline Model Name & Description \\
\hline G2WSCC & Double derivative hydro governor and turbine \\
\hline GPWSCC & PID governor and turbine \\
\hline HYG3 & PID governor, double derivative governor, and turbine \\
\hline HYGOV4 & $\begin{array}{l}\text { Hydro turbine and governor model for plants with straightforward penstock } \\
\text { configurations and traditional dashpot-type hydraulic governors }\end{array}$ \\
\hline HYGOV & $\begin{array}{l}\text { Hydro turbine and governor model for plants with straightforward penstock } \\
\text { configurations and electro-hydraulic governors that mimic the } \\
\text { permanent/temporary droop characteristics of traditional dashpot-type hydraulic } \\
\text { governors }\end{array}$ \\
\hline HYGOVR & Fourth order lead-lag governor and hydro turbine \\
\hline HYPID & $\begin{array}{l}\text { Hydro turbine and governor model for plants with straightforward penstock } \\
\text { configurations and proportional-integral-derivative governor. Includes capability } \\
\text { to represent blade angle adjustment of Kaplan and diagonal flow turbines. }\end{array}$ \\
\hline HYST1 & $\begin{array}{l}\text { Hydro turbine with Woodward electric-hydraulic PID governor, penstock, surge } \\
\text { tank, and inlet tunnel }\end{array}$ \\
\hline IEEEG3 & $\begin{array}{l}\text { IEEE hydro turbine and governor model for plants with straightforward penstock } \\
\text { configurations and hydraulic-dashpot governors with optional deadband and } \\
\text { nonlinear gain }\end{array}$ \\
\hline PIDGOV & $\begin{array}{l}\text { Hydro turbine and governor model for plants with straightforward penstock } \\
\text { configurations and three-term electro-hydraulic governors (Woodward electronic) }\end{array}$ \\
\hline W2301 & Woodward 2301 governor and basic turbine model \\
\hline
\end{tabular}


Because the water flow rate $(\mathrm{Q})$ at half load is about half its value at full load while the net hydraulic head $(\mathrm{H})$ remains fairly constant, the water column time constant $T_{W}$ varies significantly with the loading level. The linear models are used for small signal stability analysis and are valid only for the small deviations in system frequency and wicket gate position that are typical in hydro power stations in large power systems. These models also require that the user recalculate the value of $T_{W}$ for each new initial loading level.

Nonlinear models, on the other hand, take into consideration this dependency of $T_{W}$ with loading. The linearization of the nonlinear model of the penstock/turbine transfer function for small perturbations around a $\mathrm{Q}_{0}, \mathrm{H}_{0}$ operating point results in:

$$
p / g=\left(1-T_{W \operatorname{lin}} \times s\right) /\left(1+T_{W \operatorname{lin}} \times s / 2\right)
$$

This is the same as given above for the linearized model, except that the water column time constant used in the above linearized equation is now defined as:

$$
T_{W \text { lin }}=T_{W} \times Q_{0} / H_{0}
$$

where $T_{w}$ in this equation is calculated as shown above but using the base flow and base head. Base flow is defined as the turbine flow rate when gates are fully open ( $g=1$ p.u.). The base hydraulic head is the net head available to the hydraulic turbine when the flow rate is the base flow. $\mathrm{Q}_{0}$ and $\mathrm{H}_{0}$ are per-unit quantities for the flow rate and net hydraulic head at the initial loading, respectively $\left(\mathrm{Q}_{0}=\right.$ initial flow / base flow and $\mathrm{H}_{0}=$ initial head / base head).

By multiplying the water time constant $\mathrm{T}_{w}$ by $\mathrm{Q}_{0}$ and $1 / \mathrm{H}_{0}$, the model automatically accounts for dynamic changes in its effective value; thus, the penstock/turbine model is valid for the full range of hydro turbine operations, from no load to maximum gate opening. It is used in transient stability analysis and is also valid for large speed deviations, and it can be used to simulate load rejection overspeed conditions if no relief valve or jet deflector action is expected.

More detailed models may also take into account other nonlinear effects, such as the nonlinear relationship between gate and flow (which can be significant in some turbines), the elasticity of the penstock conduit, and the compressibility of the working fluid. Other dynamics can also be included in the model, such as a more detailed modeling of the penstock dynamics and the effects of, for example, surge tanks.

Note that the models based on use of a water column time constant $T_{w}$ as described above may not adequately represent all of the pertinent dynamics of plants with very long penstocks. The modeling of the penstock dynamics using $T_{W}$ is valid only if the wave travelling time is much shorter than the water starting time. IEEE Standard 1207-2011, "IEEE Guide for the Application of Turbine Governing Systems for Hydroelectric Generating Units" states:

"For very long penstocks, the wave travel time of the water column becomes significant, and the reflected pressure waves in the watercolumn cause the preceding treatment of water start time to no longer be valid. When the wave travel time 
approaches $25 \%$ of the $T_{W}$, engineers should not rely on only the classic value of $T_{W}$, and the performance of the turbine governing system should be evaluated by considering the effects of both the water starting time and the wave travel time."

While this standard is discussing hydro governor tuning, the comment is also valid for hydro modeling.

The wave travel time, also referred to at the elastic time $T_{e}$, is defined as $L / a$ where $L$ is the length of the penstock as defined above and $a$ is the wave velocity. The wave velocity is a function of the properties of water and of the material the penstock is made of as well as the diameter and thickness of the penstock. Typical values of the water velocity are as follows ${ }^{2}$ :

- $1220 \mathrm{~m} / \mathrm{s}$ for steel conduit

- $1420 \mathrm{~m} / \mathrm{s}$ for rock tunnels

It should also be noted that plants with long penstocks also often have surge tanks. If so, then the impacts of the surge tank must also be properly taken into account in the modeling of the plant.

\subsection{Simulation Models in PSS $B E$}

The commercial-grade Power System Simulator for Engineering (PSS $\left.{ }^{\circledR} E\right)$ software includes models for hydro power plants that can be used for large signal time domain simulations for transient, mid-term, and long-term dynamics. The following turbine-governor and penstock dynamic models are part of the standard dynamic model library in $\mathrm{PSS}^{\circledR} \mathrm{E}$.

\subsubsection{HYGOV Model}

HYGOV represents a straightforward hydroelectric plant governor, with a simple hydraulic representation of the penstock with unrestricted head race and tail race, and no surge tank. The hydraulic and governor model is shown in Figure 3-1.

1 "IEEE Guide for the Application of Turbine Governing Systems for Hydroelectric Generating Units," IEEE Std 1207-2011 (Revision to IEEE Std 1207-2004), June 20, 2011.

2 Kundur, Prabha. Power System Stability and Control, McGraw-Hill Companies, Incorporated,1994. 


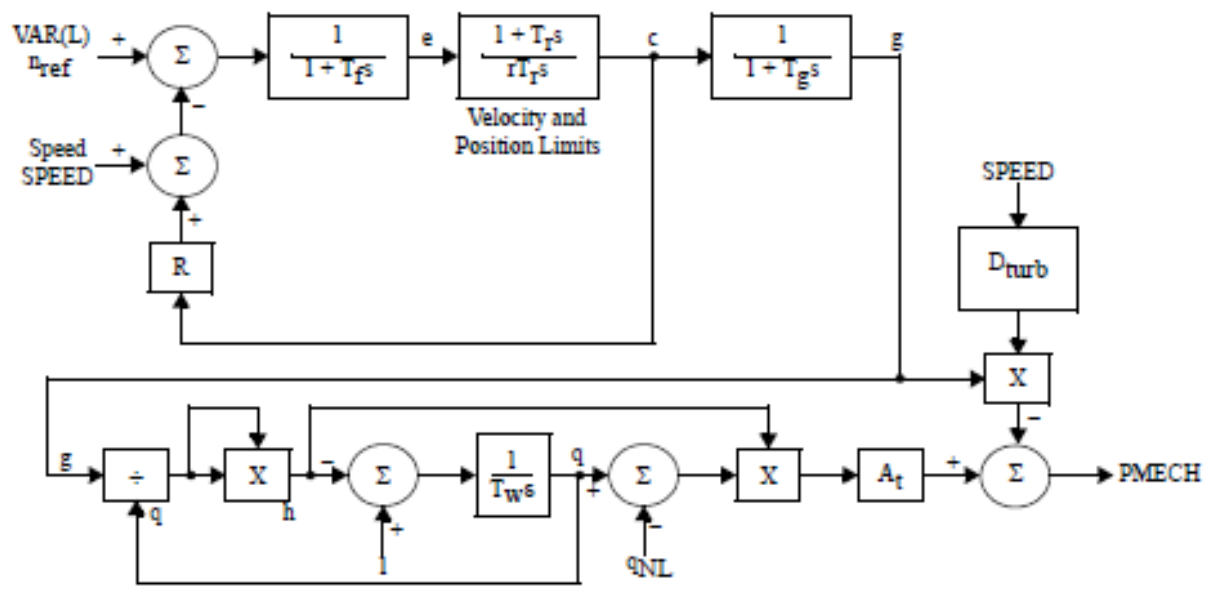

Figure 3-1 HYGOV Model Block Diagram for Turbine-Governor/Penstock Dynamics

In the figure,

$\mathrm{R}=$ permanent droop (p.u. on generator (megavolt ampere [MVA] rating)

$r=$ transient droop (p.u. on generator MVA rating)

$\mathrm{T}_{\mathrm{r}}=$ governor time constant $(\mathrm{s})$

$\mathrm{T}_{\mathrm{f}}=$ filter time constant (s)

$\mathrm{T}_{\mathrm{g}}=$ servo time constant (s)

VELM = gate velocity limit (p.u./s)

GMAX = maximum gate limit (p.u.)

GMIN = minimum gate limit (p.u.)

$\mathrm{T}_{\mathrm{W}}=$ water time constant $(\mathrm{s})$

$A_{t}=$ turbine gain (p.u.)

$D_{\text {turb }}=$ turbine mechanical damping (p.u. on generator MVA rating)

$\mathrm{q}_{\mathrm{NL}}=$ no-load water flow rate that accounts for the fixed losses in the turbine (p.u. of base water flow)

Linearization of the penstock/turbine transfer function for small perturbations around a $\mathrm{Q}_{0}, \mathrm{H}_{0}$ operating point results in:

$$
\mathrm{p} / \mathrm{g}=\left(1-\mathrm{T}_{\mathrm{W} \text { lin }} \times \mathrm{s}\right) /\left(1+\mathrm{T}_{\mathrm{Wlin}} \times \mathrm{s} / 2\right)
$$

where:

$$
\mathrm{T}_{\mathrm{W} \text { lin }}=\mathrm{T}_{\mathrm{W}} \times \mathrm{Q}_{0} / \mathrm{H}_{0}
$$


$T_{W}$ is calculated by using the base flow rate and base net hydraulic head; and thus, is independent of the initial loading level. By multiplying the water time constant $T_{W}$ by $Q_{0}$ and $1 / \mathrm{H}_{0}$, the model automatically accounts for dynamic changes in its effective value.

The penstock/turbine model is valid for the full range of hydro turbine operations, from speeds at no load to the maximum gate opening. This governor model is valid for dashpot-type mechanical governors (e.g., Woodward, English Electric) and for dashpot-equivalent electrohydraulic governors (e.g., ASEA). No acceleration governing (derivative control action) term is included because this is used only in specialized situations in most interconnected power systems.

The permanent droop, $\mathrm{R}$, and temporary droop, $\mathrm{r}$, are specified in per unit on a base equal to the generator three-phase MVA rating. The velocity limit, VELM, is the reciprocal of the time taken for the wicket gates to move from fully open to fully closed. The maximum gate limit, GMAX, is equal to the gate limit setting as established by the operator at the governor console; it cannot exceed 1 p.u. The minimum gate position is normally zero. The no-load flow rate, $q_{N L}$, is the flow rate required to maintain the rated speed when the unit is off line; $\mathrm{q}_{\mathrm{NL}}$ is expressed in p.u. of the base flow rate.

The turbine gain, $A_{t}$, is given by:

$$
1 /\left(g_{\mathrm{FL}}-g_{\mathrm{NL}}\right)
$$

where:

$$
\begin{aligned}
& g_{\mathrm{FL}}=\text { full load gate opening (p.u.) }\left(0<g_{\mathrm{FL}} \leq 1\right) \\
& g_{\mathrm{NL}}=\text { no load gate opening (p.u.) }\left(0<g_{\mathrm{NL}}<1\right)
\end{aligned}
$$

\subsubsection{HYGOV2 Model}

The hydro turbine-governor HYGOV2 model has the same basic permanent and transient droop elements as the HYGOV model but adds a slightly different representation of the time lags within the governor hydraulic servo system and of the shaft speed deviation signal filtering (Figure 3-2). 


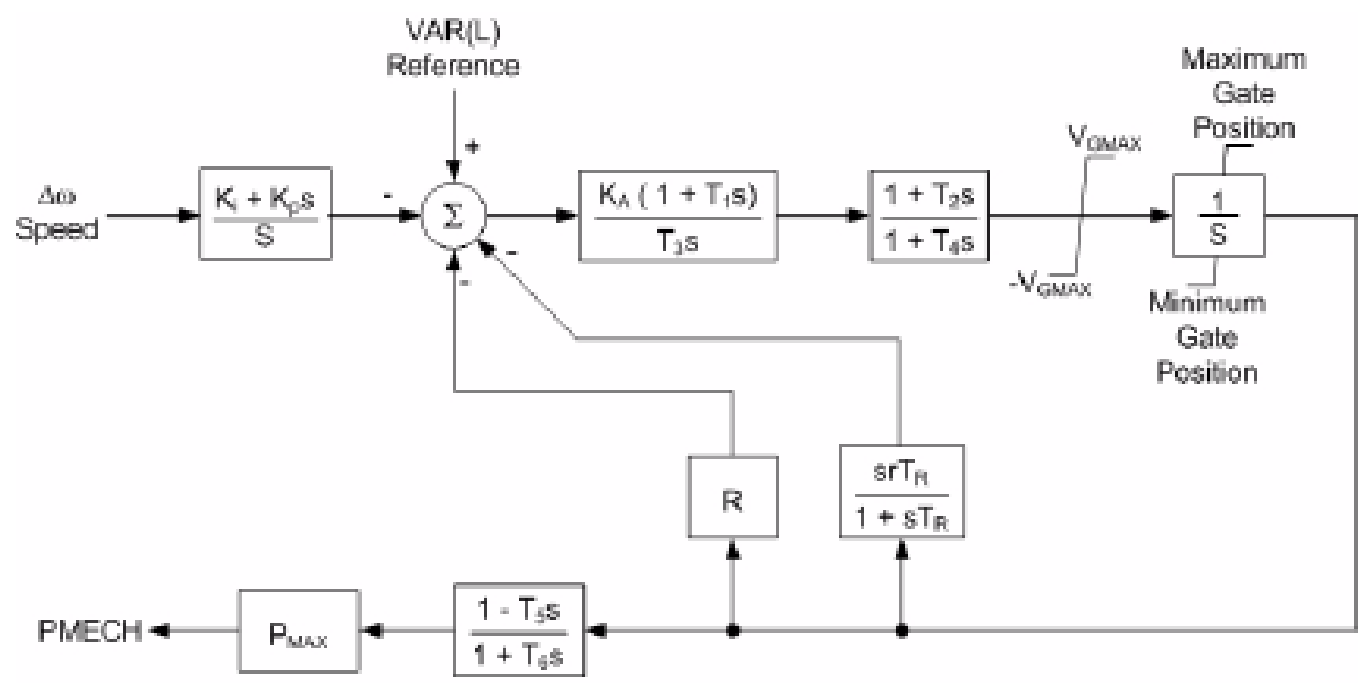

Figure 3-2 HYGOV2 Model Block Diagram for Turbine-Governor/Penstock Dynamics

The penstock/turbine-governor model of HYGOV2 is highly simplified and is valid only for small deviations of the gate position from its initial condition. Unlike HYGOV, HYGOV2 requires the user to recalculate the value of the water column time constants for each new initial loading level. The water column time constants, $T_{5}$ and $T_{6}$, of HYGOV2 are related to the water inertia time constant $\mathrm{T}_{\mathrm{w}}$ by:

$$
T_{5}=P_{0} T_{W}(s)
$$

and

$$
T_{6}=P_{0} T_{w} / 2(s)
$$

where:

$\mathrm{P}_{0}=$ the initial power in per unit of rated power (power developed at the base flow rate and net hydraulic head as defined above).

HYGOV2 was developed for a specific hydraulic plant and should not be used except in appropriate special situations. For the great majority of situations, HYGOV is the preferred choice.

\subsubsection{HYGOVM Model}

In hydro power plant layouts where a long supply penstock conduit is required, it is fairly common practice to use a surge tank. The purpose of the surge tank is to provide a degree of hydraulic isolation to the turbine from the hydraulic head deviations generated by hydraulic transients in the longest portion of the penstock. Many surge tanks also include an orifice where head loss serves to dissipate the energy of hydraulic oscillations generated by changes in gate position. The orifice introduces a damping effect. The lumped parameters 
hydraulic system model in HYGOVM is designed to allow detailed simulation of the representation of the surge tank system:

- Penstock dynamics

- Surge tank chamber dynamics

- Tunnel dynamics

- Penstock, tunnel, and surge tank chamber orifice losses

- Surge tank chamber level beyond maximum or minimum alarm

The HYGOVT model is similar to the HYGOVM model, but it uses a traveling wave calculation for the tunnel and penstock dynamics. The HYGOVM and HYGOVT models should be used for dynamic analyses of hydro plants when the time range of interest is comparable to the surge tank natural period, including long-term stability analyses, surge tank chamber dynamics analyses, and load rejection analyses involving relief valve or jet deflector action.

For shorter time periods, the simpler HYGOV model can be used. The HYGOV model assumes an infinite surge tank and is appropriate unless relief valve or jet deflector action is expected.

The surge tank natural period is defined as:

surge tank natural period $=($ SCHARE $\times$ TUNL/A $) /$ gravitational acceleration

Penstock dynamics are largely determined by the upper loop in the block diagram of the HYGOVM model shown in Figure 3-3.

The loop gain is proportional to the inverse of the square of gate position and thereby increases significantly for small openings. Under load rejection conditions, near total gate closure, the loop effective time constant will tend to approach zero. The model cannot handle low time constants without incurring numerical instability. It deals with this problem by assuming an algebraic solution (i.e., an instantaneous response, just before numerical instability would occur). This change in model response can be visualized by an instantaneous drop in the turbine's hydraulic head to values close to the head at the surge tank chamber opening. At the time the algebraic solution is applied, power and flows at the penstock are negligible and would not affect governor or surge tank chamber studies.

The turbine-governor system used in the HYGOVM model is shown in Figure 3-4. It is based on the HYGOV turbine-governor representation with these additional features:

- Separate maximum opening and closing gate rate limits. The maximum gate closing rate (MXGTCR) is usually a compromise between constraints due to maximum scroll case head, surge tank overflows, and unit overspeed under load rejection. A representative value for this parameter is 0.125 p.u./s. The maximum gate opening 
rate (MXGTOR) determines the minimum surge chamber levels when accepting load. A value of 0.1 p.u./s is representative.

- Buffered opening and closing rates when gate opening is near full closure. Buffering the gate closure may produce a reduction in overpressures under load rejection. This feature will reduce impact loadings on the gate linkage and limit the magnitude of the pressure pulsations that occur while the gates are fully closed during the decay of load rejection overspeed. A representative value for the maximum buffered closing gate rate (MXBGCR) is -0.05 p.u./s, and 0.15 p.u. for the buffer limit (BUFLIM). The maximum buffered opening rate (MXBGOR) is normally equal to MXGTOR.

- Pressure regulator (relief valve) simulation. This regulator is a bypass, generally attached to the turbine casing. It is operated directly from the governor or the gate mechanism of the turbine. The amount of water bypassed is sufficient to keep the total discharge through the penstock fairly constant and thereby control the rise in pressure. The maximum relief valve opening (RVLMAX) can be set equal to GMAX. For the water-wasting type, the maximum relief valve closing rate (RVLVCR) should be set to 0.0 p.u./s; for the water-saving type, a representative value for RVLVCR is -0.0143 p.u./s.

- Jet deflector simulation. Plants with long penstocks and impulse turbines (Pelton) are not allowed to have rapid reductions in water velocity because of the pressure rise that would occur. To minimize the rise in pressure that follows a sudden load rejection, a governor-controlled jet deflector is normally placed between the needle nozzle and the runner. The governor moves this deflector rapidly into the jet, cutting off the load. Typical values for maximum jet deflector opening and closing rates (MXJDOR and MXJDCR) are 0.5 p.u./s and -0.5 p.u./s, respectively. 


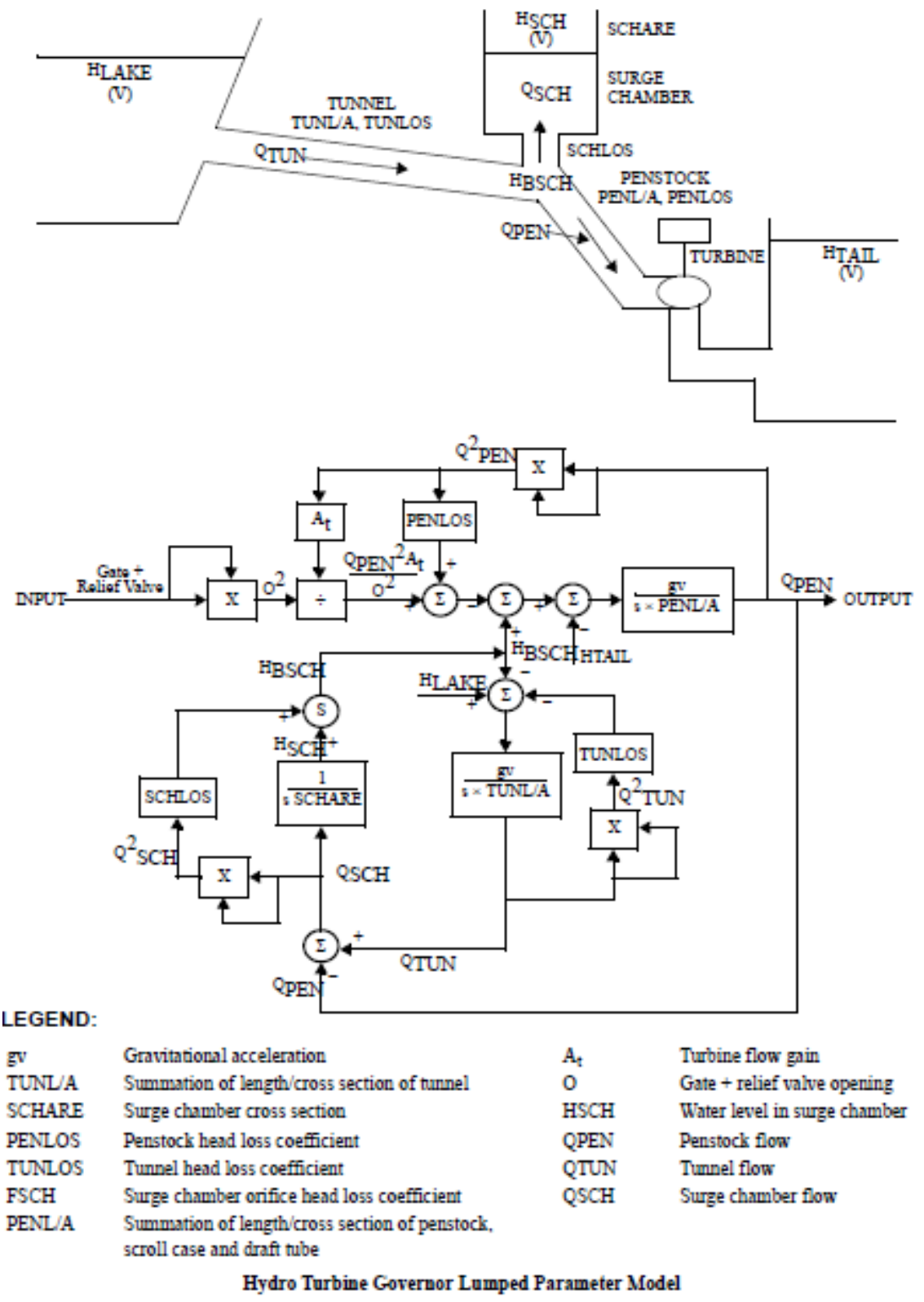

Figure 3-3 HYGOVM Model for Penstock Dynamics 

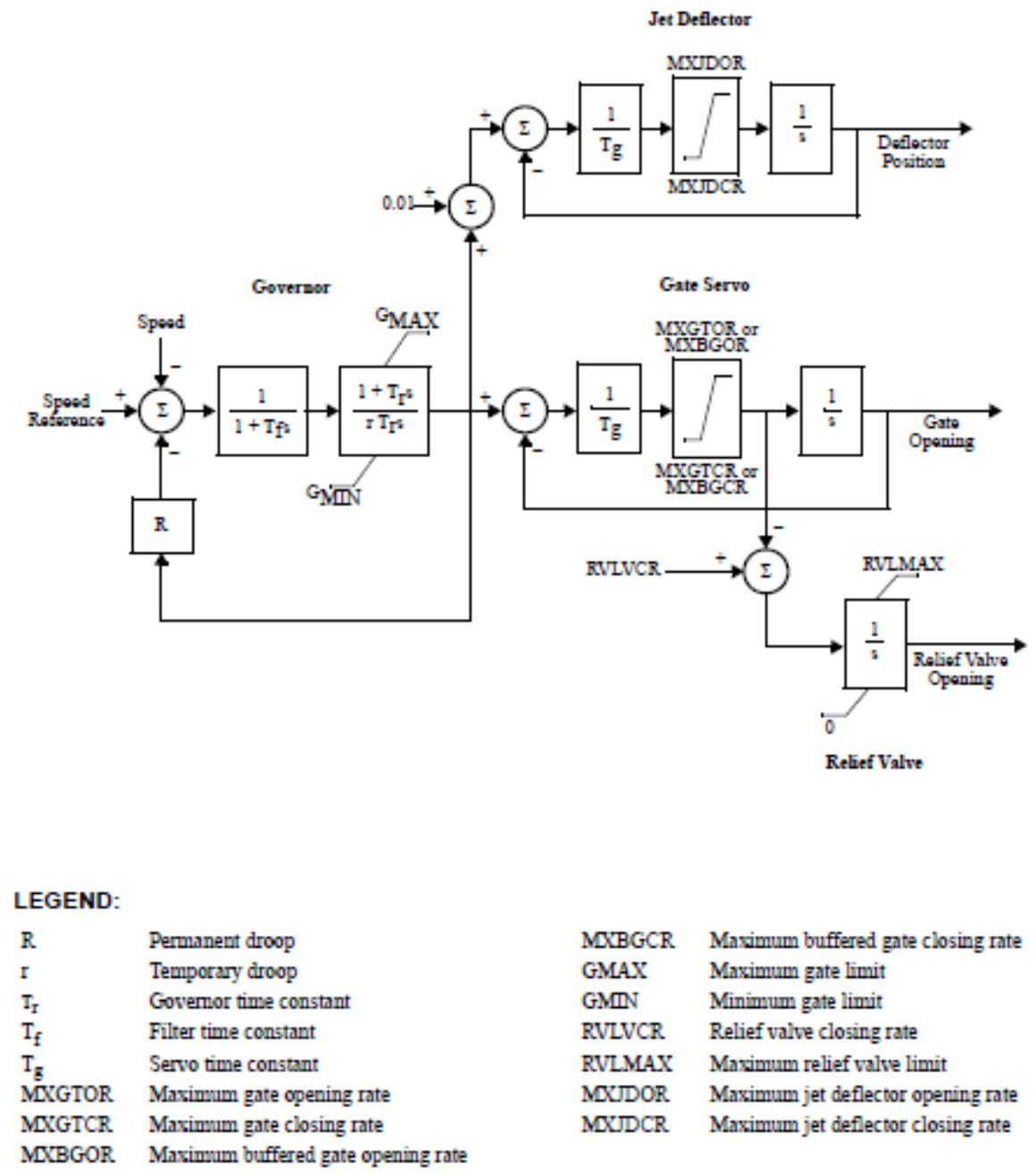

Figure 3-4 HYGOVM and HYGOVT Model Block Diagram for Turbine-Governor Dynamics

Turbine characteristics in HYGOVM are defined based on these rated conditions:

Rated power, $P_{\text {rated }}(\mathrm{MW})$

Rated flow, $\mathrm{Q}_{\text {Rated }}\left(\mathrm{m}^{3} / \mathrm{s}\right.$ or $\left.\mathrm{ft}^{3} / \mathrm{s}\right)$

Rated head, $\mathrm{H}_{\text {Rated }}(\mathrm{m}$ or $\mathrm{ft})$

Gate opening at rated operating point, $G_{\text {Rated }}$ (p.u.)

Flow at no load, $\mathrm{Q}_{\text {No load }}$ (p.u. of rated water flow rate)

The following parameters are calculated by the model:

$$
\begin{aligned}
& \mathrm{K}_{\mathrm{t}}(\text { turbine power gain })=\mathrm{P}_{\text {rated }} /\left[\left(\mathrm{Q}_{\text {Rated }}-\mathrm{Q}_{\text {No load }}\right) \times \mathrm{H}_{\text {Rated }} \times \text { MVABase }\right] \\
& \left.\mathrm{T}_{\mathrm{fg}} \text { (turbine flow gain }\right)=\mathrm{Q}_{\text {Rated }} /\left[\left(\mathrm{G}_{\text {Rated }} \times \sqrt{ }\left(\mathrm{H}_{\text {Rated }}\right)\right]\right.
\end{aligned}
$$

Turbine power is a function of turbine flow and turbine head; and thus, a function of penstock flow, gate position, and relief valve or jet deflector position. 
For turbines with a relief valve:

Turbine flow $=\left(\mathrm{Q}_{\text {penstock }} \times\right.$ gate opening $) /($ gate opening + relief valve opening $)$

Turbine head $=\left(Q_{\text {penstock }}\right)^{2} \times A_{t} /(\text { gate opening }+ \text { relief valve opening })^{2}$

For turbines with a jet deflector:

Turbine flow $=Q_{\text {penstock }} \times$ MIN (1., jet position/gate opening) $\left(\mathrm{m}^{3} / \mathrm{s}\right.$ or $\left.\mathrm{ft}^{3} / \mathrm{s}\right)$

Turbine head $=Q_{\text {penstock }}^{2} A_{t} /$ (gate opening $)^{2} \quad(m$ or $\mathrm{ft})$

For turbines with neither a relief valve nor a jet deflector:

Turbine flow $=Q_{\text {penstock }}\left(\mathrm{m}^{3} / \mathrm{s}\right.$ or $\left.\mathrm{ft}^{3} / \mathrm{s}\right)$

Turbine head $=Q_{\text {penstock }}^{2} A_{t} /$ (gate opening $)^{2} \quad$ ( $m$ or $\left.\mathrm{ft}\right)$

Turbine power and damping are as follows:

Turbine power $=\mathrm{K}_{\mathrm{t}} \times$ turbine head $\times($ turbine flow - turbine no-load flow $)-$ damping

Turbine damping $=$ DAMP $\times$ pu speed deviation $\times$ MIN (jet position, gate position)

where:

$$
\begin{aligned}
\text { DAMP } & =\text { DAMP1 for overspeeds under RPM1, } \\
& =\text { DAMP2 for overspeeds above RPM2, and } \\
& =\text { linearly interpolated for overspeeds between RPM1 and RPM2. }
\end{aligned}
$$

\subsubsection{HYGOVT Model}

In this model, a traveling-wave solution is applied to the penstock and tunnel dynamics. The traveling wave model for the penstock and tunnel dynamics is shown in Figure 3-5. The penstock and tunnel are divided into 9 to 19 segments, and the characteristics solution method is applied to the resulting time-space lattice. Boundary conditions and head losses are fully recognized. For accurate results, the simulation time step should be no larger than:

PENLGTH/(9 x PENSPD) (s)

where PENLGTH is the penstock conduit length and PENSPD is the penstock wave velocity. Maximum accuracy is attained when simulation time step is equal to, or a submultiple of

PENLGTH/(19 x PENSPD) (s)

Conduit wave velocity alone, when rigid walls are assumed and water compressibility is accounted for, is $1,420 \mathrm{~m} / \mathrm{s}(4,659 \mathrm{ft} / \mathrm{s})$. This wave velocity is the maximum that can be physically attained. Actual conduits do not have rigid walls. A representative value for penstock conduits is $1,100 \mathrm{~m} / \mathrm{s}(3,609 \mathrm{ft} / \mathrm{s})$. 
For this model, the governor and turbine models are the same as in the HYGOVM model (Figure 3-4). The decision to use the inelastic (HYGOVM) model or elastic (HYGOVT) model relies on the hydraulic system characteristics and the study scope. Because of time-step constraints, traveling-wave simulation turnover may be penalized by the need to use a smaller time step than would otherwise be required with the inelastic model. However, some error is involved with the use of an inelastic model. This error can be quantified by the difference between the elastic and the inelastic frequency response of the hydraulic head/flow rate transfer functions. This difference, in p.u. of the elastic case, is approximately:

$$
-\left(T_{p}^{2} \times s^{2}\right) / 3
$$

where $T_{p}$ is the penstock wave travel time constant (PENLGTH/PENSPD) in seconds and $\mathrm{s}$ is the Laplace operator. The time constant $\mathrm{T}_{\mathrm{p}}$ is typically 0.5 second but can be as high as 1.5 seconds for long penstocks. For normal governor action, the speed loop crossover frequency (i.e., the dominant mode) occurs at about $1 /\left(2 \mathrm{~T}_{\mathrm{W}}\right)$ rad per second. With the water time constant $T_{W}$ being typically 1 to 2 seconds, $s$ is on the order of 0.25 to 0.5 rad per second. The difference between elastic and inelastic response is usually negligible, unless very long penstocks are studied. A critical case run using both model assumptions could prove to be the easiest way to assess this difference.

There are times when traveling wave analysis is essential. Overpressures due to load rejection are critical just before or at gate closure time; the ensuing pressure pulsations occur after the gate is totally closed. A closed or an almost-closed gate results in infinitely small penstock time constants and infinitely large values for $\mathrm{s}$. 

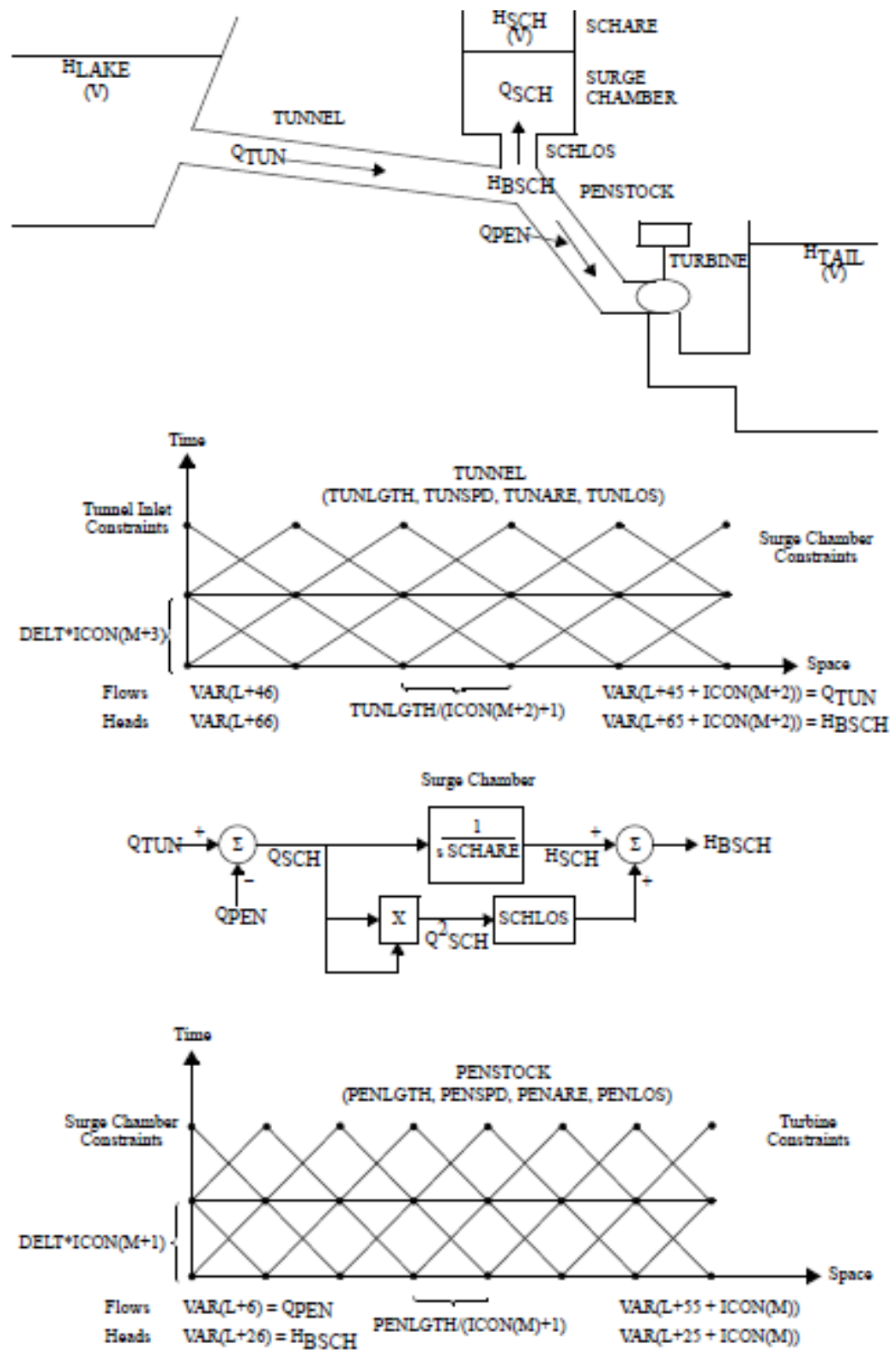

Figure 3-5 HYGOVT Traveling-Wave Model for Penstock Dynamics 


\subsubsection{IEEEG2 Model}

This is a general-purpose linearized model for representing a hydro turbine-governor and penstock dynamics (Figure 3-6). Its use is generally not recommended, since the parameters are valid only at the load for which they are calculated. Thus, use of a dynamics database containing such models with load flow cases having different dispatches on the units may yield inaccurate results, unless the parameters are updated to match the revised dispatch.

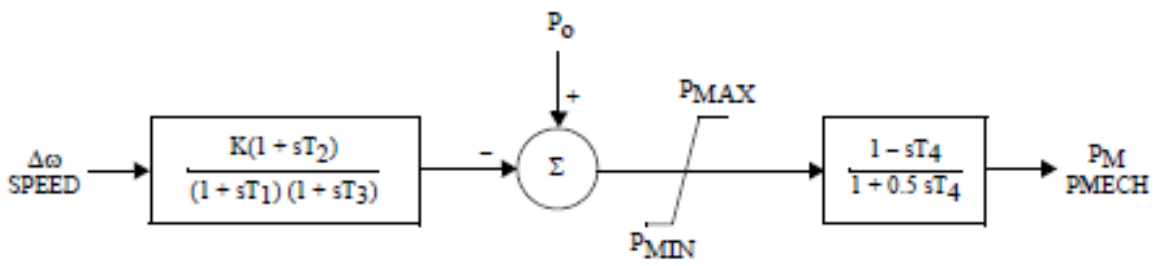

Figure 3-6 IEEEG2 Model Block Diagram for Turbine-Governor/Penstock Dynamics

In this model,

$$
\begin{aligned}
& \mathrm{K}=\text { permanent governor gain }(1 / \mathrm{R}) \text { (p.u. on generator MVA rating) } \\
& \mathrm{T}_{1}=\text { compensator time constant }(\mathrm{s}) \\
& \mathrm{T}_{2}=\text { compensator time constant }(\mathrm{s}) \\
& \mathrm{T}_{3}=\text { governor time constant }(\mathrm{s}) \\
& \mathrm{T}_{4}=\text { water time constant }(\mathrm{s}) \\
& \mathrm{P}_{\mathrm{MAX}}=\text { maximum gate position (p.u. on generator MVA rating) } \\
& \mathrm{P}_{\mathrm{MIN}}=\text { minimum gate position (p.u. on generator MVA rating) }
\end{aligned}
$$




\subsubsection{IEEEG3 Model}

This is a general-purpose model for representing a hydro turbine-governor and penstock dynamics (Figure 3-7). It includes a more complex representation of the governor controls than does IEEEG2. It also uses a linearized model of the penstock dynamics, albeit one that is a bit more complex. Its use is generally not recommended, since the parameters are valid only at the load for which they are calculated. Thus, use of a dynamics database containing such models with load flow cases having different dispatches on the hydro-turbine-driven generating units may yield inaccurate results, unless the parameters are updated to match the revised dispatch.

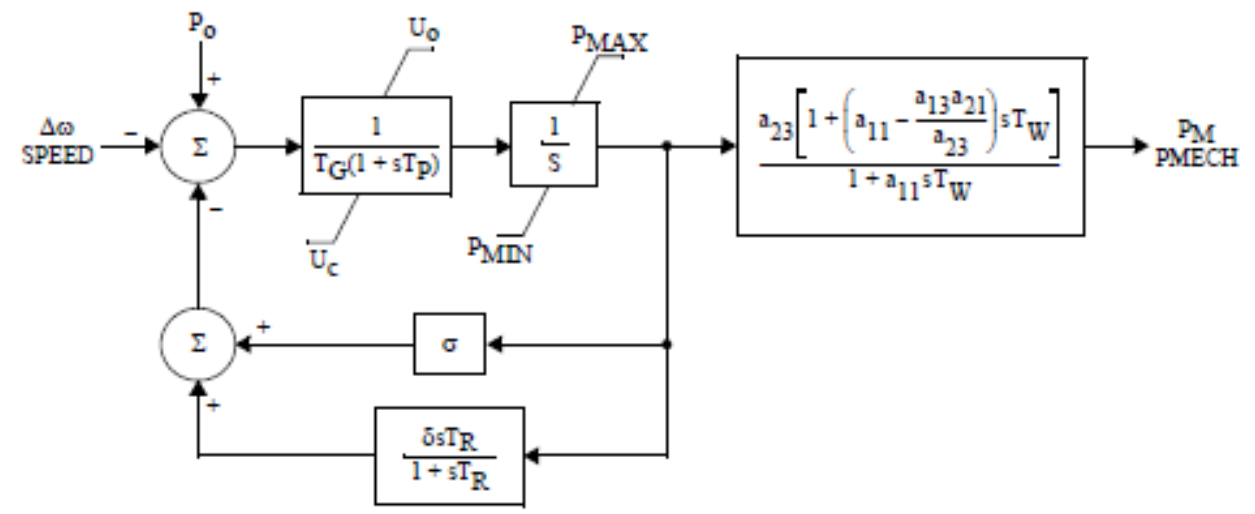

Figure 3-7 IEEG3 Model Block Diagram for Turbine-Governor/Penstock Dynamics

In this model,

$$
\begin{aligned}
& T_{G}=\text { gate servomotor time constant }(\mathrm{s}) \\
& T_{P}=\text { pilot value time constant (s) } \\
& \mathrm{U}_{\mathrm{O}}=\text { opening gate rate limit }(\mathrm{p} . \mathrm{u} . / \mathrm{s}) \\
& \mathrm{U}_{\mathrm{C}}=\text { closing gate rate limit }(\mathrm{p} . \mathrm{u} . / \mathrm{s}) \\
& \mathrm{P}_{\mathrm{MAX}}=\text { maximum gate position (p.u. on generator MVA rating) } \\
& \mathrm{P}_{\mathrm{MIN}}=\text { minimum gate position (p.u. on generator MVA rating) } \\
& \sigma=\text { permanent speed droop coefficient (p.u. on generator MVA rating) } \\
& \delta=\text { transient speed droop coefficient (p.u. on generator MVA rating) } \\
& T_{R}=\text { governor time constant (s) } \\
& T_{W}=\text { water starting time constant (s) } \\
& a_{11}, a_{13}, a_{21}, a_{23}=\text { penstock coefficients }
\end{aligned}
$$




\subsubsection{PIDGOV Model}

The PIDGOV hydro turbine governor model represents hydro power plants with straightforward penstock configurations and three term electro-hydraulic governors (i.e., Woodard electronic) (Figure 3-8). This model uses a simplified turbine-governor and penstock model that does not account for the variation of the water inertia effect with the gate opening. This model can be made to correspond to other models by using the classical turbine-governor/penstock model by setting $A_{t w}$ (factor that multiplies the water inertia time constant) to unity.

The feedback signal used by the governor can either be the gate position or the electrical power, and it can be selected by setting the feedback flag to 1 for gate position or to 0 for electrical power. The input to this model is the shaft speed deviation, and the outputs are turbine gate position and mechanical power.

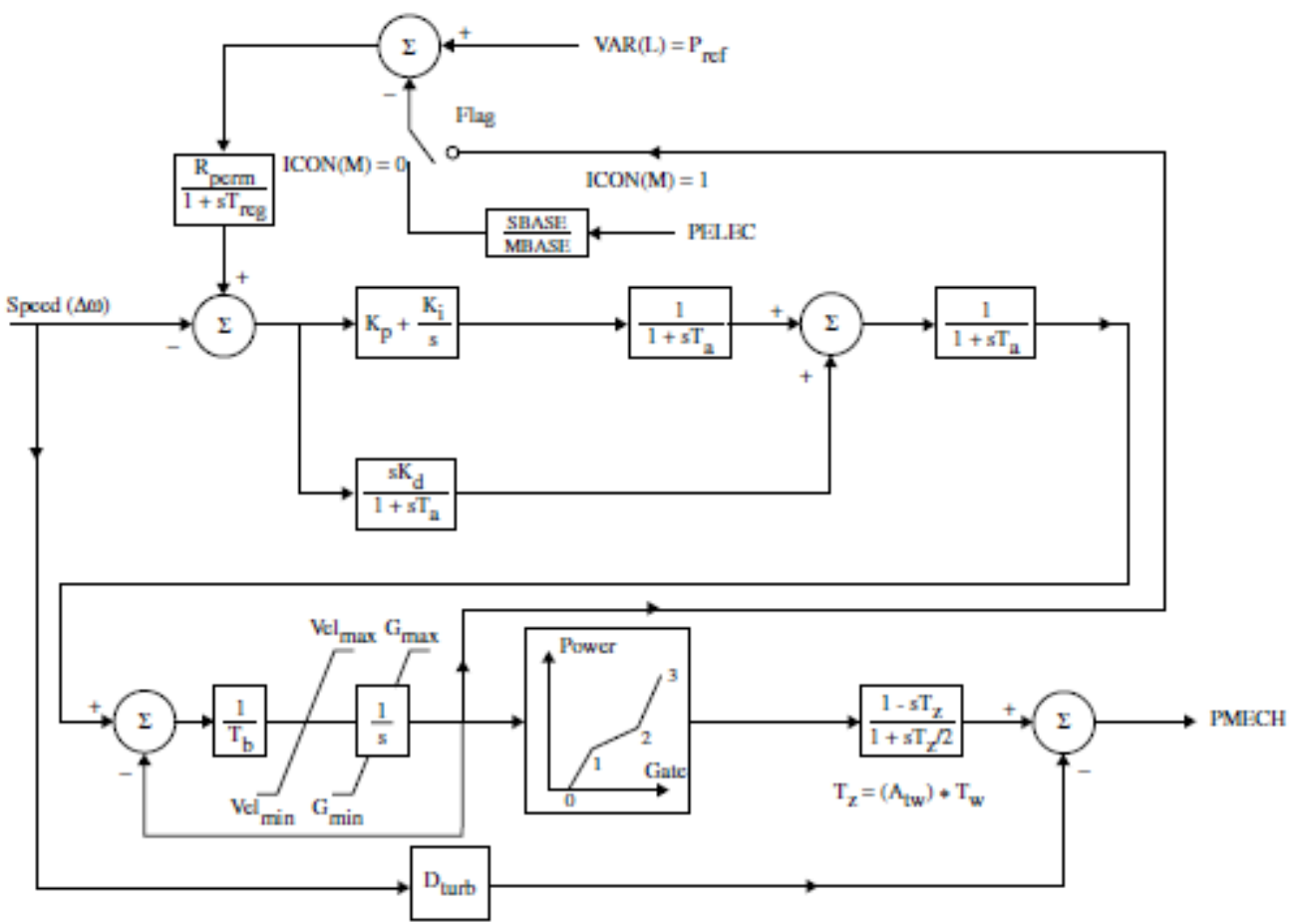

Figure 3-8 PIDGOV Model Block Diagram for Turbine-Governor and Penstock Dynamics

In this model,

$\mathrm{R}_{\text {perm }}=$ permanent droop (p.u. on generator MVA rating)

$\mathrm{T}_{\text {reg }}=$ speed probe time constant (s)

$\mathrm{K}_{\mathrm{p}}=$ controller proportional gain (p.u.)

$\mathrm{K}_{\mathrm{i}}=$ controller integral gain (p.u./s)

$\mathrm{K}_{\mathrm{d}}=$ controller derivative gain (p.u./s) 


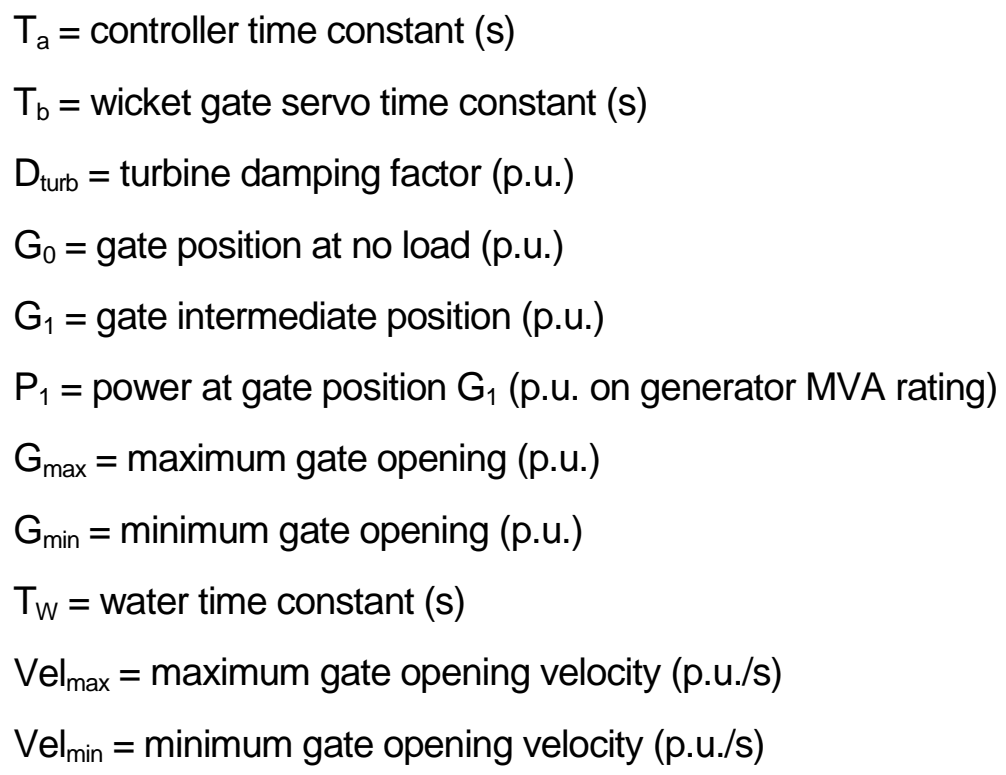




\subsubsection{TURCZT Model}

This is a general-purpose hydro and thermal turbine-governor model (Figure 3-9). A hydro turbine or steam turbine dynamic model can be selected by setting a flag to 1 for a steam turbine and to 0 for a hydro turbine. Penstock dynamic is not included in the model. The model was developed for a specific user and it is not recommended for general use.

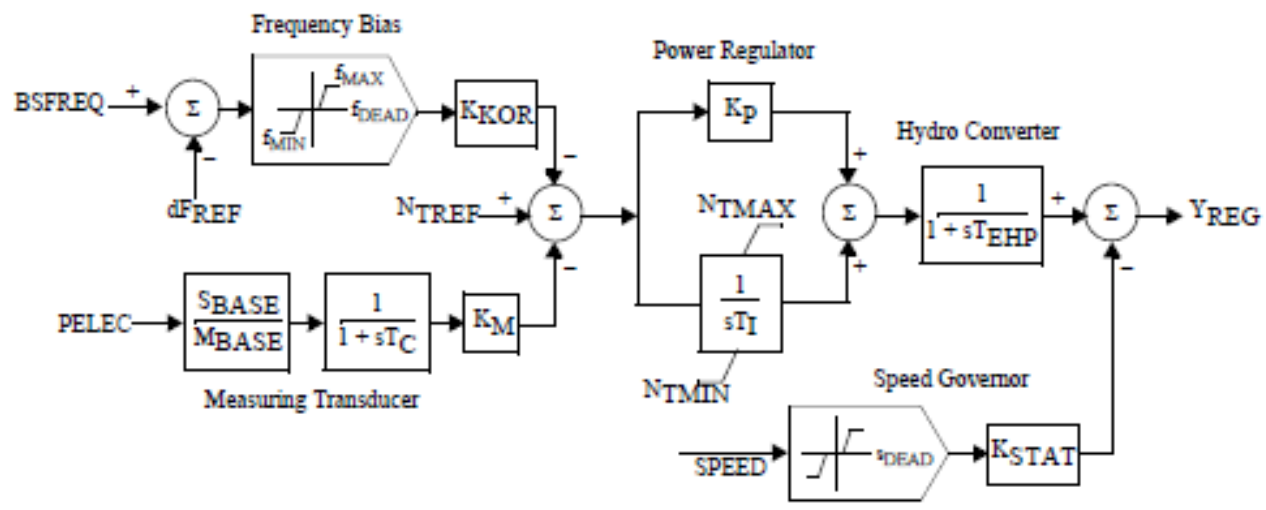

Governor

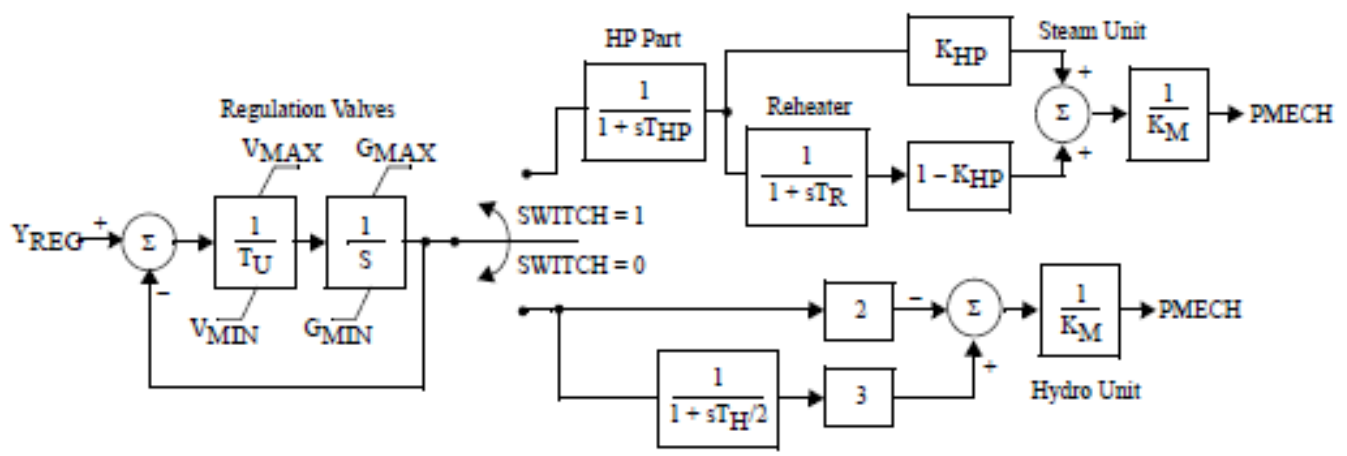

Turbine

Figure 3-9 TURCZT Model Block Diagram for Turbine-Governor Dynamics 


\subsubsection{TWDM1T Model}

The hydro turbine-governor model TWDM1T has the same basic permanent and transient droop elements as the HYGOV model, but it adds a representation for a tail water depression protection system (Figure 3-10).

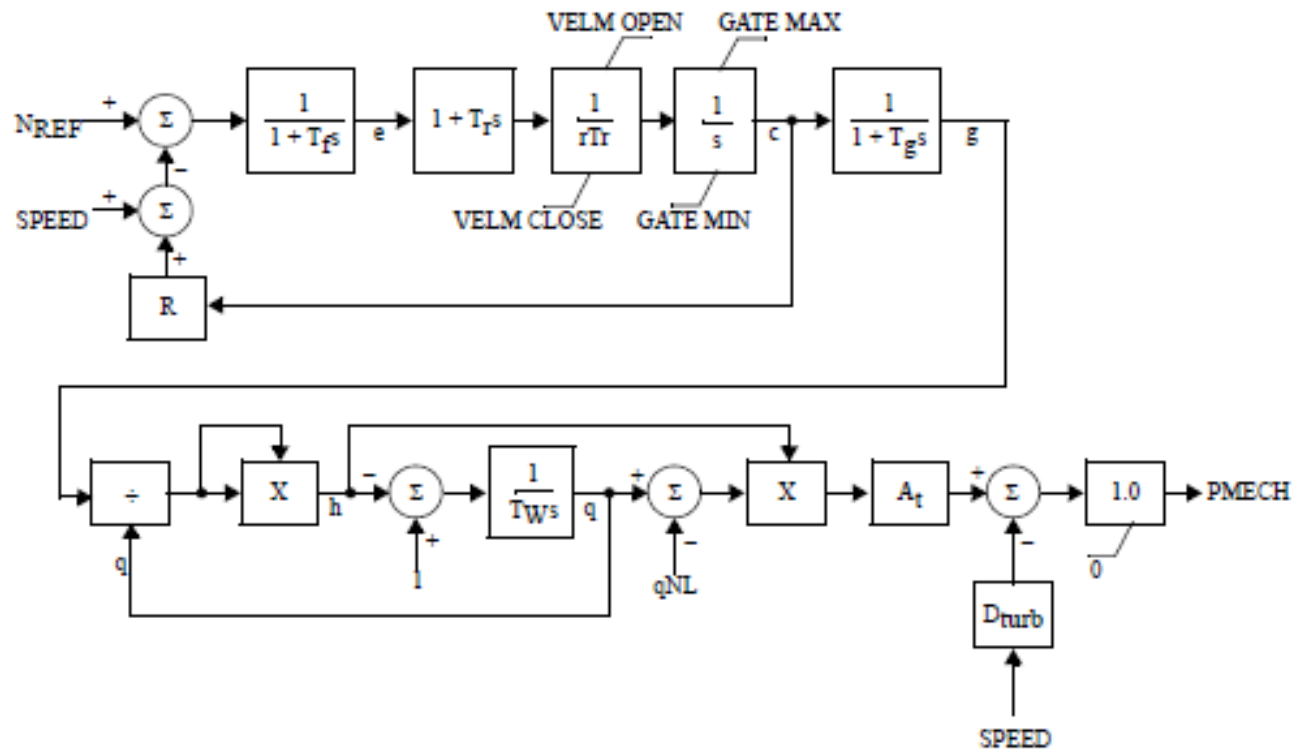

Tail Water Depression Model 1

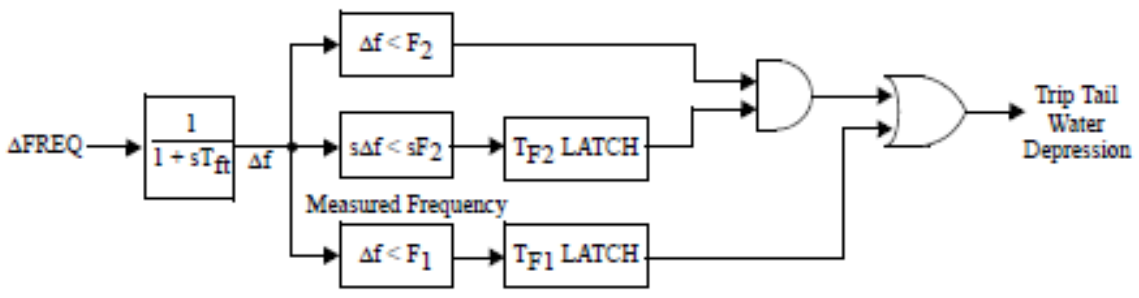

Tail Water Depression Trip Model

Figure 3-10 TWDM1T Model Block Diagram for Turbine-Governor/Penstock Dynamics

In this model,

$$
\begin{aligned}
& R=\text { permanent droop (p.u. on generator MVA rating) } \\
& r=\text { transient droop (p.u. on generator MVA rating) } \\
& T_{r}=\text { governor time constant }(s) \\
& T_{f}=\text { filter time constant }(s) \\
& T_{g}=\text { servo time constant }(s)
\end{aligned}
$$


VELMX = open gate velocity limit (p.u./s)

VELMN = close gate velocity limit (p.u./s)

GMAX = maximum gate limit (p.u.)

GMIN = minimum gate limit (p.u.)

$\mathrm{T}_{\mathrm{W}}=$ water time constant $(\mathrm{s})$

$A_{t}=$ turbine gain (p.u.)

Dturb = turbine damping factor (p.u.)

$q_{\mathrm{NL}}=$ flow rate at no load (p.u.)

$F_{1}=$ frequency deviation (p.u.)

$\mathrm{T}_{\mathrm{F} 1}=$ time delay $(\mathrm{s})$

$F_{2}=$ frequency deviation (p.u.)

sF2 = frequency (p.u.)

$\mathrm{T}_{\mathrm{F} 2}=$ time delay (p.u.)

GMXRT = rate at which GMAX changes when $T_{\text {WD }}$ is tripped (p.u./s)

$\mathrm{N}_{\mathrm{REF}}=$ set point frequency deviation (p.u.)

$\mathrm{T}_{\mathrm{ft}}=$ frequency filter time constant $(\mathrm{s})$ 


\subsubsection{TWDM2T Model}

The hydro turbine-governor model TWDM2T has the same basic turbine/penstock elements as the HYGOV model but it adds a representation for a tail water depression protection system and uses a governor proportional-integral-derivative (PID) controller (Figure 3-11).

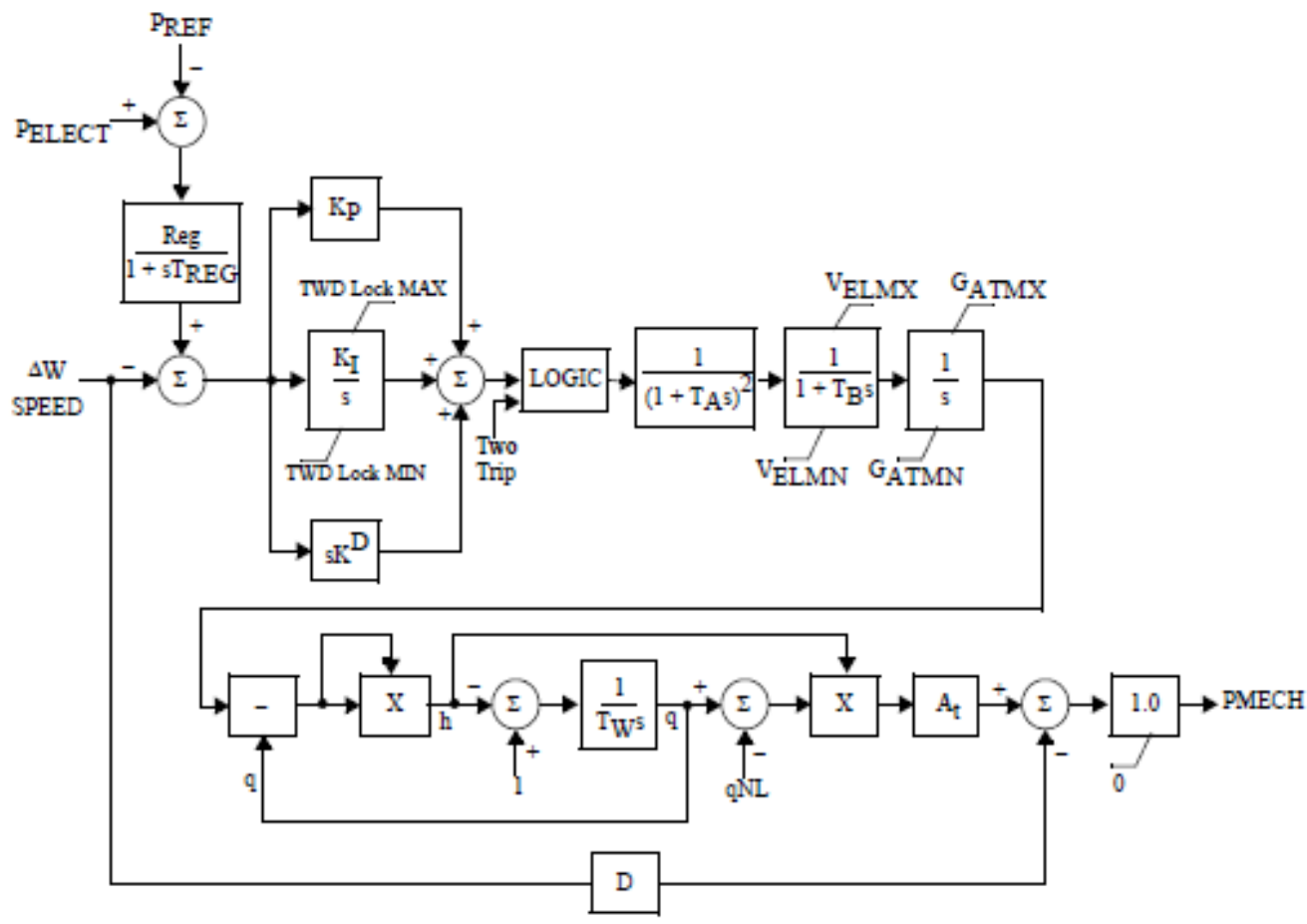

Tail Water Depression Model 2

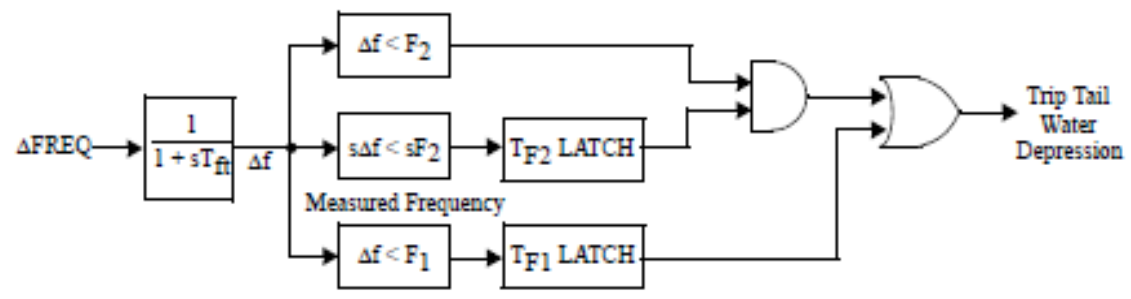

Tail Water Depression Trip Model

Figure 3-11 TWDM2T Model Block Diagram for Turbine-Governor/Penstock Dynamics 
In this model,

$$
\begin{aligned}
& \text { Reg = permanent droop (p.u. on generator MVA rating) } \\
& K_{P}=\text { controller proportional gain (p.u.) } \\
& K_{1}=\text { controller integral gain (p.u./s) } \\
& K_{D}=\text { controller derivative gain (p.u.-s) } \\
& T_{A}=\text { controller time constant (s) } \\
& T_{B}=\text { controller time constant (s) } \\
& \text { VELMX = open gate velocity limit (p.u./s) } \\
& V E L M N=\text { close gate velocity limit (p.u./s) } \\
& G_{A T M X}=\text { maximum gate limit (p.u.) } \\
& G_{A T M N}=\text { minimum gate limit (p.u.) } \\
& T_{W}=\text { water time constant (s) } \\
& A_{t}=\text { turbine gain (p.u.) } \\
& q_{N L}=\text { flow rate at no load (p.u.) } \\
& D_{\text {turb }}=\text { turbine damping factor (p.u.) } \\
& F_{1}=\text { frequency deviation (p.u.) } \\
& T_{F 1}=\text { time delay (s) } \\
& F_{2}=\text { frequency deviation (p.u.) } \\
& T_{F 2}=\text { frequency (p.u.) } \\
& T_{f t}=\text { frequency filter time constant (s) }
\end{aligned}
$$




\subsubsection{WEHGOV Model}

WEHGOV is a model of a Woodward Electronic hydro-governor with PID control (Figures 3-12 and 3-13). The turbine is represented by a nonlinear model for the penstock dynamics in a fashion similar to that used for HYGOV, but the model includes look-up tables to allow the user to represent nonlinearities in flow rate versus gate position and in mechanical power versus flow rate during steady-state operation. The model allows for the use of two feedback signals for droop: (1) electrical power and gate position and (2) PID output.

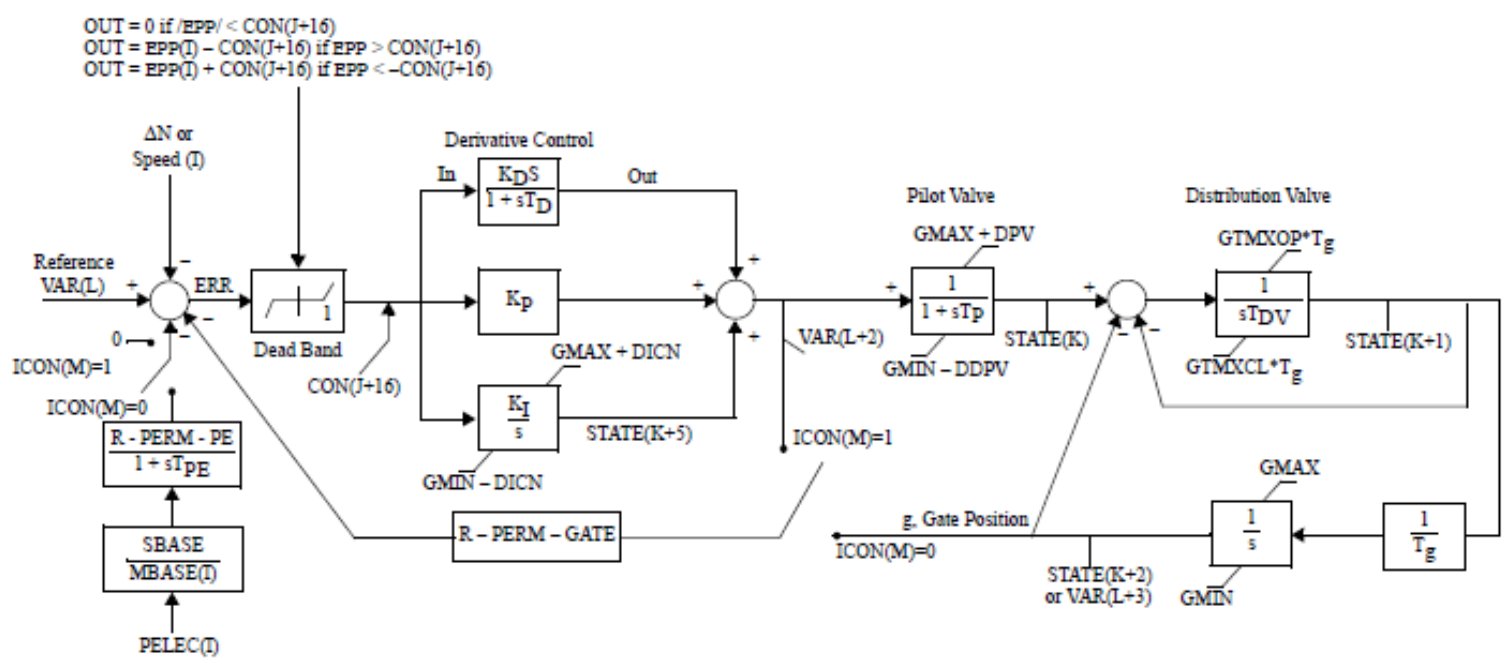

Governor and Hydraulic Actuators

Figure 3-12 WEHGOV Model Block Diagram for Governor Dynamics

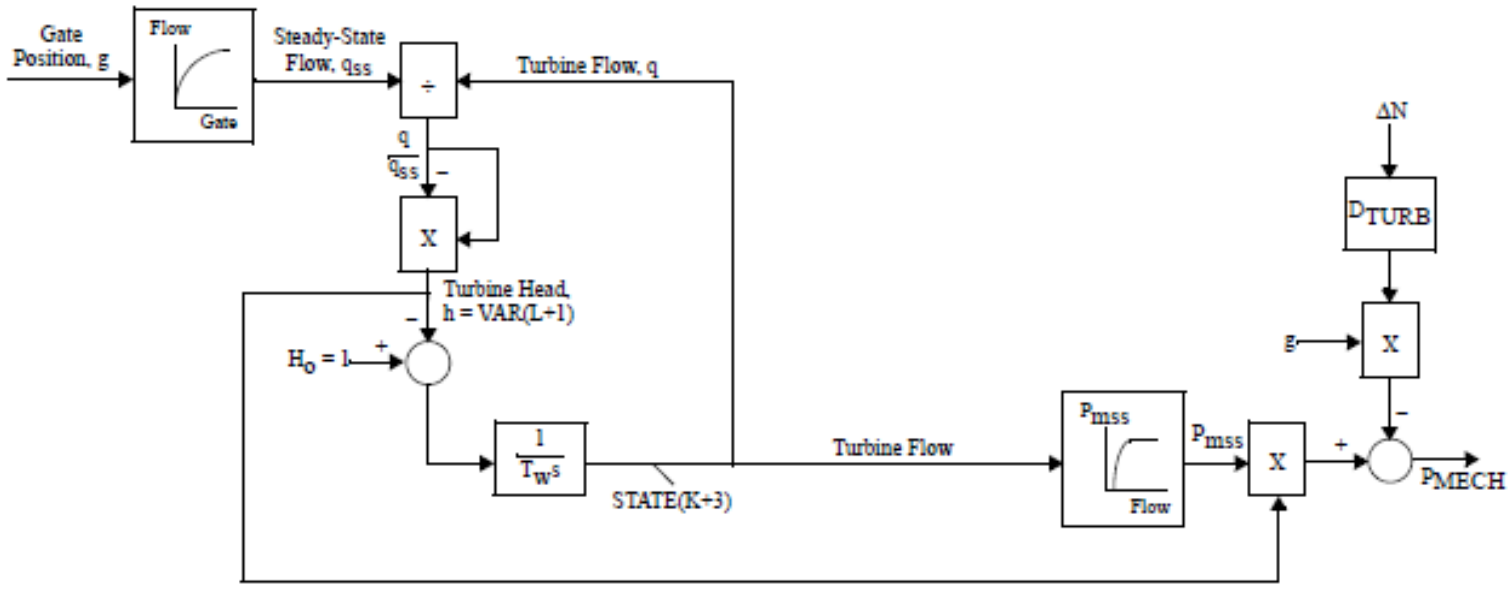

Turbine Dynamics

Figure 3-13 WEHGOV Model Block Diagram for Turbine/Penstock Dynamics 


\section{PID Controller}

The derivative controller has a time constant to limit the derivative characteristic beyond a breakdown frequency to avoid amplification of high-frequency noise. This time constant is labeled $T_{D}$, and its value is typically 0.10 second. The PID controller also has a limiter on the integral control to prevent windup when the gates are at their limits. The gate position limits are set in GMAX for maximum and GMIN for minimum. For the integral controller, there is another variable called DICN, which allows the integral controller to advance beyond the values for the gate limits. The maximum limit for the integral controller is:

$$
\text { GMAX + DICN (p.u.) }
$$

The minimum limit is:

$$
\text { GMIN - DICN (p.u.) }
$$

The value for DICN ranges from $0 \%$ to $10 \%$, and is set with the field tuning for the governor.

\section{Pilot Valve}

The output signal of the PID controller is fed into the pilot valve. The pilot valve also has a set of limits that are similar to those for the integral controller. The maximum limit for the pilot valve output is:

$$
\text { GMAX + DPV (p.u.) }
$$

The minimum limit is:

$$
\text { GMIN - DPV (p.u.) }
$$

The value for DPV is typically about $2 \%$ to ensure that the gate can be fully opened or closed.

\section{Distribution Valve}

The output signal of the pilot valve is fed into the distribution valve. The limits of the distribution valve define the maximum rates to open or close the gates. These two rate limits are:

GTMXOP, maximum gate opening rate (p.u./s)

GTMXCL, maximum gate closing rate (p.u./s)

The values for both parameters are in p.u. gate position per second. Note that the value for GTMXCL must be less than 0 .

\section{Turbine Model}

The model for the penstock hydraulics is similar to that for HYGOV. However, the turbine model includes two look-up tables to account for steady-state nonlinearities in the model. The first table represents the water flow rate through the turbine as a function of gate position. The second table represents p.u. mechanical power on the generator MVA rating as a function of water flow rate. 


\subsubsection{WPIDHY Model}

This is a hydro turbine-governor/penstock model that includes governor controls representing a Woodward PID hydro governor (Figure 3-14). The model includes a nonlinear gate/power relationship and a linearized turbine/penstock model.

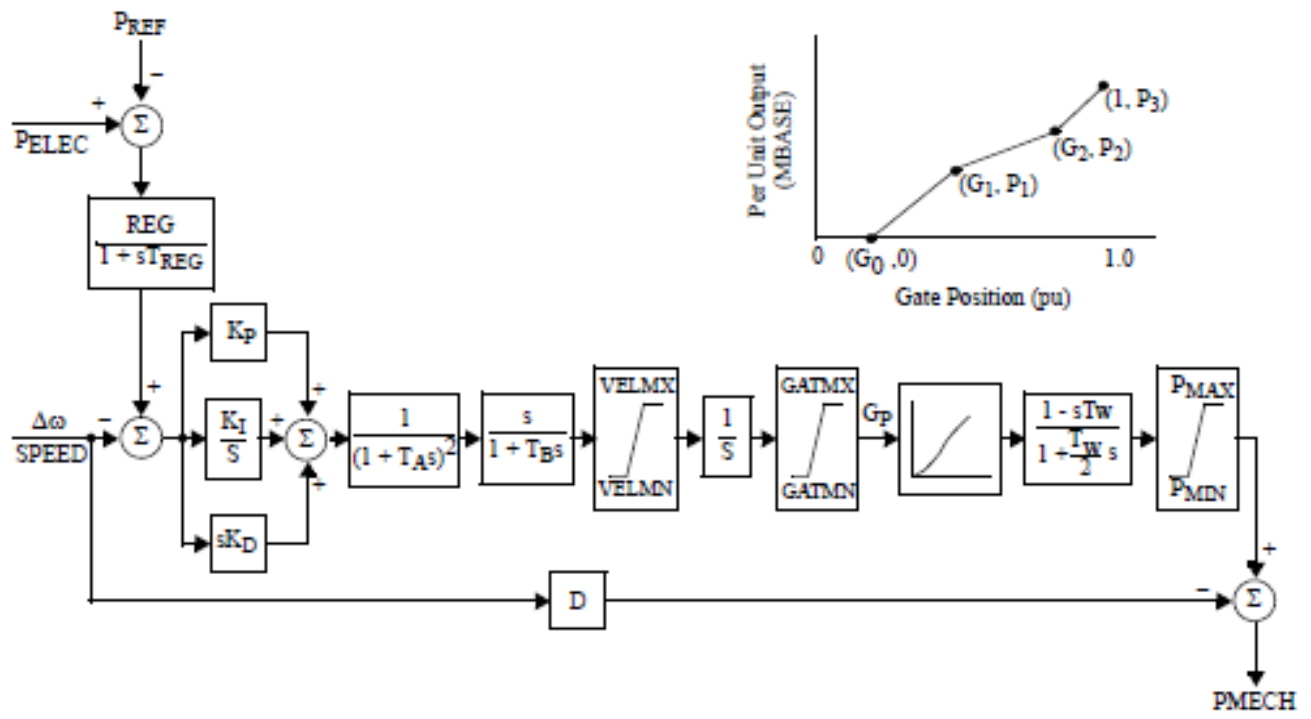

Figure 3-14 WPIDHY Model Block Diagram for Turbine-Governor/Penstock Dynamics

In this model,

REG = permanent droop (p.u. on generator MVA base)

$\mathrm{T}_{\mathrm{REG}}=$ governor time constant (s)

$\mathrm{K}_{\mathrm{P}}=$ controller proportional gain (p.u.)

$\mathrm{K}_{\mathrm{l}}=$ controller integral gain (p.u./s)

$\mathrm{K}_{\mathrm{D}}=$ controller derivative gain (p.u./s)

$\mathrm{T}_{\mathrm{A}}=$ controller time constant (s)

$\mathrm{T}_{\mathrm{B}}=$ controller time constant ( $\mathrm{s}$ )

VELMX = open gate velocity limit (p.u./s)

VELMN = close gate velocity limit (p.u./s)

GATMX = maximum gate limit (p.u.)

GATMN = minimum gate limit (p.u.)

$\mathrm{T}_{\mathrm{W}}=$ water time constant (s)

$\mathrm{P}_{\mathrm{MAX}}=$ maximum gate position (p.u.)

$\mathrm{P}_{\mathrm{MIN}}=$ minimum gate position (p.u.) 


$$
\begin{aligned}
& G_{0}=\text { gate position at no load (p.u.) } \\
& G_{1}=\text { first gate intermediate position (p.u.) } \\
& P_{1}=\text { power at gate position } G_{1} \text { (p.u. on generator MVA rating) } \\
& G_{2}=\text { second gate intermediate position (p.u.) } \\
& P_{2}=\text { power at gate position } G_{2} \text { (p.u. on generator MVA rating) } \\
& P_{3}=\text { power at fully open gate (p.u. on generator MVA rating) }
\end{aligned}
$$

\subsubsection{WSHYDD Model}

This is the WECC double-derivative hydro turbine-governor model (Figure 3-15). This model includes two deadbands. One "intentional" deadband is implemented at the input. It has a "bowtie" hysteresis form when $\mathrm{db}_{1}$ is set equal to err, and it has no hysteresis when err is set to 0 . The second deadband in the gate controls loop is "unintentional," which describes mechanical backlash with a hysteresis form. When $\mathrm{db}_{2}$ is set to 0 , the mechanical backlash is ignored. This dynamic model also includes a nonlinear gate/power relationship and a linearized turbine/penstock model. The governor's permanent droop $(R)$ is entered in p.u. on the turbine $\mathrm{MW}$ rating $\mathrm{T}_{\text {rate }}$
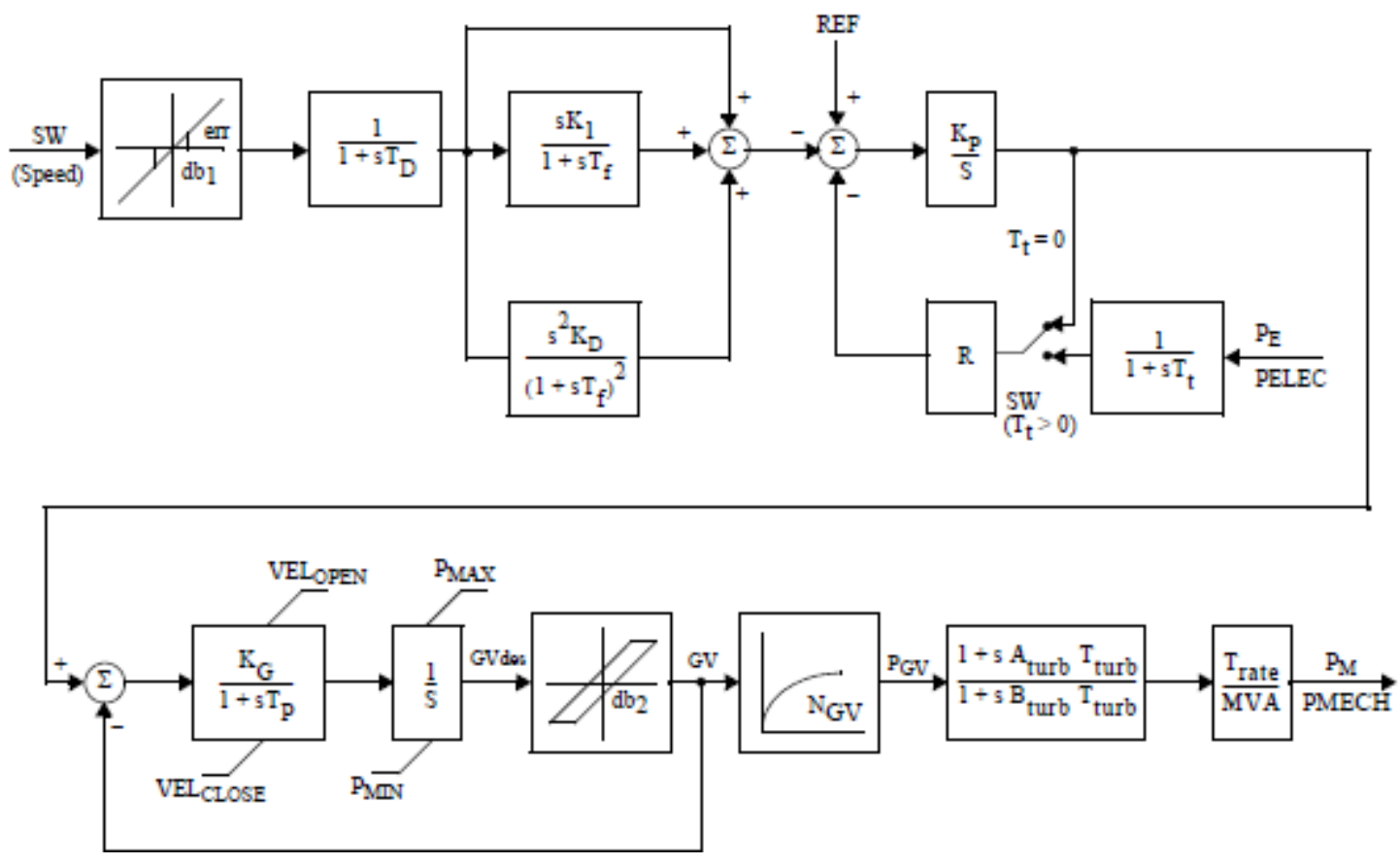

Figure 3-15 WSHYDD Model Block Diagram for Turbine-Governor/Penstock Dynamics

In this model,

$$
\begin{aligned}
& \mathrm{db}_{1}=\text { deadband width (p.u.) } \\
& \text { err = deadband hysteresis (p.u.) } \\
& \mathrm{T}_{\mathrm{D}}=\text { input filter time constant (s) }
\end{aligned}
$$


$\mathrm{K}_{1}$ = derivative gain (p.u.)

$\mathrm{T}_{\mathrm{f}}=$ derivative time constant $(\mathrm{s})$

$\mathrm{K}_{\mathrm{D}}=$ double derivative gain (p.u.)

$\mathrm{K}_{\mathrm{P}}=$ integral gain (p.u.)

$\mathrm{R}=$ droop (p.u. on Trate)

$\mathrm{T}_{\mathrm{t}}=$ power feedback time constant (s)

$\mathrm{K}_{\mathrm{G}}=$ gate servo gain (p.u.)

$\mathrm{T}_{\mathrm{P}}=$ gate servo time constant ( $\mathrm{s}$ )

VEL $L_{\text {OPEN }}=$ maximum gate opening rate (p.u./s)

$\mathrm{VEL}_{\text {CLOSE }}=$ maximum gate closing rate (p.u./s)

$\mathrm{P}_{\text {MAX }}=$ maximum gate opening (p.u.)

$\mathrm{P}_{\mathrm{MIN}}=$ minimum gate opening (p.u.)

$\mathrm{db}_{2}=$ deadband (p.u.)

$\mathrm{GV}_{1}=$ coordinate of power-gate look-up table (p.u. gate)

$\mathrm{PGV}_{1}=$ coordinate of power-gate look-up table (p.u. power)

$\mathrm{GV}_{2}=$ coordinate of power-gate look-up table (p.u. gate)

$\mathrm{PGV}_{2}=$ coordinate of power-gate look-up table (p.u. power)

$\mathrm{GV}_{3}=$ coordinate of power-gate look-up table (p.u. gate)

$\mathrm{PGV}_{3}=$ coordinate of power-gate look-up table (p.u. power)

$\mathrm{GV}_{4}=$ coordinate of power-gate look-up table (p.u. gate)

$\mathrm{PGV}_{4}=$ coordinate of power-gate look-up table (p.u. power)

$\mathrm{GV}_{5}=$ coordinate of power-gate look-up table (p.u. gate)

$\mathrm{PGV}_{5}=$ coordinate of power-gate look-up table (p.u. power)

$A_{\text {turb }}=$ turbine lead time constant multiplier

$\mathrm{B}_{\text {turb }}(>0)=$ turbine lag time constant multiplier

$\mathrm{T}_{\text {turb }}(>0)=$ turbine time constant $(\mathrm{s})$

$\mathrm{T}_{\text {rate }}=$ turbine rating $(\mathrm{MW})$ 


\subsubsection{WSHYPG Model}

This is the WECC GP hydro turbine-governor model with a PID controller (Figure 3-16). The penstock dynamics are similar to those of the WECC WSHYDD hydro turbine-governor model.
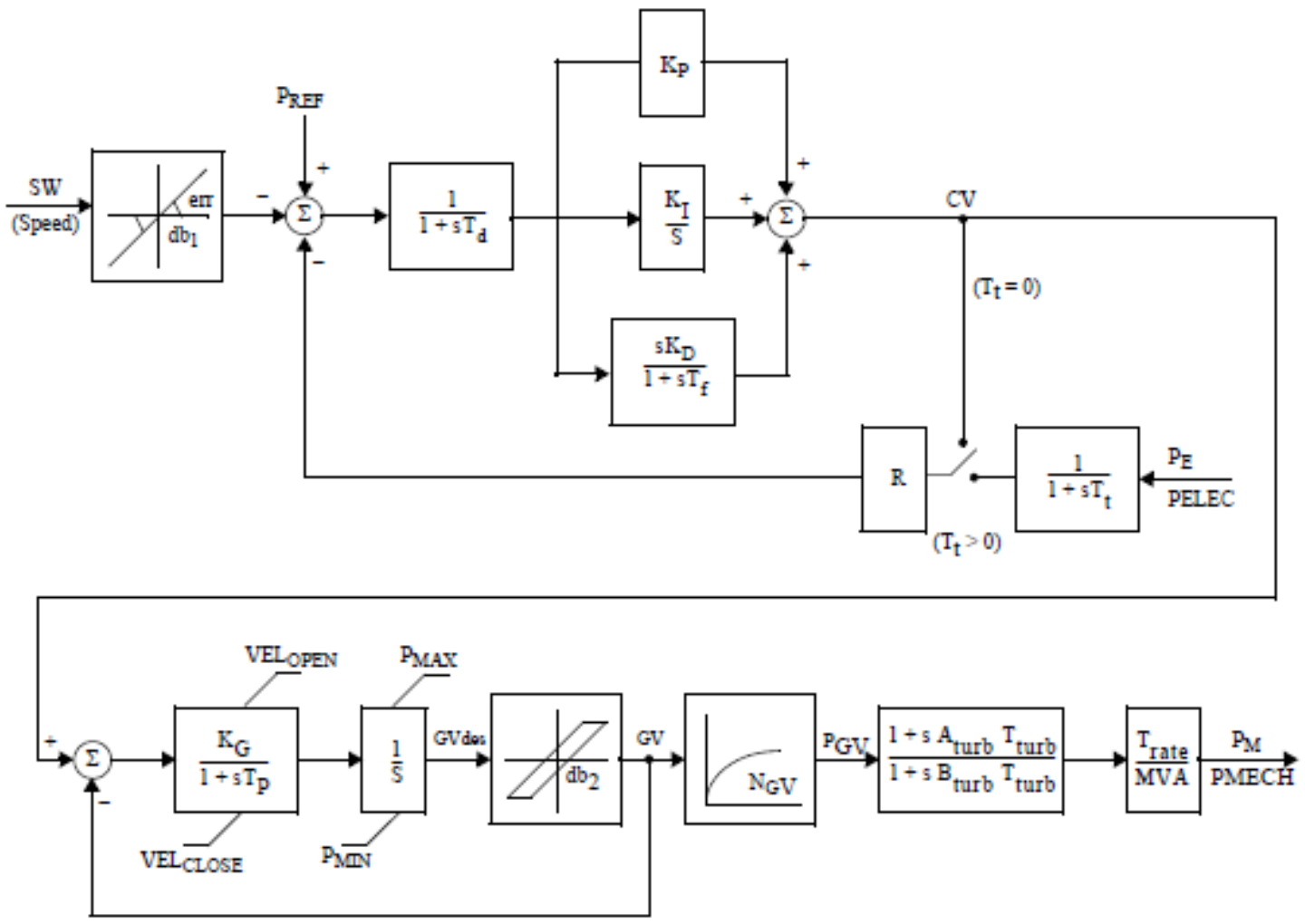

Figure 3-16 WSHYPG Model Block Diagram for Turbine-Governor/Penstock Dynamics

In this model,

$\mathrm{db}_{1}=$ deadband width (p.u.)

err = deadband hysteresis (p.u.)

$\mathrm{T}_{\mathrm{d}}=$ input filter time constant (s)

$\mathrm{K}_{\mathrm{I}}=$ integral gain (p.u.)

$\mathrm{T}_{\mathrm{f}}=$ derivative time constant $(\mathrm{s})$

$\mathrm{K}_{\mathrm{D}}=$ derivative gain (p.u.)

$\mathrm{K}_{\mathrm{P}}=$ proportional gain (p.u.)

$R=\operatorname{droop}($ p.u. on Trate)

$\mathrm{T}_{\mathrm{t}}=$ power feedback time constant (s)

$\mathrm{K}_{\mathrm{G}}=$ gate servo gain (p.u.) 
$\mathrm{T}_{\mathrm{P}}=$ gate servo time constant $(\mathrm{s})$

$\mathrm{VEL}_{\mathrm{OPEN}}=$ maximum gate opening rate $($ p.u./s)

$\mathrm{VEL}_{\mathrm{CLOSE}}=$ maximum gate closing rate (p.u./s)

$P_{\text {MAX }}=$ maximum gate opening (p.u.)

$\mathrm{P}_{\mathrm{MIN}}=$ minimum gate opening (p.u.)

$\mathrm{db}_{2}=$ deadband (p.u.)

$\mathrm{GV}_{1}=$ coordinate of power-gate look-up table ( p.u. gate)

$\mathrm{PGV}_{1}=$ coordinate of power-gate look-up table (p.u. power)

$\mathrm{GV}_{2}=$ coordinate of power-gate look-up table (p.u. gate)

$\mathrm{PGV}_{2}=$ coordinate of power-gate look-up table (p.u. power)

$\mathrm{GV}_{3}=$ coordinate of power-gate look-up table (p.u. gate)

$\mathrm{PGV}_{3}=$ coordinate of power-gate look-up table (p.u. power)

$\mathrm{GV}_{4}=$ coordinate of power-gate look-up table (p.u. gate)

$\mathrm{PGV}_{4}=$ coordinate of power-gate look-up table (p.u. power)

$\mathrm{GV}_{5}=$ coordinate of power-gate look-up table (p.u. gate)

$\mathrm{PGV}_{5}=$ coordinate of power-gate look-up table (p.u. power)

$A_{\text {turb }}=$ turbine lead time constant multiplier

$\mathrm{B}_{\text {turb }}(>0)=$ turbine lag time constant multiplier

$\mathrm{T}_{\text {turb }}(>0)=$ turbine time constant $(\mathrm{s})$

$\mathrm{T}_{\text {rate }}=$ turbine rating $(\mathrm{MW})$ 


\subsection{An Example of the Prevalence of the Hydro Models in a Large U.S. Simulation Database Using the PSS ${ }^{\circledR} E$ Software}

Section 3.2 showed that the $\mathrm{PSS}^{\circledR} E$ software package has a wide variety of models to represent hydro units. Some of these models are used much more often than others. To illustrate this, a typical representation of the eastern U.S. power system was analyzed.

An official MMWG PSS ${ }^{\circledR} E$ stability database named "2016SUM-2010Series-Final-ds_rev3" was used to demonstrate the governor/turbine models that are being used to represent hydro machines in the Eastern Interconnection for stability studies. Table 3.1 shows how often each hydro turbine-governor model in this database is used. Note that this table is provided for illustrative purposes only and should not be construed to imply that any model is better than another model or that the results shown here are typical of those from other systems. Also note that some utilities may use more detailed models when studying dynamic phenomena associated with their particular plants.

The most commonly used hydro model in the Eastern Interconnection is the HYGOV model, which is used to represent about $64 \%$ of the units. The next most commonly used model is the IEEEG2 model, which is used for about $15 \%$ of the units. Most of the remaining units are modeled using one of the several models that represent PID governors. 
Table 3-1 Governor/Turbine Models Used to Represent Hydroelectric Units in a Typical Eastern Interconnection Stability Database Using the PSS ${ }^{\circledR} E$ Software

\begin{tabular}{|c|c|c|c|c|c|c|c|c|}
\hline Area No. & Area Name & HYGOV & HYGOV2 & IEEEG2 & IEEEG3 & PIDGOV & WEHGOV & WPIDHY \\
\hline 1 & West & 12 & & & & & & \\
\hline 5 & Mohawk & 2 & & & & & & \\
\hline 6 & Capital & 7 & & 2 & & & & \\
\hline 7 & Hudson & 1 & & & & & & \\
\hline 9 & Dunwoodie & 1 & & & & & & \\
\hline 101 & ISO-NE & 29 & & 5 & & 17 & & 14 \\
\hline 103 & IESO & 102 & & & 8 & & 43 & 9 \\
\hline 105 & NB & 8 & & 9 & & & & \\
\hline 106 & NS & 31 & & & & & & \\
\hline 201 & $A P$ & 3 & & & & & & \\
\hline 205 & AEP & 11 & & & & & & \\
\hline 208 & DEM & 3 & & & & & & \\
\hline 210 & SIGE & & & & & 3 & & \\
\hline 226 & PENLEC & 11 & & & & & & \\
\hline 227 & METED & 1 & & & & & & \\
\hline 228 & JCP\&L & 3 & & & & & & \\
\hline 229 & PPL & 17 & & & & & & \\
\hline 230 & PECO & 12 & & & & & & 7 \\
\hline 295 & WEC & 29 & & & & & & \\
\hline 320 & EKPC & 4 & & & & & & \\
\hline 340 & CPLE & & & & 10 & & & \\
\hline 341 & CPLW & & & & 5 & & & \\
\hline 343 & SCEG & & & 13 & & & & \\
\hline 344 & SCEG & & & 8 & & & & \\
\hline 345 & DVP & & & 8 & & & 6 & 7 \\
\hline 346 & SOCO & & & 80 & & & 1 & 2 \\
\hline 347 & TVA & 153 & & & & & & \\
\hline 351 & EES & 7 & & & & & & \\
\hline 354 & SERU & & & 8 & & & & \\
\hline 355 & SETH & & & 4 & & & & \\
\hline 356 & AMMO & & & 2 & & & & \\
\hline 363 & LGEE & 8 & & & & & & \\
\hline 402 & PEF & 4 & & & & & & \\
\hline 515 & SWPA & 57 & & & & & & \\
\hline 520 & AEPW & 4 & & & & & & \\
\hline 523 & GRDA & 8 & & & & & & \\
\hline 544 & EMDE & 4 & & & & & & \\
\hline 608 & MP & 6 & & & & & & \\
\hline 640 & NPPD & 1 & & & & & & \\
\hline 667 & $\mathrm{MH}$ & & 29 & & & & 12 & \\
\hline 672 & SPC & 7 & & & 8 & & 3 & \\
\hline 694 & ALTE & 6 & & & & & & \\
\hline 696 & WPS & 30 & & & & & & \\
\hline \multirow[t]{3}{*}{698} & UPPC & 7 & & & & & & \\
\hline & Total & 589 & 29 & 139 & 31 & 20 & 65 & 39 \\
\hline & $\%$ of Total & 64.3 & 3.2 & 15.4 & 3.4 & 2.2 & 7.2 & 4.3 \\
\hline
\end{tabular}


This page intentionally left blank 


\section{Section \\ 4}

\section{PSLF Hydro Turbine-Governor Simulation Models}

The PSLF program is the second most widely used power system simulation package in the United States. It is used widely in the Western Interconnection, which contains many large hydroelectric plants.

The explanations for the PSLF models are arranged in this section in about the same order as those for the $\mathrm{PSS}^{\circledR} \mathrm{E}$ models. There are some differences in the models, and these are mentioned as appropriate.

\subsection{Simulation Models in PSLF Version 18}

\subsubsection{GPWSCC Model}

The GPWSCC governor model has a PID governor that represents the WECC type GP governor/turbine model. It is similar to the PSS ${ }^{\circledR} \mathrm{E}$ model WHHYPG, and the comments given about that model also apply to GPWSCC.

The model block diagram is shown in Figure 4-1, and the parameters of the model are defined in Table 4-1. 

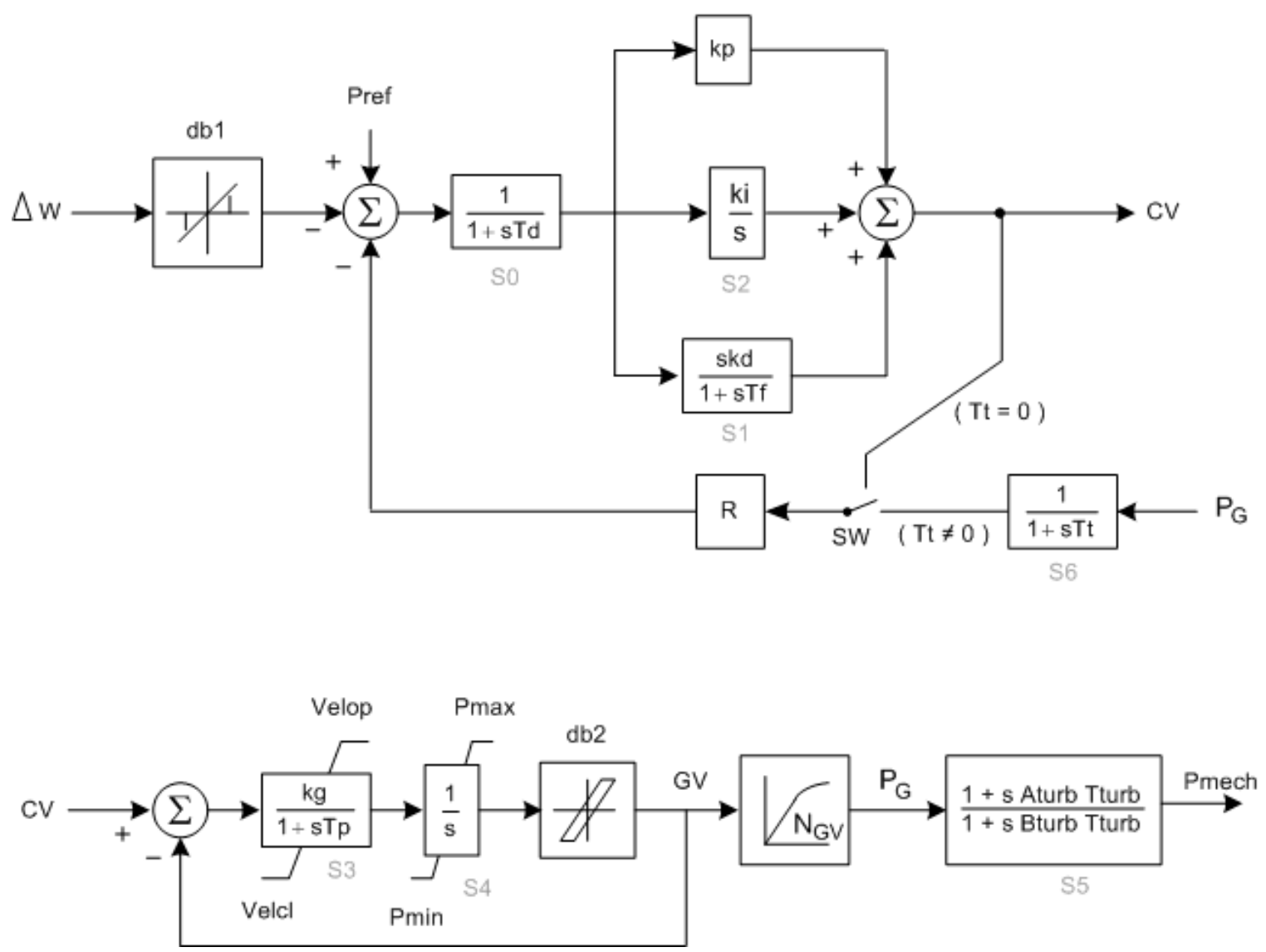

Figure 4-1 Block Diagram of the PSLF GPWSCC Model 
Table 4-1 Parameters Used in the PSLF GPWSCC Model

\begin{tabular}{|c|c|}
\hline Pmax & Maximum gate opening, p.u. of mwcap \\
\hline Pmin & Minimum gate opening, p.u. of mwcap \\
\hline$R$ & Steady-state droop, p.u. \\
\hline $\mathrm{Td}$ & Input filter time constant, s \\
\hline Tf & Washout time constant, s \\
\hline$T p$ & Gate servo time constant, $\mathrm{s}$ \\
\hline Velop & Maximum gate opening velocity, p.u./s \\
\hline Velcl & Maximum gate closing velocity, p.u./s $(<0)$ \\
\hline Kp & Proportional gain, p.u. \\
\hline Kd & Derivative gain, p.u. \\
\hline $\mathrm{Ki}$ & Integral gain, p.u. \\
\hline $\mathrm{Kg}$ & Gate servo gain, p.u. \\
\hline Tturb & Turbine time constant, $\mathrm{s}$ \\
\hline Aturb & Turbine numerator multiplier \\
\hline Bturb & Turbine denominator multiplier \\
\hline $\mathrm{Tt}$ & Power feedback time constant, $\mathrm{s}$ \\
\hline $\mathrm{db} 1$ & Intentional deadband width, $\mathrm{Hz}$ \\
\hline eps & Intentional deadband hysteresis, $\mathrm{Hz}$ \\
\hline $\mathrm{db} 2$ & Unintentional deadband, MW \\
\hline Gv1 & Nonlinear gain point 1, p.u. gv \\
\hline Pgv1 & Nonlinear gain point 1 , p.u. power \\
\hline Gv2 & Nonlinear gain point 2, p.u. gv \\
\hline Pgv2 & Nonlinear gain point 2, p.u. power \\
\hline Gv3 & Nonlinear gain point 3, p.u. gv \\
\hline Pgv3 & Nonlinear gain point 3, p.u. power \\
\hline Gv4 & Nonlinear gain point 4, p.u. gv \\
\hline Pgv4 & Nonlinear gain point 4, p.u. power \\
\hline Gv5 & Nonlinear gain point 5, p.u. gv \\
\hline Pgv5 & Nonlinear gain point 5, p.u. power \\
\hline Gv6 & Nonlinear gain point 6, p.u. gv \\
\hline Pgv6 & Nonlinear gain point 6, p.u. power \\
\hline
\end{tabular}




\subsubsection{G2WSCC Model}

The G2WSCC governor model has a double derivative governor that represents the WECC type G2 governor/ turbine model. It is similar to the PSS ${ }^{\circledR} \mathrm{E}$ model WHHYDD, and the comments given about that model also apply to G2WSCC.

The model block diagram is shown in Figure 4-2, and the parameters of the model are defined in Table 4-2.

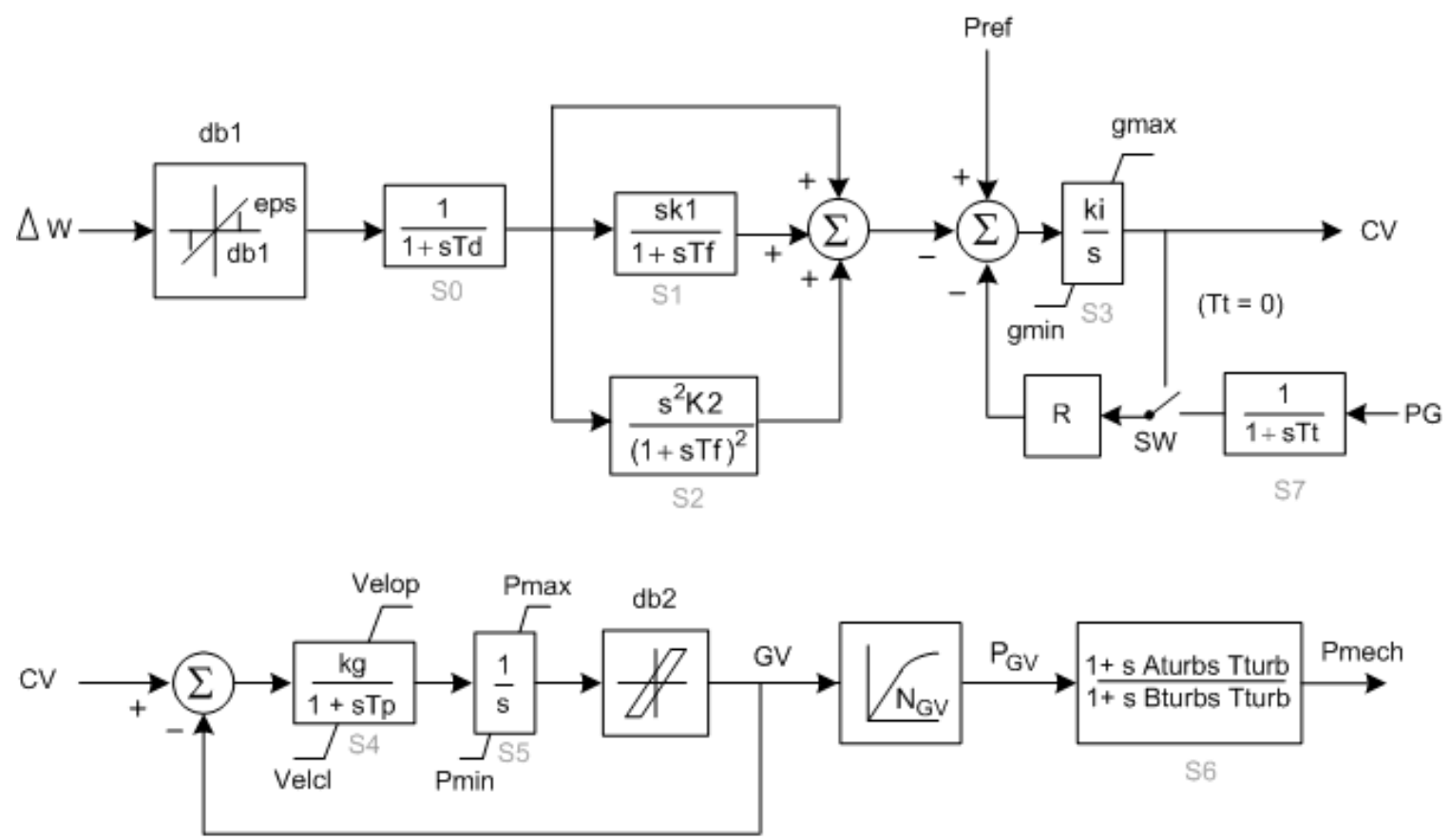

Figure 4-2 Block Diagram of the PSLF G2WSCC Model 
Table 4-2 Parameters Used in the PSLF G2WSCC Model

\begin{tabular}{|c|c|}
\hline Pmax & Maximum gate opening, p.u. of mwcap \\
\hline Pmin & Minimum gate opening, p.u. of mwcap \\
\hline $\mathrm{R}$ & Steady state droop, p.u. \\
\hline $\mathrm{Td}$ & Input filter time constant, s \\
\hline Tf & Washout time constant, $\mathrm{s}$ \\
\hline $\mathrm{Tp}$ & Gate servo time constant, $\mathrm{s}$ \\
\hline Velop & Maximum gate opening velocity, p.u./s \\
\hline Velcl & Maximum gate closing velocity, p.u./s $(<0)$ \\
\hline $\mathrm{K} 1$ & Single derivative gain, p.u. \\
\hline $\mathrm{K} 2$ & Double derivative gain, p.u. \\
\hline $\mathrm{Ki}$ & Integral gain, p.u. \\
\hline $\mathrm{Kg}$ & Gate servo gain, p.u. \\
\hline Tturb & Turbine time constant, $\mathrm{s}$ \\
\hline Aturb & Turbine numerator multiplier \\
\hline Bturb & Turbine denominator multiplier \\
\hline $\mathrm{Tt}$ & Power feedback time constant, $\mathrm{s}$ \\
\hline $\mathrm{db} 1$ & Intentional deadband width, $\mathrm{Hz}$ \\
\hline eps & Intentional deadband hysteresis, $\mathrm{Hz}$ \\
\hline $\mathrm{db} 2$ & Unintentional deadband, MW \\
\hline Gv1 & Nonlinear gain point 1 , p.u. gv \\
\hline Pgv1 & Nonlinear gain point 1, p.u. power \\
\hline Gv2 & Nonlinear gain point 2, p.u. gv \\
\hline Pgv2 & Nonlinear gain point 2, p.u. power \\
\hline Gv3 & Nonlinear gain point 3, p.u. gv \\
\hline Pgv3 & Nonlinear gain point 3, p.u. power \\
\hline Gv4 & Nonlinear gain point 4, p.u. gv \\
\hline Pgv4 & Nonlinear gain point 4 , p.u. power \\
\hline Gv5 & Nonlinear gain point 5 , p.u. gv \\
\hline Pgv5 & Nonlinear gain point 5, p.u. power \\
\hline Gv6 & Nonlinear gain point 6 , p.u. gv \\
\hline Pgv6 & Nonlinear gain point 6, p.u. power \\
\hline
\end{tabular}




\subsubsection{HYG3 Model}

The HYG3 governor model includes a PID governor that can be used to represent the WECC type GP governor/turbine model and a double derivative governor that represents the WECC type G2 governor/turbine model.

The model block diagram is shown in Figure 4-3, and the parameters of the model are defined in Table 4-3.

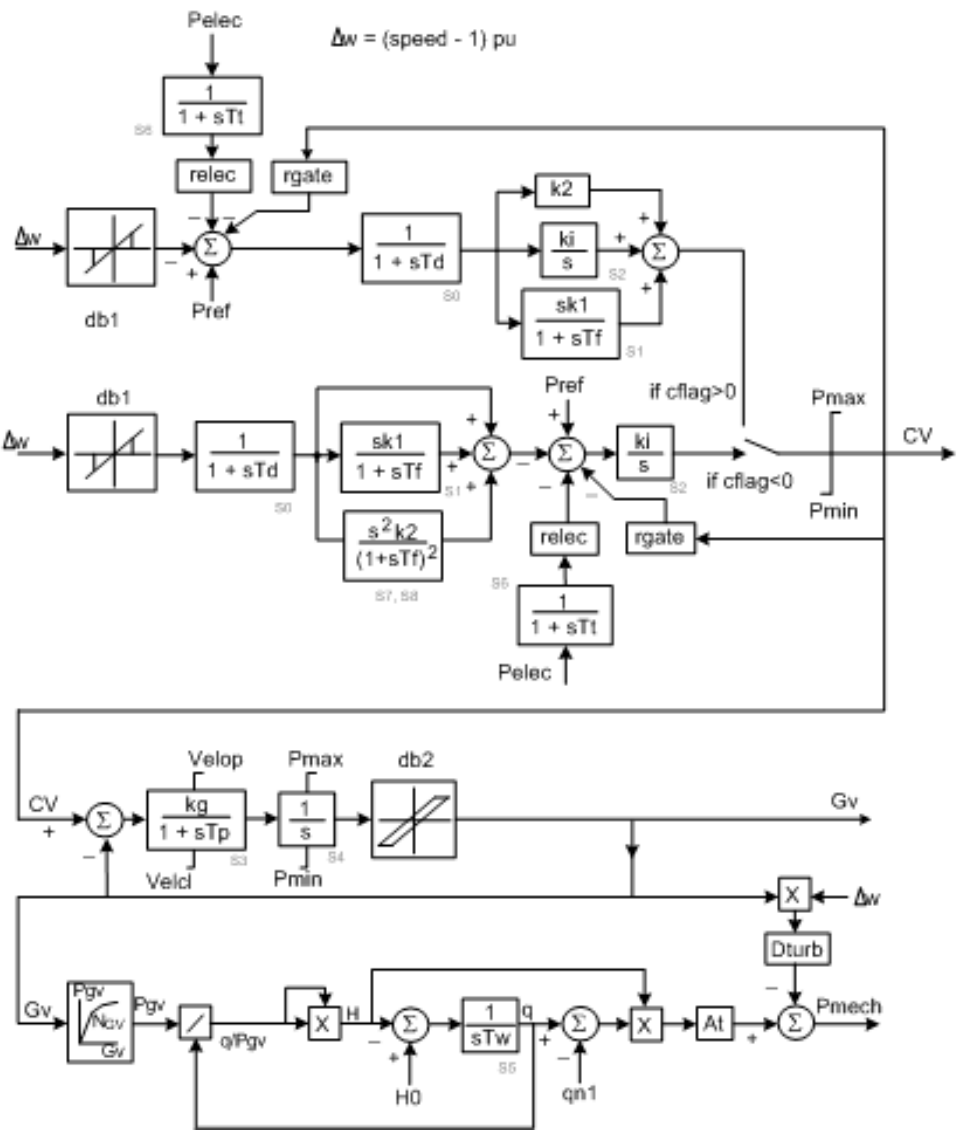

Figure 4-3 Block Diagram of the PSLF HYGOV Model 
Table 4-3 Parameters Used in the PSLF HYG3 Model

\begin{tabular}{|c|c|}
\hline Variable & Description \\
\hline Pmax & Maximum gate opening, p.u. of mwcap \\
\hline Pmin & Minimum gate opening, p.u. of mwcap \\
\hline Cflag & Governor control flag, 1:PID, -1 :double derivative \\
\hline Rgate & Steady-state droop, p.u., for governor output feedback \\
\hline Relec & Steady-state droop, p.u., for electrical power feedback \\
\hline $\mathrm{Td}$ & Input filter time constant, s \\
\hline Tf & Washout time constant, $\mathrm{s}$ \\
\hline$T p$ & Gate servo time constant, $\mathrm{s}$ \\
\hline Velop & Maximum gate opening velocity, p.u./s \\
\hline Velcl & Maximum gate closing velocity, p.u./s $(<0)$ \\
\hline K1 & Derivative gain, p.u. \\
\hline K2 & Double derivative gain, p.u., if Cflag $=-1$ \\
\hline $\mathrm{Ki}$ & Integral gain, p.u. \\
\hline $\mathrm{Kg}$ & Gate servo gain, p.u. \\
\hline $\mathrm{Tt}$ & Power feedback time constant, s \\
\hline $\mathrm{db1}$ & Intentional deadband width, $\mathrm{Hz}$ \\
\hline eps & Intentional deadband hysteresis, $\mathrm{Hz}$ \\
\hline $\mathrm{db} 2$ & Unintentional deadband, $\mathrm{MW}$ \\
\hline Tw & Water inertia time constant, $\mathrm{s}$ \\
\hline At & Turbine gain, p.u. \\
\hline Dturb & Turbine damping factor, p.u. \\
\hline qnl & No-load turbine flow at nominal head, p.u. \\
\hline $\mathrm{HO}$ & Turbine nominal head, p.u. \\
\hline Gv1 & Nonlinear gain point 1, p.u. gv \\
\hline Pgv1 & Nonlinear gain point 1, p.u. power \\
\hline Gv2 & Nonlinear gain point 2, p.u. gv \\
\hline Pgv2 & Nonlinear gain point 2, p.u. power \\
\hline Gv3 & Nonlinear gain point 3, p.u. gv \\
\hline Pgv3 & Nonlinear gain point 3, p.u. power \\
\hline Gv4 & Nonlinear gain point 4 , p.u. gv \\
\hline Pgv4 & Nonlinear gain point 4, p.u. power \\
\hline Gv5 & Nonlinear gain point 5, p.u. gv \\
\hline Pgv5 & Nonlinear gain point 5, p.u. power \\
\hline Gv6 & Nonlinear gain point 6 , p.u. gv \\
\hline Pgv6 & Nonlinear gain point 6, p.u. power \\
\hline
\end{tabular}




\subsubsection{HYGOV Model}

As discussed in the section on PSS ${ }^{\circledR}$ models, HYGOV represents a straightforward hydroelectric plant governor with a simple hydraulic representation of the penstock with unrestricted head race and tail race and no surge tank. The PSLF drawing of this governor is shown in Figure 4-4, and the parameters of the model are defined in Table 4-4. There are some model differences between the two programs. The PSLF model includes a deadband and lead/lag filter on the primary speed input. It also has a curve that relates power to gate opening to model nonlinearities in this relationship. This curve can be set to represent linear, Francis/Pelton, or Kaplan turbine constants.

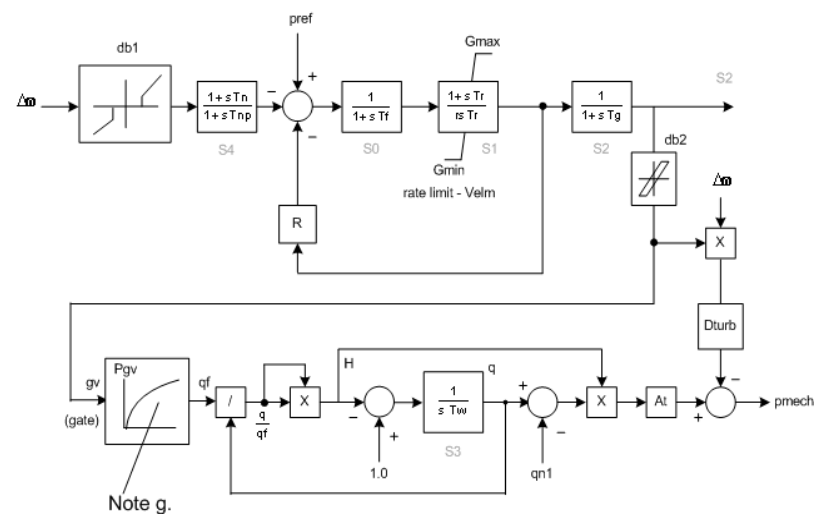

Figure 4-4 Block Diagram of the PSLF HYGOV Model 
Table 4-4 Parameters used in the PSLF HYGOV Model

\begin{tabular}{|c|c|}
\hline Variable & Description \\
\hline Rperm & Permanent droop (R), p.u. \\
\hline rtemp & Temporary droop (r), p.u. \\
\hline $\operatorname{Tr}$ & Washout time constant, $\mathrm{s}$ \\
\hline Tf & Filter time constant, $\mathrm{s}$ \\
\hline $\mathrm{Tg}$ & Gate servo time constant, s \\
\hline Velm & Maximum gate velocity, p.u./s \\
\hline Gmax & Maximum gate opening, p.u. of mwcap \\
\hline Gmin & Minimum gate opening, p.u. of mwcap \\
\hline Tw & Water inertia time constant, $\mathrm{s}$ \\
\hline At & Turbine gain, p.u. \\
\hline Dturb & Turbine damping factor, p.u. \\
\hline qnl & No-load flow at nominal head, p.u. \\
\hline ttrip & Not used \\
\hline tn & Lead time constant, $\mathrm{s}$ \\
\hline tnp & Lag time constant, $\mathrm{s}$ \\
\hline $\mathrm{db} 1$ & Intentional deadband width, $\mathrm{Hz}$ \\
\hline eps & Intentional deadband hysteresis, $\mathrm{Hz}$ \\
\hline $\mathrm{db} 2$ & Unintentional deadband, MW \\
\hline GV0 & Nonlinear gain point 0, p.u. gv \\
\hline Pgv0 & Nonlinear gain point 0, p.u. power \\
\hline GV1 & Nonlinear gain point 1, p.u. gv \\
\hline Pgv1 & Nonlinear gain point 1 , p.u. power \\
\hline GV2 & Nonlinear gain point 2, p.u. gv \\
\hline Pgv2 & Nonlinear gain point 2 , p.u. power \\
\hline GV3 & Nonlinear gain point 3, p.u. gv \\
\hline Pgv3 & Nonlinear gain point 3, p.u. power \\
\hline GV4 & Nonlinear gain point 4, p.u. gv \\
\hline Pgv4 & Nonlinear gain point 4, p.u. power \\
\hline GV5 & Nonlinear gain point 5, p.u. gv \\
\hline Pgv5 & Nonlinear gain point 5, p.u. power \\
\hline hdam & Head available at dam, p.u. \\
\hline Bgv0 & Kaplan blade servo point 0, p.u. \\
\hline Bgv1 & Kaplan blade servo point 1, p.u. \\
\hline Bgv2 & Kaplan blade servo point 2, p.u. \\
\hline Bgv3 & Kaplan blade servo point 3, p.u. \\
\hline Bgv4 & Kaplan blade servo point 4, p.u. \\
\hline Bgv5 & Kaplan blade servo point 5, p.u. \\
\hline bmax & Maximum blade adjustment factor \\
\hline tblade & Blade servo time constant, $\mathrm{s}$ \\
\hline
\end{tabular}




\subsubsection{HYGOV4 Model}

This governor represents plants with a straightforward penstock configuration and hydraulic governor of the traditional dashpot design. It has the same capability to model the Francis/Pelton or Kaplan turbine as the PSLF HYGOV model. The model block diagram is shown in Figure 4-5 and the parameters of the model are defined in Table 4-5.

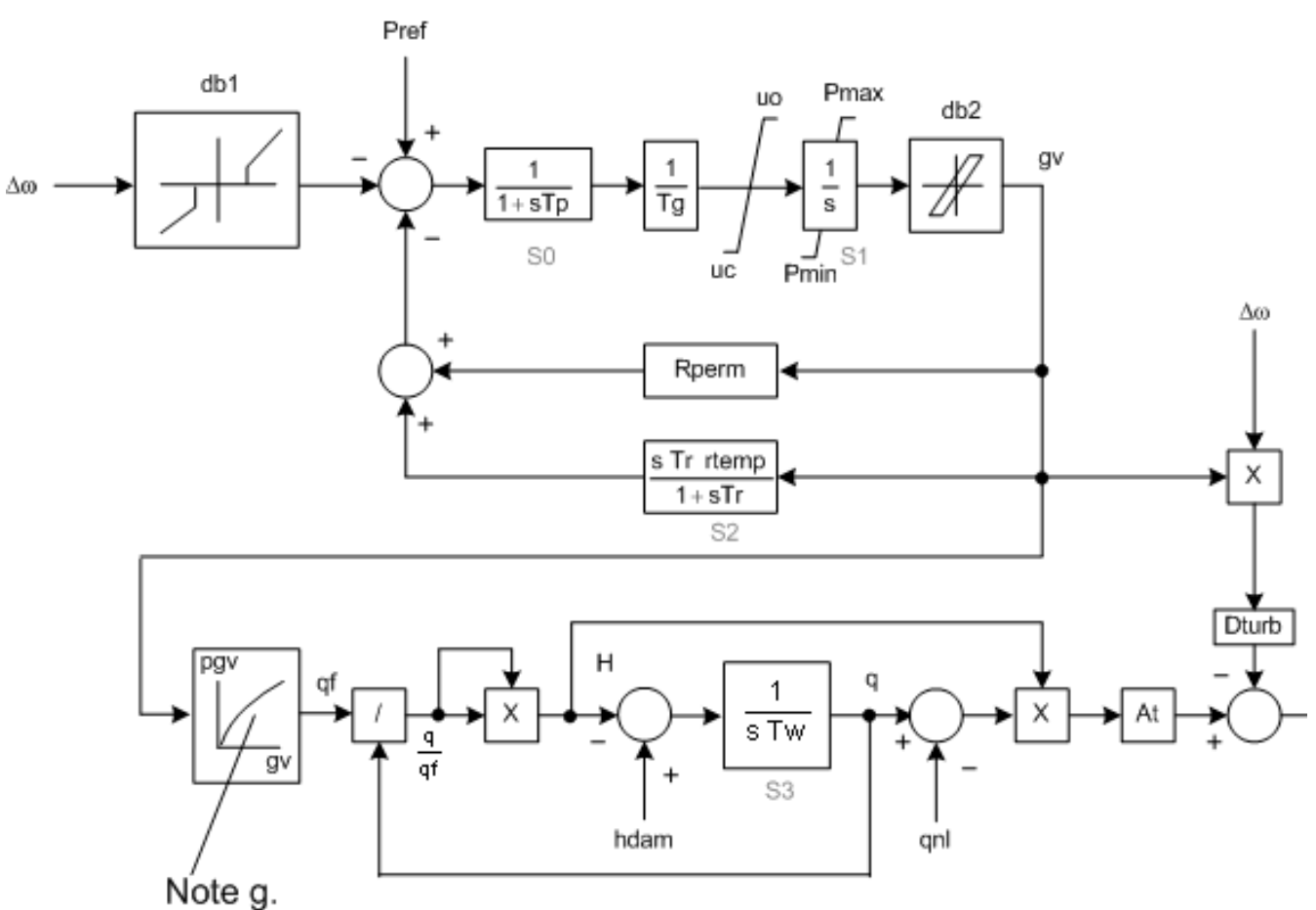

Figure 4-5 Block Diagram of the PSLF HYGOV4 Model 
Table 4-5 Parameters Used in the PSLF HYGOV4 Model

\begin{tabular}{|c|c|}
\hline Variable & Description \\
\hline $\mathrm{Tg}$ & Gate servo time constant, $\mathrm{s}$ \\
\hline $\mathrm{Tp}$ & Pilot servo time constant, $\mathrm{s}$ \\
\hline uo & Max gate opening velocity, p.u./s \\
\hline uc & Max gate closing velocity, p.u./s \\
\hline Pmax & Maximum gate opening, p.u. of mwcap \\
\hline Pmin & Minimum gate opening, p.u. of mwcap \\
\hline Rperm & Permanent droop (R), p.u. \\
\hline rtemp & Temporary droop (r), p.u. \\
\hline $\mathrm{Tr}$ & Dashpot time constant, s \\
\hline Tw & Water inertia time constant, $\mathrm{s}$ \\
\hline At & Turbine gain, p.u. \\
\hline Dturb & Turbine damping factor, p.u. \\
\hline hdam & Head available at dam, p.u. \\
\hline qnl & 0 No-load flow at nominal head, p.u. \\
\hline $\mathrm{db} 1$ & Intentional deadband width, $\mathrm{Hz}$ \\
\hline eps & Intentional db hysteresis, $\mathrm{Hz}$ \\
\hline $\mathrm{db} 2$ & Unintentional deadband, MW \\
\hline GVO & Nonlinear gain point 0, p.u. gv \\
\hline Pgv0 & Nonlinear gain point 0, p.u. power \\
\hline GV1 & Nonlinear gain point 1, p.u. gv \\
\hline Pgv1 & Nonlinear gain point 1, p.u. power \\
\hline GV2 & Nonlinear gain point 2, p.u. gv \\
\hline Pgv2 & Nonlinear gain point 2, p.u. power \\
\hline GV3 & Nonlinear gain point 3, p.u. gv \\
\hline Pgv3 & Nonlinear gain point 3, p.u. power \\
\hline GV4 & Nonlinear gain point 4 , p.u. gv \\
\hline Pgv4 & Nonlinear gain point 4, p.u. power \\
\hline GV5 & Nonlinear gain point 5, p.u. gv \\
\hline Pgv5 & Nonlinear gain point 5, p.u. power \\
\hline hdam & Head available at dam, p.u. \\
\hline Bgv0 & Kaplan blade servo point 0, p.u. \\
\hline Bgv1 & Kaplan blade servo point 1, p.u. \\
\hline Bgv2 & Kaplan blade servo point 2, p.u. \\
\hline Bgv3 & Kaplan blade servo point 3, p.u. \\
\hline Bgv4 & Kaplan blade servo point 4, p.u. \\
\hline Bgv5 & Kaplan blade servo point 5, p.u. \\
\hline Bmax & Maximum blade adjustment factor \\
\hline tblade & Blade servo time constant, $\mathrm{s}$ \\
\hline
\end{tabular}

Note: The parameter hdam appears in the data list twice. Please see the PSLF manual for the full explanation of its use. 


\subsubsection{HYGOVR Model}

This is the PSLF fourth-order lead/lag governor for a unit with digital controls. The PSLF model allows a nonlinear relationship between the gate position and power. The block diagram is shown in Figure 4-6, and the parameters of the model are defined in Table 4-6.

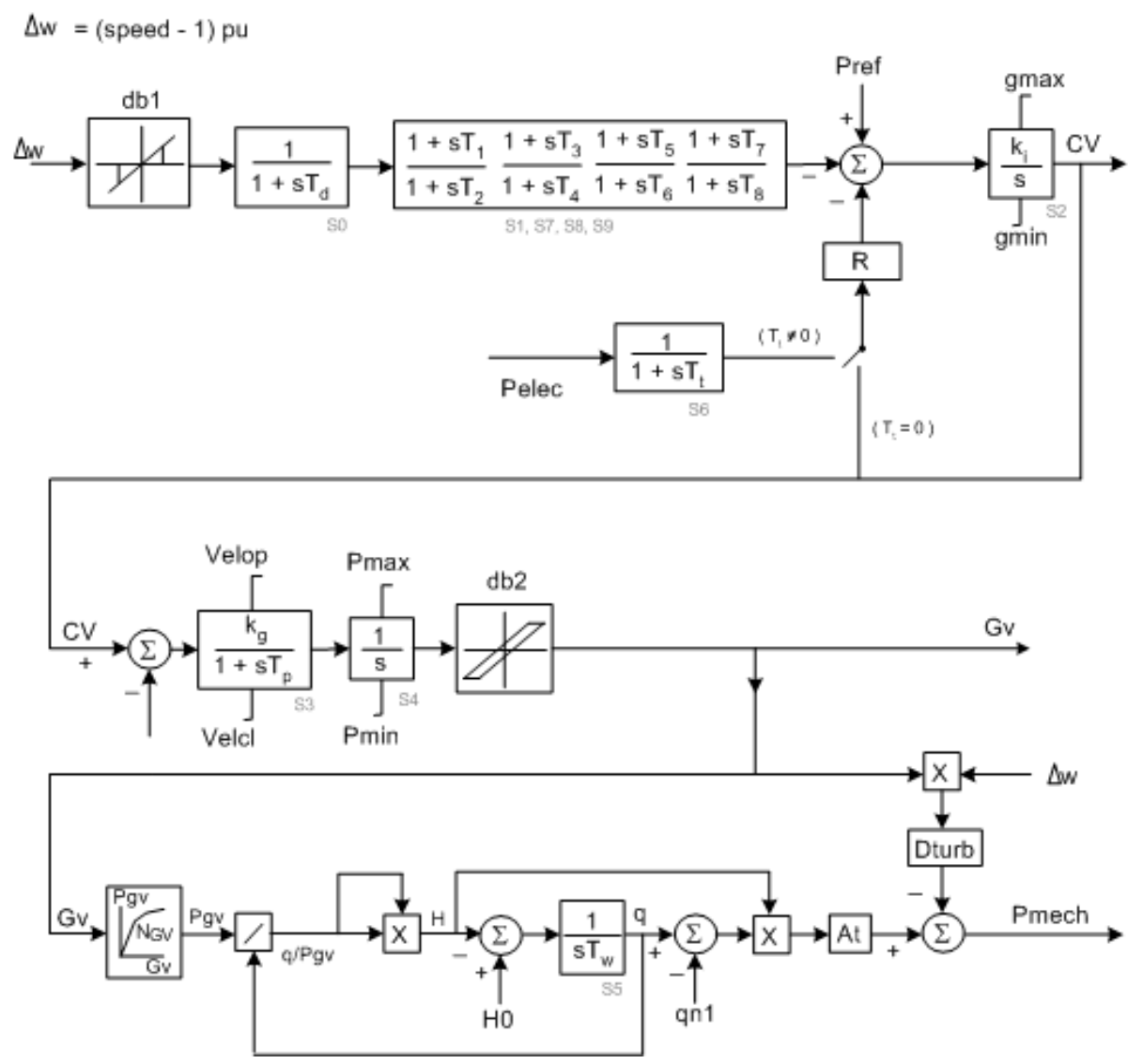

Figure 4-6 Block Diagram of the PSLF HYGOVR Model 
Table 4-6 Parameters Used in the PSLF HYGOVR Model

\begin{tabular}{|c|c|}
\hline Variable & Description \\
\hline Pmax & Maximum gate opening, p.u. of mwcap \\
\hline Pmin & Minimum gate opening, p.u. of mwcap \\
\hline$R$ & Steady-state droop, p.u. \\
\hline $\mathrm{Td}$ & Input filter time constant, s \\
\hline T1 & Lead time constant $1, \mathrm{~s}$ \\
\hline T2 & Lag time constant $1, \mathrm{~s}$ \\
\hline T3 & Lead time constant $2, \mathrm{~s}$ \\
\hline T4 & Lag time constant $2, \mathrm{~s}$ \\
\hline T5 & Lead time constant $3, \mathrm{~s}$ \\
\hline T6 & Lag time constant $3, \mathrm{~s}$ \\
\hline T7 & Lead time constant $4, \mathrm{~s}$ \\
\hline T8 & Lag time constant $4, \mathrm{~s}$ \\
\hline $\mathrm{Tp}$ & Gate servo time constant, s \\
\hline Velop & Maximum gate opening velocity, p.u./s \\
\hline Velcl & Maximum gate closing velocity, p.u./s $(<0)$ \\
\hline Ki & Integral gain, p.u. \\
\hline $\mathrm{Kg}$ & Gate servo gain, p.u. \\
\hline gmax & Maximum governor output, p.u. \\
\hline gmin & Minimum governor output, p.u. \\
\hline $\mathrm{Tt}$ & Power feedback time constant, $\mathrm{s}$ \\
\hline $\mathrm{db1}$ & Intentional deadband width, $\mathrm{Hz}$ \\
\hline eps & Intentional deadband hysteresis, $\mathrm{Hz}$ \\
\hline $\mathrm{db} 2$ & Unintentional deadband, MW \\
\hline Tw & Water inertia time constant, $\mathrm{s}$ \\
\hline At & Turbine gain, p.u. \\
\hline Dturb & Turbine damping factor, p.u. \\
\hline qnl & No-load turbine flow at nominal head, p.u. \\
\hline $\mathrm{HO}$ & Turbine nominal head, p.u. \\
\hline Gv1 & Nonlinear gain point 1 , p.u. gv \\
\hline Pgv1 & Nonlinear gain point 1, p.u. power \\
\hline Gv2 & Nonlinear gain point 2, p.u. gv \\
\hline Pgv2 & Nonlinear gain point 2, p.u. power \\
\hline Gv3 & Nonlinear gain point 3, p.u. gv \\
\hline Pgv3 & Nonlinear gain point 3, p.u. power \\
\hline Gv4 & Nonlinear gain point 4, p.u. gv \\
\hline Pgv4 & Nonlinear gain point 4, p.u. power \\
\hline Gv5 & Nonlinear gain point 5, p.u. gv \\
\hline Pgv5 & Nonlinear gain point 5, p.u. power \\
\hline Gv6 & Nonlinear gain point 6 , p.u. gv \\
\hline Pgv6 & Nonlinear gain point 6, p.u. power \\
\hline
\end{tabular}




\subsubsection{IEEEG3 Model}

This is the standard IEEE hydro turbine/governor model for a unit with straightforward penstock design and hydraulic dashpot governors. The PSLF model includes an optional deadband and nonlinear gain. The block diagram for this model is shown in Figure 4-7, and the parameters of the model are defined in Table 4.7.

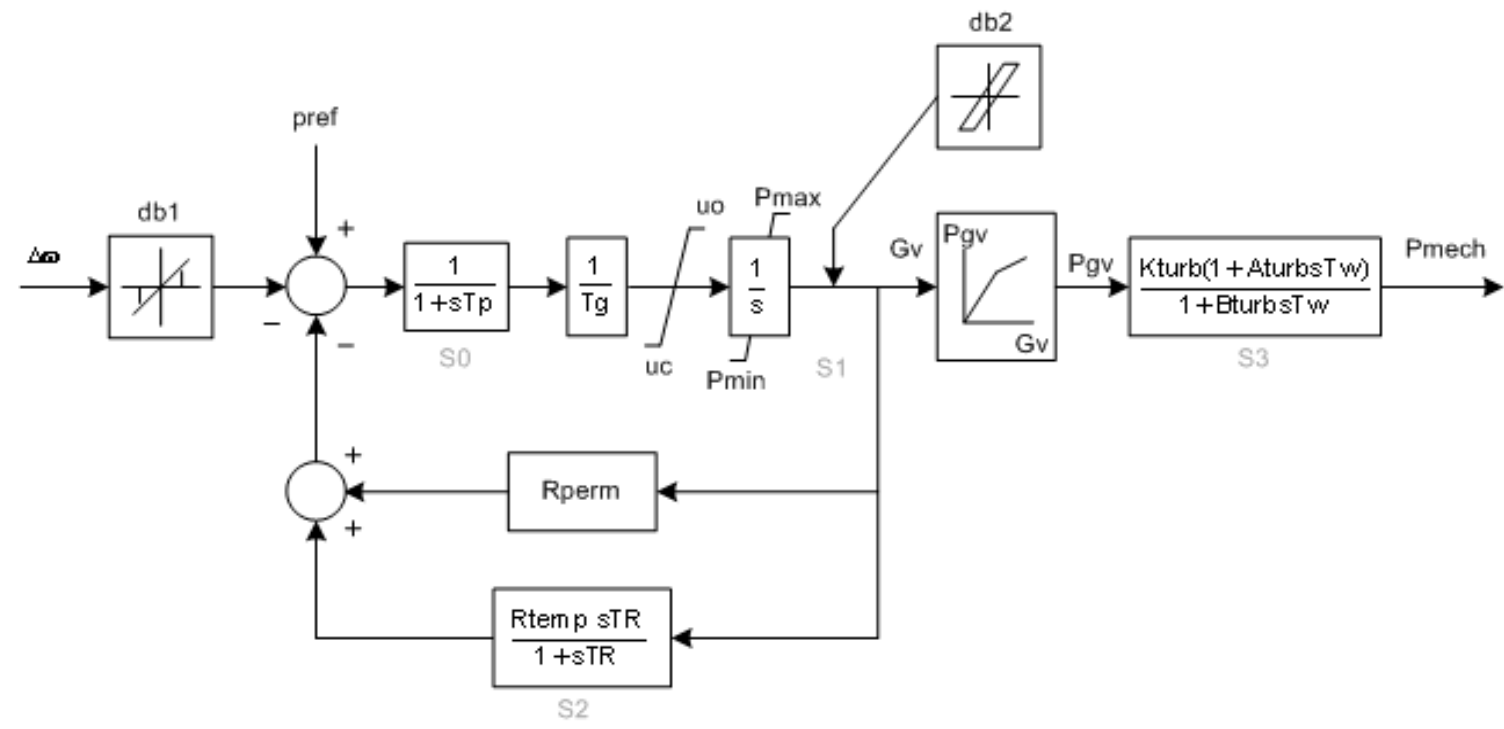

Figure 4-7 Block Diagram of the PSLF IEEEG3 Model 
Table 4-7 Parameters Used in the PSLF IEEEG3 Model

\begin{tabular}{|c|c|}
\hline Variable & Description \\
\hline $\mathrm{Tg}$ & Gate servo time constant, s \\
\hline $\mathrm{Tp}$ & Pilot servo valve time constant, s \\
\hline Uo & Maximum gate opening velocity, p.u./s \\
\hline Uc & Maximum gate closing velocity, p.u./s $(<0)$ \\
\hline Pmax & Maximum gate opening, p.u. of mwcap \\
\hline Pmin & Minimum gate opening, p.u. of mwcap \\
\hline Rperm & Permanent droop, p.u. \\
\hline Rtemp & Temporary droop, p.u. \\
\hline $\operatorname{Tr}$ & Dashpot time constant, s \\
\hline Tw & Water inertia time constant, s \\
\hline Kturb & Turbine gain, p.u. \\
\hline Aturb & Turbine numerator multiplier \\
\hline Bturb & Turbine denominator multiplier \\
\hline Spare & Unused parameter \\
\hline $\mathrm{db} 1$ & Intentional deadband width, $\mathrm{Hz}$ \\
\hline eps & Intentional deadband hysteresis, $\mathrm{Hz}$ \\
\hline $\mathrm{db} 2$ & Unintentional deadband, MW \\
\hline Gv1 & Nonlinear gain point 1, p.u. gv \\
\hline Pgv1 & Nonlinear gain point 1, p.u. power \\
\hline Gv2 & Nonlinear gain point 2, p.u. gv \\
\hline Pgv2 & Nonlinear gain point 2, p.u. power \\
\hline Gv3 & Nonlinear gain point 3, p.u. gv \\
\hline Pgv3 & Nonlinear gain point 3, p.u. power \\
\hline Gv4 & Nonlinear gain point 4, p.u. gv \\
\hline Pgv4 & Nonlinear gain point 4, p.u. power \\
\hline Gv5 & Nonlinear gain point 5, p.u. gv \\
\hline Pgv5 & Nonlinear gain point 5, p.u. power \\
\hline Gv6 & Nonlinear gain point 6, p.u. gv \\
\hline Pgv6 & Nonlinear gain point 6, p.u. power \\
\hline
\end{tabular}




\subsubsection{PIDGOV Model}

This model represents hydro turbine/governor units with straightforward penstock configurations and three term electro/hydraulic governors (also sometimes called Woodward electronic governors). The block diagram for the model is shown in Figure 4-8, and the parameters of the model are defined in Table 4-8.

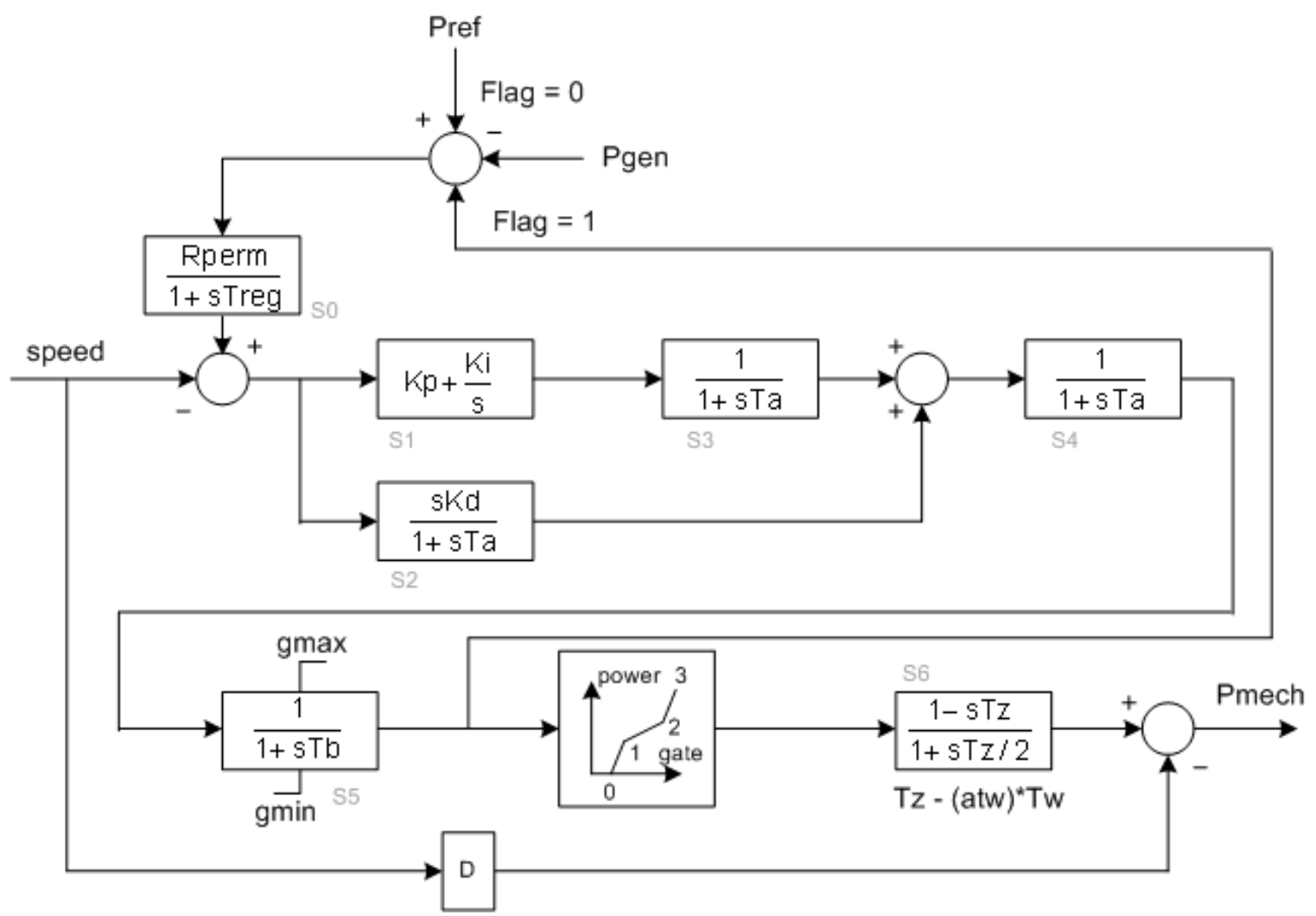

Figure 4-8 Block Diagram of the PSLF PIDGOV Model 
Table 4-8 Parameters Used in the PSLF PIDGOV Model

\begin{tabular}{|l|l|}
\hline Variable & Description \\
\hline Treg & Speed detector time constant, s \\
\hline rperm & Permanent drop, p.u. \\
\hline Kp & Proportional gain, p.u. \\
\hline Ki & Reset gain, p.u./s \\
\hline Kd & Derivative gain, p.u. \\
\hline Ta & Controller time constant, s \\
\hline Tb & Gate servo time constant, s \\
\hline Velmax & Maximum gate opening velocity, p.u./s \\
\hline Velmin & Maximum gate closing velocity, p.u./s \\
\hline Gmax & Maximum gate opening, p.u. \\
\hline Gmin & Minimum gate opening, p.u. \\
\hline Tw & Water inertia time constant, p.u. \\
\hline Pmax & Maximum power, p.u. (not used) \\
\hline Pmin & Minimum power, p.u. (not used) \\
\hline Dturb & Turbine damping factor, p.u. \\
\hline g0 & Gate opening at speed no load, p.u. \\
\hline g1 & Intermediate gate opening, p.u. \\
\hline p1 & Power at gate opening g1, p.u. \\
\hline g2 & Intermediate gate opening, p.u. \\
\hline p2 & Power at gate opening g2, p.u. \\
\hline p3 & Power at full opened gate, p.u. \\
\hline atw & Factor multiplying Tw, p.u. \\
\hline Flag & Feedback signal type flag \\
\hline
\end{tabular}




\subsubsection{HYPID Model}

This model also represents the straight forward penstock configuration. The governor has a PID controller. The model can model Kaplan blade angle adjustment and diagonal flow turbines. A block diagram of the model is shown in Figure 4-9 and the parameters of the model are defined in Table 4-9.

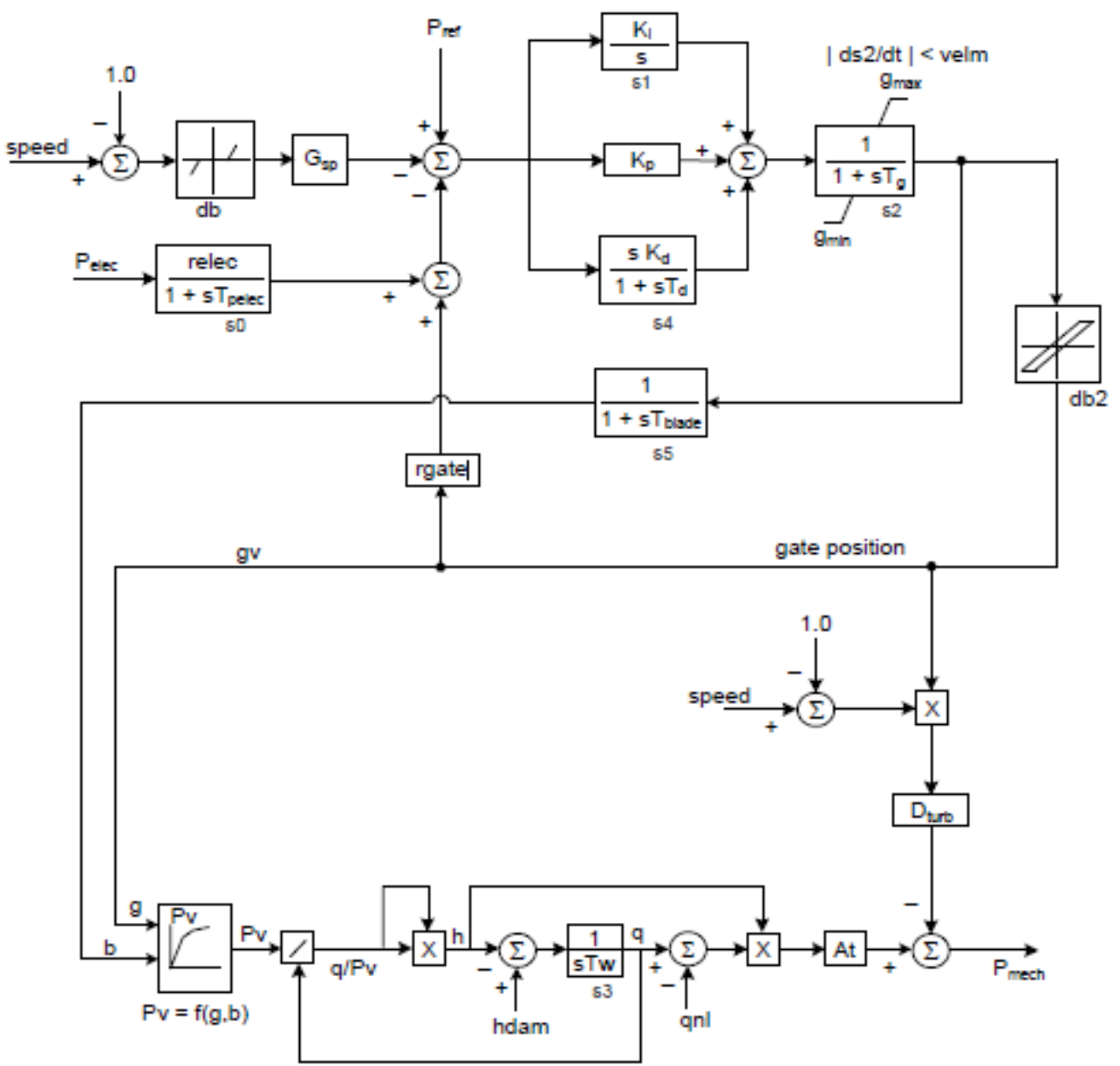

Figure 4-9 Block Diagram of the PSLF HYPID Model 
Table 4-9 Parameters Used in the HYPID Model

\begin{tabular}{|c|c|}
\hline Variable & Description \\
\hline relec & Governing droop, p.u. \\
\hline tpelec & Power transducer time constant, $\mathrm{s}$ \\
\hline $\mathrm{kp}$ & Proportional gain \\
\hline $\mathrm{ki}$ & Integral gain \\
\hline kd & Derivative gain \\
\hline $\mathrm{td}$ & Derivative element time constant, $\mathrm{s}$ \\
\hline $\operatorname{tg}$ & Gate servo time constant, $\mathrm{s}$ \\
\hline velm & Maximum gate velocity, p.u./s \\
\hline gmax & Maximum gate opening, p.u. of mwcap \\
\hline gmin & Minimum gate opening, p.u. of mwcap \\
\hline tw & Water inertia time constant, s \\
\hline at & Turbine gain, p.u. \\
\hline dturb & Turbine damping factor, p.u. \\
\hline qnl & No-load flow at nominal head, p.u. \\
\hline gsp & Speed input gain (nominally 1.0 ) \\
\hline $\mathrm{db} 1$ & Intentional deadband width, $\mathrm{Hz}$ \\
\hline eps & Intentional deadband hysteresis, $\mathrm{Hz}$ \\
\hline $\mathrm{db} 2$ & Unintentional deadband, MW \\
\hline GV0 & Nonlinear gain point 0, p.u. gv \\
\hline Pgv0 & Nonlinear gain point 0, p.u. power \\
\hline GV1 & Nonlinear gain point 1 , p.u. gv \\
\hline Pgv1 & Nonlinear gain point 1 , p.u. power \\
\hline GV2 & Nonlinear gain point 2, p.u. gv \\
\hline Pgv2 & Nonlinear gain point 2, p.u. power \\
\hline GV3 & Nonlinear gain point 3 , p.u. gv \\
\hline Pgv3 & Nonlinear gain point 3 , p.u. power \\
\hline GV4 & Nonlinear gain point 4 , p.u. gv \\
\hline Pgv4 & Nonlinear gain point 4 , p.u. power \\
\hline GV5 & Nonlinear gain point 5, p.u. gv \\
\hline Pgv5 & Nonlinear gain point 5, p.u. power \\
\hline hdam & Head available at dam, p.u. \\
\hline Bgv0 & Kaplan blade servo point 0, p.u. \\
\hline Bgv1 & Kaplan blade servo point 1, p.u. \\
\hline Bgv2 & Kaplan blade servo point 2, p.u. \\
\hline Bgv3 & Kaplan blade servo point 3, p.u. \\
\hline Bgv4 & Kaplan blade servo point 4, p.u. \\
\hline Bgv5 & Kaplan blade servo point 5, p.u. \\
\hline bmax & Maximum blade adjustment factor \\
\hline tblade & Blade servo time constant, $\mathrm{s}$ \\
\hline rgate & ning droop using gate position, p.u \\
\hline
\end{tabular}




\subsubsection{HYST1 Model}

This PSLF model is for a hydro unit with a penstock, surge tank and inlet tunnel. The governor is a Woodward electro hydraulic PID. A block diagram of the model is shown in Figure 4-10, and the parameters of the model are defined in Table 4-10. The turbine/ penstock characteristics are contained in the function $\mathrm{G}(\mathrm{s})$ shown in the diagram.

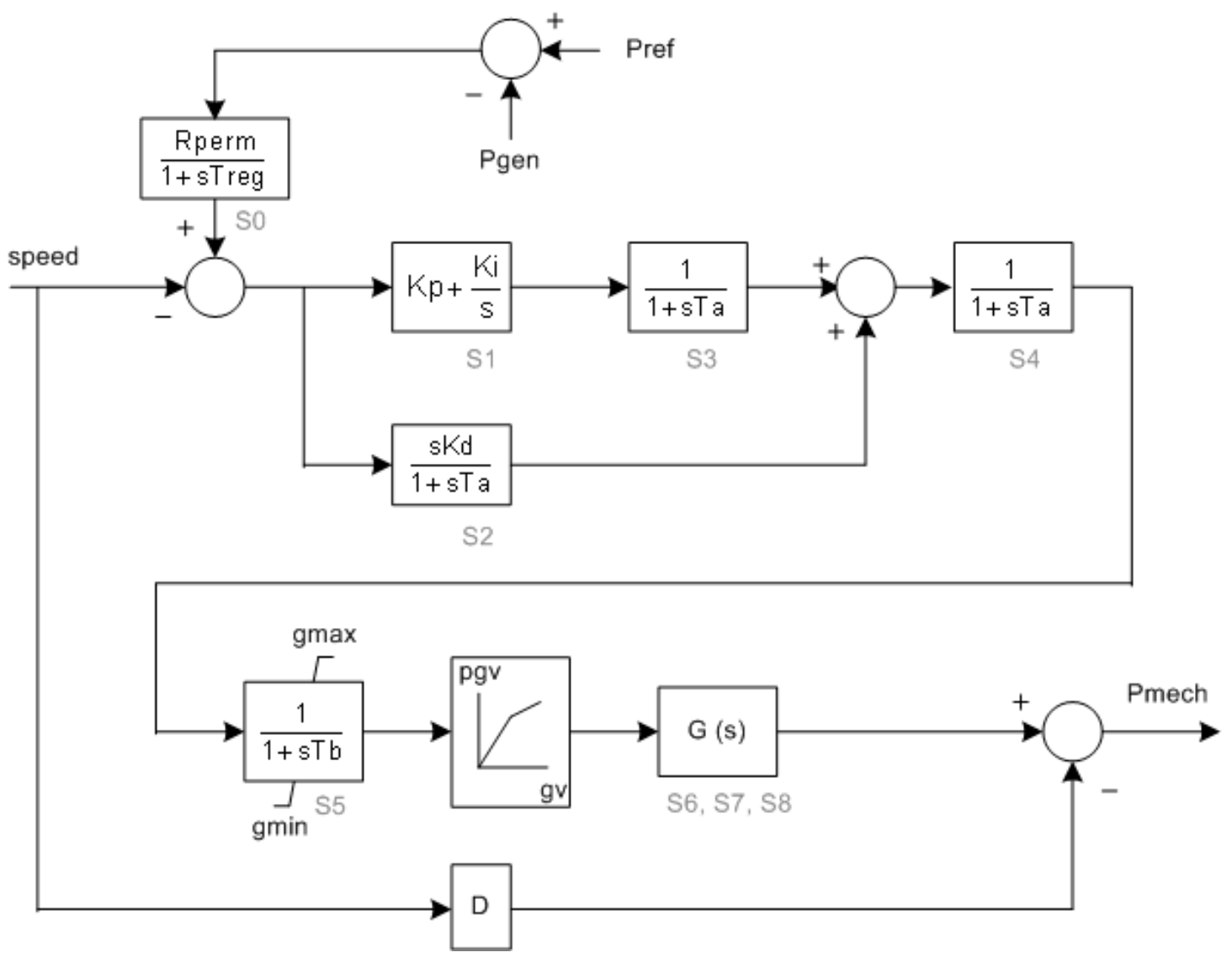

Figure 4-10 Block Diagram of the PSLF HYST1 Model 
Table 4-10 Parameters Used in the PSLF HYST1 Model

\begin{tabular}{|l|l|}
\hline Variable & Description \\
\hline Treg & Input time constant of governor, s \\
\hline Rperm & Governor droop, per unit \\
\hline $\mathrm{Kp}$ & Governor proportional gain \\
\hline $\mathrm{Ki}$ & Governor integral gain \\
\hline Kd & Governor derivative gain \\
\hline Ta & Governor high-frequency cutoff time constant \\
\hline Tb & Gate servo time constant \\
\hline Velmax & Max gate opening velocity, p.u./s \\
\hline Velmin & Min gate closing velocity, p.u./s \\
\hline Gmax & Max gate opening, p.u. \\
\hline Gmin & Min gate opening, p.u. \\
\hline Pmax & Not used \\
\hline Pmin & Not used \\
\hline D & Turbine damping coefficient \\
\hline Twp & Penstock water time constant, s \\
\hline Twt & Tunnel water time constant, s \\
\hline flos & Tunnel Loss Coefficient, p.u. \\
\hline As1 & Area constant of Upper Surge Tank, s \\
\hline As2 & Area constant of Lower Surge Tank, s \\
\hline h2 & Level of surge tank size change, p.u. \\
\hline
\end{tabular}




\subsubsection{W2301 Model}

The PSLF W2301 model is for a hydro unit with a Woodward 2301 controller. The block diagram is shown in Figure 4-11, and the parameters of the model are defined in Table 4-11.

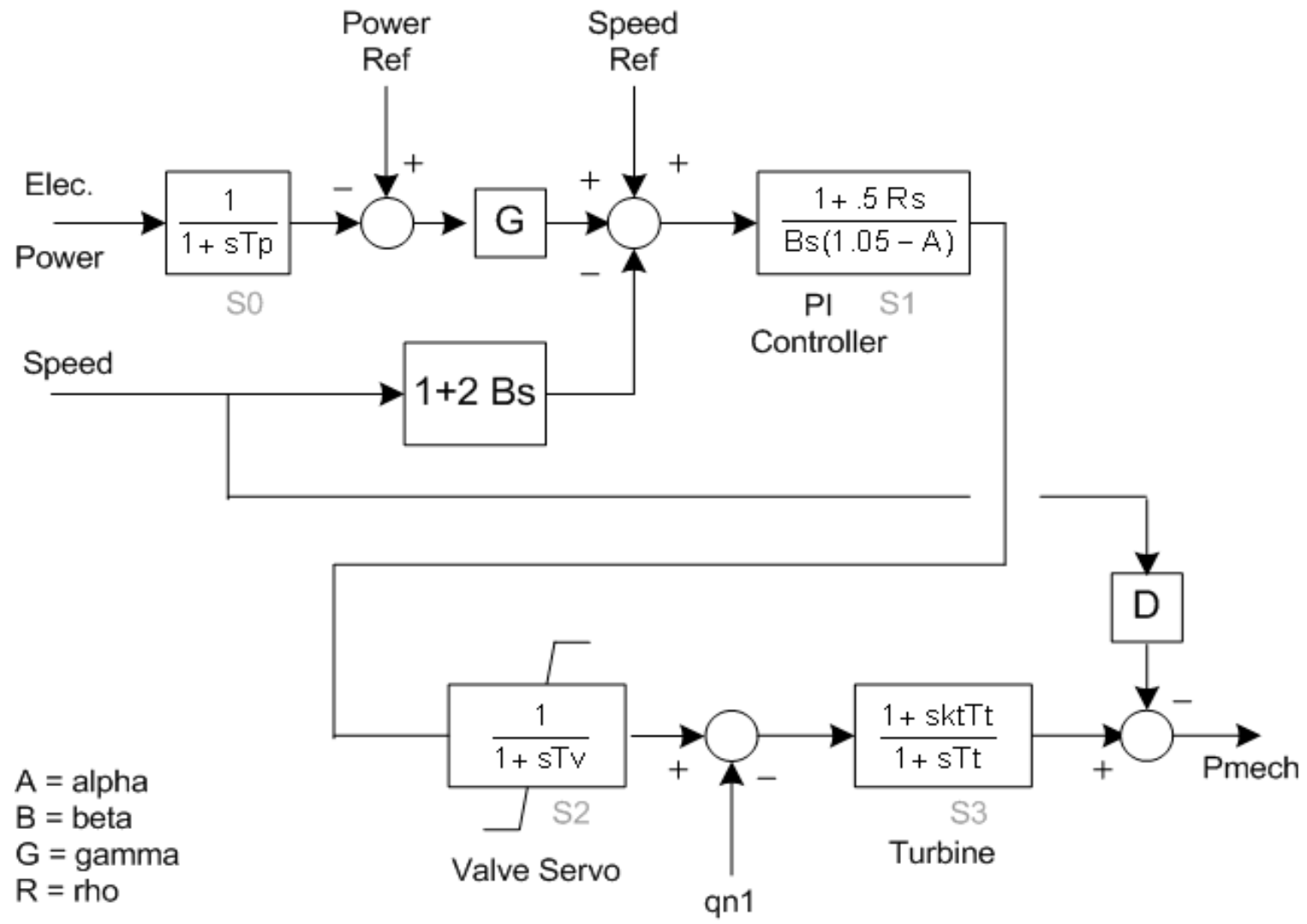

Figure 4-11 Block Diagram of the PSLF W2301 Model 
Table 4-11 Parameters Used in the PSLF W2301 Model

\begin{tabular}{|l|l|}
\hline Variable & Description \\
\hline tp & Power transducer time constant \\
\hline alpha & Droop setting \\
\hline beta & Reset setting \\
\hline rho & Compensation \\
\hline gamma & Gain setting, p.u. \\
\hline gain & Turbine gain \\
\hline tv & Valve actuator time constant, s \\
\hline velamx & Maximum valve velocity, ps \\
\hline gmax & Maximum valve opening, p.u. \\
\hline gmin & Minimum valve opening, p.u. \\
\hline gnl & Valve opening at no load, p.u. \\
\hline tturb & Turbine time constant, $\mathrm{s}$ \\
\hline $\mathrm{d}$ & Turbine damping coefficient \\
\hline kt & Turbine lead-lag ratio \\
\hline
\end{tabular}




\subsubsection{HYGOV8 Model}

The HYGOV8 hydro governor model can represent up to four units on a common penstock. It represents a PID governor. The block diagram of the HYGOV8 model is shown in Figure 4-12, and the parameters of the model are defined in Table 4-12.

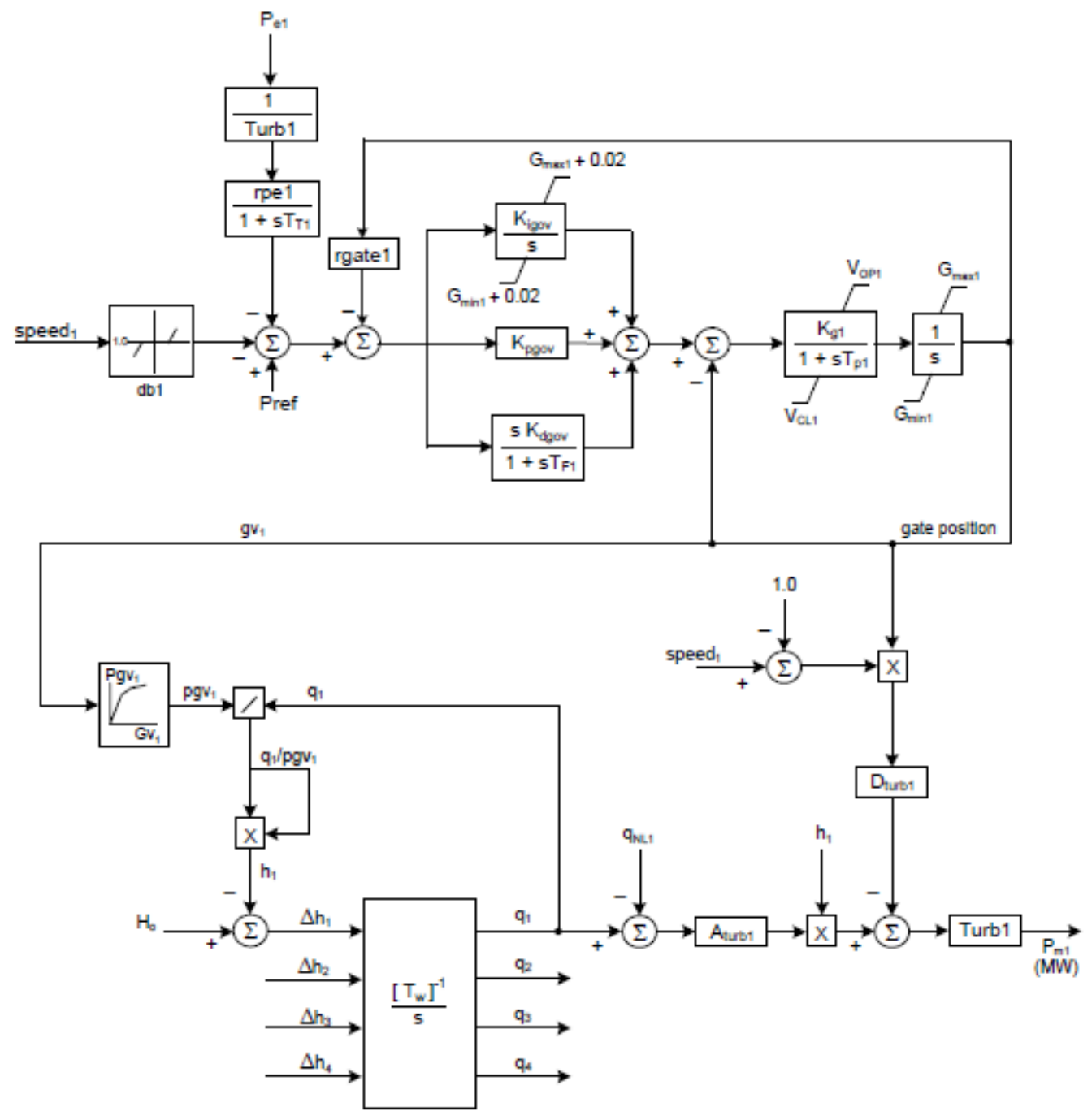

Figure 4-12 Block Diagram of the PSLF HYGOV8 Model 
Table 4-12 Parameters Used in the PSLF HYGOV8 Model

\begin{tabular}{|c|c|}
\hline Variable & Description \\
\hline ibus1 & Bus number of Unit 1 \\
\hline ibus2 & Bus number of Unit 2 , may be set to 0 to disable the portion of model for this unit \\
\hline ibus3 & Bus number of Unit 3 , may be set to 0 to disable the portion of model for this unit \\
\hline ibus4 & Bus number of Unit 4 , may be set to 0 to disable the portion of model for this unit \\
\hline id1 & Machine ID (real variable) for Unit 1 \\
\hline id2 & Machine ID (real variable) for Unit 2 \\
\hline id3 & Machine ID (real variable) for Unit 3 \\
\hline id4 & Machine ID (real variable) for Unit 4 \\
\hline turb1 & Turbine MW rating for Unit 1 \\
\hline \multicolumn{2}{|c|}{ The following parameters are for Unit 1 governor } \\
\hline rgate1 & Steady-state droop for gate position feedback \\
\hline rpe1 & Steady-state droop for electrical power feedback \\
\hline $\mathrm{tt} 1$ & Power feedback filter time constant, s \\
\hline $\mathrm{tf1}$ & Derivative control time constant, $\mathrm{s}$ \\
\hline kpgov1 & Governor proportional gain, p.u. \\
\hline kigov1 & Governor integral gain, p.u. \\
\hline kdgov1 & Governor derivative gain, p.u. \\
\hline tdgov1 & Share time constant \\
\hline td1 & Speed error signal filter time constant, s \\
\hline tp1 & Pilot valve time constant, $\mathrm{s}$ \\
\hline vop1 & Maximum gate opening velocity, p.u./s \\
\hline vcl1 & Maximum gate closing velocity, p.u./s \\
\hline kg1 & Distribution valve gain, p.u. \\
\hline ho & Plant net head, p.u. \\
\hline gmax1 & Maximum gate position, p.u. \\
\hline gmin1 & Minimum gate position, p.u. \\
\hline tw1 & Water starting time (s) of Unit 1 flow for entire length \\
\hline tw12 & Water starting time (s) of Unit 1 flow common length of penstock shared with Unit 2 \\
\hline tw13 & Water starting time (s) of Unit 1 flow common length of penstock shared with Unit 3 \\
\hline tw14 & Water starting time (s) of Unit 1 flow common length of penstock shared with Unit 4 \\
\hline turb2 & Turbine MW rating for Unit 2 \\
\hline \multicolumn{2}{|c|}{ The following parameters are for Unit 2 governor } \\
\hline rgate2 & Steady-state droop for gate position feedback \\
\hline rpe2 & Steady-state droop for electrical power feedback \\
\hline tt2 & Power feedback filter time constant, $\mathrm{s}$ \\
\hline $\mathrm{tf2}$ & Derivative control time constant, $\mathrm{s}$ \\
\hline kpgov2 & Governor proportional gain, p.u. \\
\hline kigov2 & Governor integral gain, p.u. \\
\hline kdgov2 & Governor derivative gain, p.u. \\
\hline tdgov2 & Share time constant \\
\hline $\mathrm{td} 2$ & Speed error signal filter time constant, $\mathrm{s}$ \\
\hline tp2 & Pilot valve time constant, $\mathrm{s}$ \\
\hline
\end{tabular}




\begin{tabular}{|c|c|}
\hline Variable & Description \\
\hline vop2 & Maximum gate opening velocity, p.u./s \\
\hline $\mathrm{vcl} 2$ & Maximum gate closing velocity, p.u./s \\
\hline kg2 & Distribution valve gain, p.u. \\
\hline gmax2 & Maximum gate position, p.u. \\
\hline gmin2 & Minimum gate position, p.u. \\
\hline tw2 & Water starting time (s) of Unit 2 flow for entire length \\
\hline tw21 & Water starting time (s) of Unit 2 flow common length of penstock shared with Unit 1 \\
\hline tw23 & Water starting time (s) of Unit 2 flow common length of penstock shared with Unit 3 \\
\hline tw24 & Water starting time (s) of Unit 2 flow common length of penstock shared with Unit 4 \\
\hline turb3 & Turbine MW rating for Unit 3 \\
\hline \multicolumn{2}{|c|}{ The following parameters are for Unit 3 governor } \\
\hline rgate3 & Steady-state droop for gate position feedback \\
\hline rpe3 & Steady-state droop for electrical power feedback \\
\hline $\mathrm{tt} 3$ & Power feedback filter time constant, $\mathrm{s}$ \\
\hline $\mathrm{tf3}$ & Derivative control time constant, $\mathrm{s}$ \\
\hline kpgov3 & Proportional gain, p.u. \\
\hline kigov3 & Governor integral gain, p.u. \\
\hline kdgov3 & Governor derivative gain, p.u. \\
\hline tdgov3 & Share time constant \\
\hline $\mathrm{td} 3$ & Speed error signal filter time constant, s \\
\hline tp3 & Pilot valve time constant, $\mathrm{s}$ \\
\hline vop3 & Maximum gate opening velocity, p.u./s \\
\hline $\mathrm{vcl3}$ & Maximum gate closing velocity, p.u./s \\
\hline kg3 & Distribution valve gain, p.u. \\
\hline gmax3 & Maximum gate position, p.u. \\
\hline $\operatorname{gmin} 3$ & Minimum gate position, p.u. \\
\hline tw3 & Water starting time (s) of Unit 3 flow for entire length \\
\hline tw31 & Water starting time (s) of Unit 3 flow common length of penstock shared with Unit 1 \\
\hline tw32 & Water starting time (s) of Unit 3 flow common length of penstock shared with Unit 2 \\
\hline tw34 & Water starting time (s) of Unit 3 flow common length of penstock shared with Unit 4 \\
\hline turb4 & Turbine MW rating for Unit 4 \\
\hline \multicolumn{2}{|c|}{ The following parameters are for Unit 4 governor } \\
\hline rgate4 & Steady-state droop for gate position feedback \\
\hline rpe4 & Steady-state droop for electrical power feedback \\
\hline $\mathrm{tt} 4$ & Power feedback filter time constant, s \\
\hline $\mathrm{tf} 4$ & Derivative control time constant, s \\
\hline kpgov4 & Governor proportional gain, p.u. \\
\hline kigov4 & Governor integral gain, p.u. \\
\hline kdgov4 & Governor derivative gain, p.u. \\
\hline tdgov4 & Share time constant \\
\hline td4 & Speed error signal filter time constant, s \\
\hline tp4 & Pilot valve time constant, $\mathrm{s}$ \\
\hline vop4 & Maximum gate opening velocity, p.u./s \\
\hline
\end{tabular}




\begin{tabular}{|c|c|}
\hline Variable & Description \\
\hline $\mathrm{vcl} 4$ & Maximum gate closing velocity, p.u./s \\
\hline kg4 & Distribution valve gain, p.u. \\
\hline gmax4 & Maximum gate position, p.u. \\
\hline gmin4 & Minimum gate position, p.u. \\
\hline tw4 & Water starting time (s) of Unit 4 flow for entire length \\
\hline tw41 & Water starting time (s) of Unit 4 flow common length of penstock shared with Unit 1 \\
\hline tw42 & Water starting time (s) of Unit 4 flow common length of penstock shared with Unit 2 \\
\hline tw43 & Water starting time (s) of Unit 4 flow common length of penstock shared with Unit 3 \\
\hline aturb1 & Turbine gain for Unit 1, p.u. \\
\hline qnl1 & No load flow for Unit 1, p.u. \\
\hline aturb2 & Turbine gain for Unit 2, p.u. \\
\hline qnl2 & No load flow for Unit 2, p.u. \\
\hline aturb3 & Turbine gain for Unit 3, p.u. \\
\hline qnl3 & No load flow for Unit 3, p.u. \\
\hline aturb4 & Turbine gain for Unit 4, p.u. \\
\hline qnl4 & No load flow for Unit 4, p.u. \\
\hline dturb1 & Turbine damping factor for Unit 1, p.u. \\
\hline dturb2 & Turbine damping factor for Unit 2, p.u. \\
\hline dturb3 & Turbine damping factor for Unit 3, p.u. \\
\hline dturb4 & Turbine damping factor for Unit 4, p.u. \\
\hline $\mathrm{db} 11$ & Intentional deadband width for Unit 1, p.u. \\
\hline $\mathrm{db} 12$ & Intentional deadband width for Unit 2, p.u. \\
\hline $\mathrm{db} 13$ & Intentional deadband width for Unit 3, p.u. \\
\hline $\mathrm{db} 14$ & Intentional deadband width for Unit 4, p.u. \\
\hline \multicolumn{2}{|c|}{ Lookup table for nonlinear gain on Unit 1} \\
\hline gv01 & Nonlinear gain point 1 , p.u. gv \\
\hline pgv01 & Nonlinear gain point 1 , p.u. power \\
\hline gv11 & Nonlinear gain point 2, p.u. gv \\
\hline pgv11 & Nonlinear gain point 2, p.u. power \\
\hline gv21 & Nonlinear gain point 3, p.u. gv \\
\hline pgv21 & Nonlinear gain point 3, p.u. power \\
\hline gv31 & Nonlinear gain point 4, p.u. gv \\
\hline pgv31 & Nonlinear gain point 4, p.u. power \\
\hline gv41 & Nonlinear gain point 5, p.u. gv \\
\hline pgv41 & Nonlinear gain point 5, p.u. power \\
\hline gv51 & Nonlinear gain point 6 , p.u. gv \\
\hline pgv51 & Nonlinear gain point 6, p.u. power \\
\hline \multicolumn{2}{|c|}{ Lookup table for nonlinear gain on Unit 2} \\
\hline gv02 & Nonlinear gain point 1, p.u. gv \\
\hline pgv02 & Nonlinear gain point 1 , p.u. power \\
\hline gv12 & Nonlinear gain point 2, p.u. gv \\
\hline pgv12 & Nonlinear gain point 2, p.u. power \\
\hline gv22 & Nonlinear gain point 3, p.u. gv \\
\hline
\end{tabular}




\begin{tabular}{|c|c|}
\hline Variable & Description \\
\hline pgv22 & Nonlinear gain point 3, p.u. power \\
\hline gv32 & Nonlinear gain point 4, p.u. gv \\
\hline pgv32 & Nonlinear gain point 4, p.u. power \\
\hline gv42 & Nonlinear gain point 5 , p.u. gv \\
\hline pgv42 & Nonlinear gain point 5, p.u. power \\
\hline gv52 & Nonlinear gain point 6, p.u. gv \\
\hline pgv52 & Nonlinear gain point 6, p.u. power \\
\hline \multicolumn{2}{|c|}{ Lookup table for nonlinear gain on Unit 3} \\
\hline gv03 & Nonlinear gain point 1 , p.u. gv \\
\hline pgv03 & Nonlinear gain point 1, p.u. power \\
\hline gv13 & Nonlinear gain point 2, p.u. gv \\
\hline pgv13 & Nonlinear gain point 2, p.u. power \\
\hline gv23 & Nonlinear gain point 3 , p.u. gv \\
\hline pgv23 & Nonlinear gain point 3, p.u. power \\
\hline gv33 & Nonlinear gain point 4 , p.u. gv \\
\hline pgv33 & Nonlinear gain point 4, p.u. power \\
\hline gv43 & Nonlinear gain point 5 , p.u. gv \\
\hline pgv43 & Nonlinear gain point 5, p.u. power \\
\hline gv53 & Nonlinear gain point 6, p.u. gv \\
\hline pgv53 & Nonlinear gain point 6, p.u. power \\
\hline \multicolumn{2}{|c|}{ Lookup table for nonlinear gain on Unit 4} \\
\hline gv04 & Nonlinear gain point 1, p.u. gv \\
\hline pgv04 & Nonlinear gain point 1, p.u. power \\
\hline gv14 & Nonlinear gain point 2, p.u. gv \\
\hline pgv14 & Nonlinear gain point 2, p.u. power \\
\hline gv24 & Nonlinear gain point 3, p.u. gv \\
\hline pgv24 & Nonlinear gain point 3, p.u. power \\
\hline gv34 & Nonlinear gain point 4, p.u. gv \\
\hline pgv34 & Nonlinear gain point 4, p.u. power \\
\hline gv44 & Nonlinear gain point 5, p.u. gv \\
\hline pgv44 & Nonlinear gain point 5, p.u. power \\
\hline gv54 & Nonlinear gain point 6, p.u. gv \\
\hline pgv54 & Nonlinear gain point 6, p.u. power \\
\hline
\end{tabular}




\subsection{An Example of the Prevalence of the Hydro Models in a WECC Region Database Using the PSLF Software}

Section 4.1 showed that the PSLF software package has a wide variety of models to represent hydro units. Some models are used much more often than others. To illustrate this, a typical representation of the Western U.S. power system was analyzed.

An official WECC PSLF power flow case named "17hw2a.sav," dated April 26, 2012, and the corresponding dynamics data file named "17hw21.dyd" of the same date were obtained and examined to demonstrate the governor/turbine models that are being used to represent hydro machines in the Western Interconnection for stability studies. Table 4-13 shows how often each hydro turbine-governor model is used. Note that this table is provided for illustrative purposes only and should not be construed to imply that any model is better than another model or that the results shown here are typical of those from other systems. Also note that some utilities may use more detailed models when studying dynamic phenomena associated with their particular plants.

The most commonly used hydro models in the Western Interconnection are the HYGOV, IEEEG3, HYG3, GPWSCC, and HYGOV4 models, all of which are used to represent more than $10 \%$ of the units.

Table 4-13 Governor/Turbine PSLF Models Used to Represent Hydroelectric Units in a Typical Western Interconnection Stability Database

\begin{tabular}{|l|l|c|c|}
\hline PSLF Model & \multicolumn{1}{|c|}{ Closest PSS ${ }^{\circledR}$ E Model } & $\begin{array}{c}\text { Number of } \\
\text { Occurrences }\end{array}$ & \% of Total \\
\hline HYG3 & WSHYGP and WSHYDD & 133 & 13.8 \\
\hline HYGOV & HYGOV and HYGOV4 & 257 & 26.7 \\
\hline HYGOV4 & HYGOV and HYGOV4 & 111 & 11.5 \\
\hline HYGOVR & & 14 & 1.5 \\
\hline HYST1 & & 0 & 0.0 \\
\hline PIDGOV & PIDGOV & 67 & 7.0 \\
\hline GPWSCC & WSHYGP and WSHYDD & 112 & 11.6 \\
\hline G2WSCC & WSHYDD & 34 & 3.5 \\
\hline HYPID & & 0 & 0.0 \\
\hline IEEEG3 & IEEEG3 & 232 & 24.1 \\
\hline W2301 & & 3 & 0.3 \\
\hline Total & & 963 & 100.0 \\
\hline
\end{tabular}


This page intentionally left blank. 


\section{Section}

\section{Modeling of Conventional Pumped Storage Hydro Plants}

Conventional pumped storage hydro (CPSH) units have many similarities to conventional hydro plants. The major difference is, of course, that the flow is bidirectional. Usually, but not always, the same equipment is used for both generation and pumping; thus, the synchronous generator also operates as a motor, and the hydro turbine also operates as a pump. Both components are therefore reversible in their functionality. Some plants, particularly those with very high heads, may require separate turbines and pumps.

In practical applications, the transition from a generating to a pumping mode of operation (or vice versa) is performed by the operator and takes several minutes (i.e., it is usually not a subject of dynamic simulation studies, except possibly for those used in the initial design of the plant). Thus, in most simulation studies, the generating and pumping modes of operation for CPSH units are studied separately. The system conditions being analyzed are appropriate for one mode or the other; for example, studies performed at peak load would model the units as generating while light load studies would model the units as pumping.

Although the following discussion is based on the PSS ${ }^{\circledR} E$ platform, the approach is applicable to any commercial simulation software package.

Suppose we are studying a CPSH plant that has six units, as shown in Figure 5-1. 


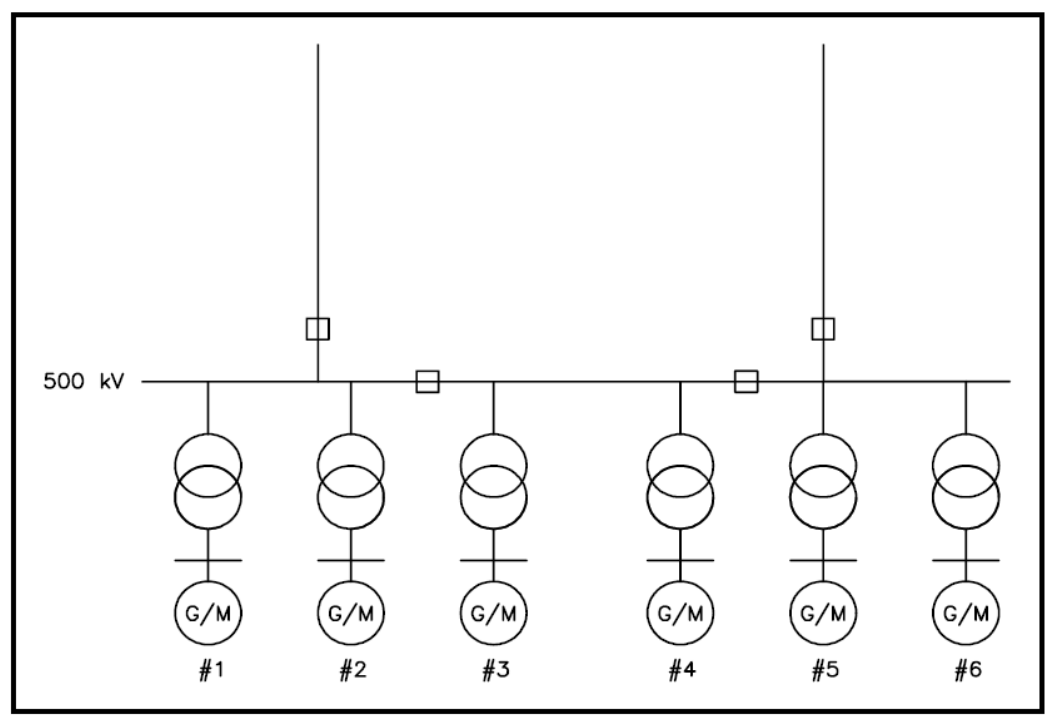

Figure 5-1 Electrical Configuration of the Plant

Since studies of both generating and pumping modes of operation are necessary, the load flow representation is created to handle both modes. It is convenient to represent each unit by two machines in the load flow and dynamic database, as shown in Figure 5-2. One machine represents the generating mode of operation, and the other machine represents the pumping mode.

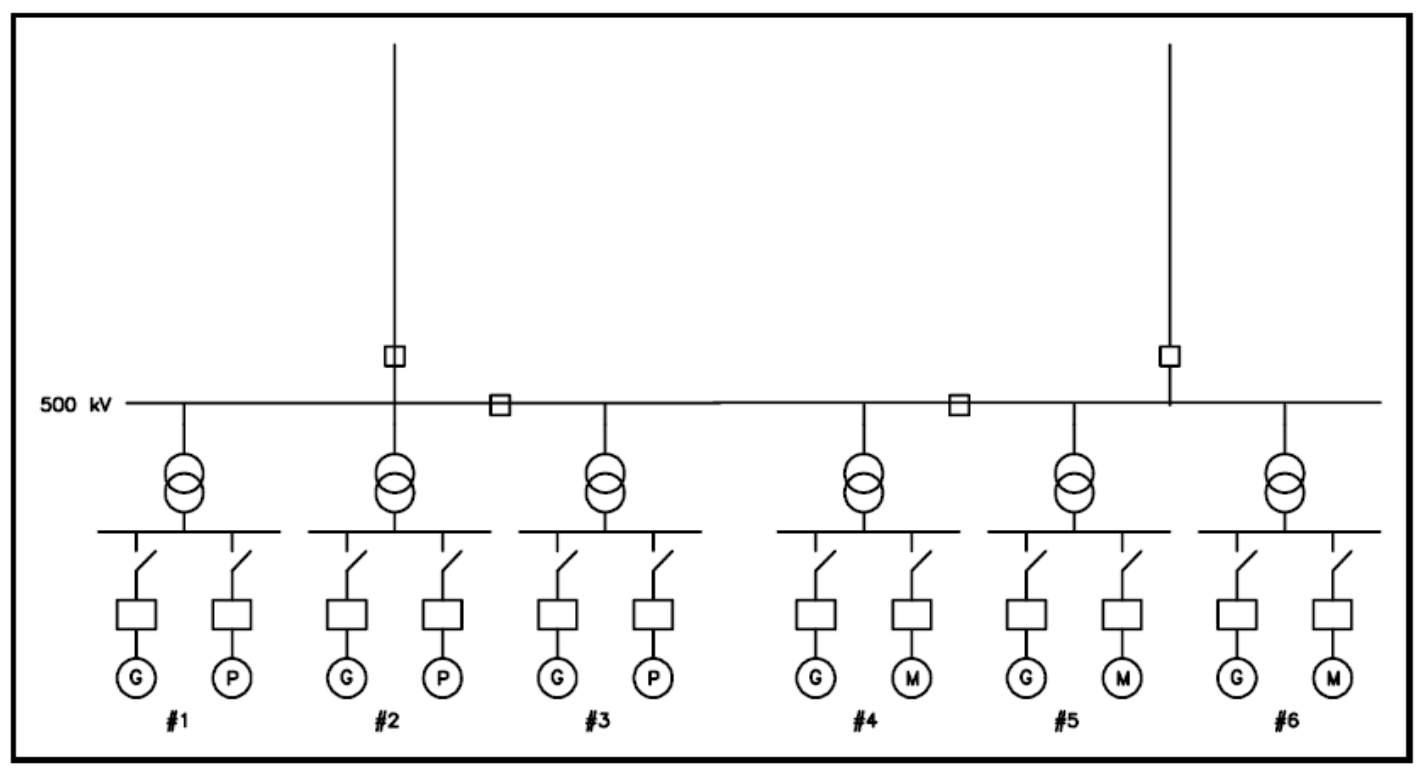

Figure 5-2 Plant Model for Electrical Network

Each of the machines is assigned a status parameter that allows the selection of either the generating or the pumping mode of operation. One can thus establish a load flow model to represent the generating conditions by turning "on" the machines that represent generators and turning "off" the machines that represent pumps. Using the opposite 
status will result in a load flow model for pumping operation. The dynamic simulation will recognize only the machines that are turned on in the load flow. Of course, only one of these machines can be online in a particular load flow case.

In the generating mode, the representation in the load flow case is exactly the same as that of a conventional hydro plant. During pumping, the electrical power consumed by the synchronous motor is negative in load flow.

The generator and pump can be represented by an identical set of generator and excitation system models. In PSS ${ }^{\circledR} E$, the dynamic simulation models GENSAL, GENSAE, and GENTPJ are generally used to simulate the salient pole hydro machines. As described in Section 1, there are many models available to represent the excitation system.

For the generating mode of operation, one of the available hydro turbine-governor models may be used. The discussion in Section 2 reveals different features of these models. Sometimes the specific design of the plant may necessitate the modification of these existing standard models or the development of new, user-written models to represent pertinent details of this equipment. For example, if several units share the same conduit, the model logic should be able to take into account that some of these units may be uncommitted for the system condition being analyzed.

To represent the hydro units in pumping operation, the "governor" model for the motor must be different from the governor model used when generating. First, generally there is no speed regulation. The operator opens and closes the gates under manual control, and the gate position remains fixed. Second, the pump head is substituted in place of the static head. The pump head is a function of the water flow, as shown in Figure 5-3 for a unit rotating at rated speed. This pump characteristic can be characterized by a quadratic equation whose coefficients can be derived from pump characteristics provided in the specifications or determined by testing. 


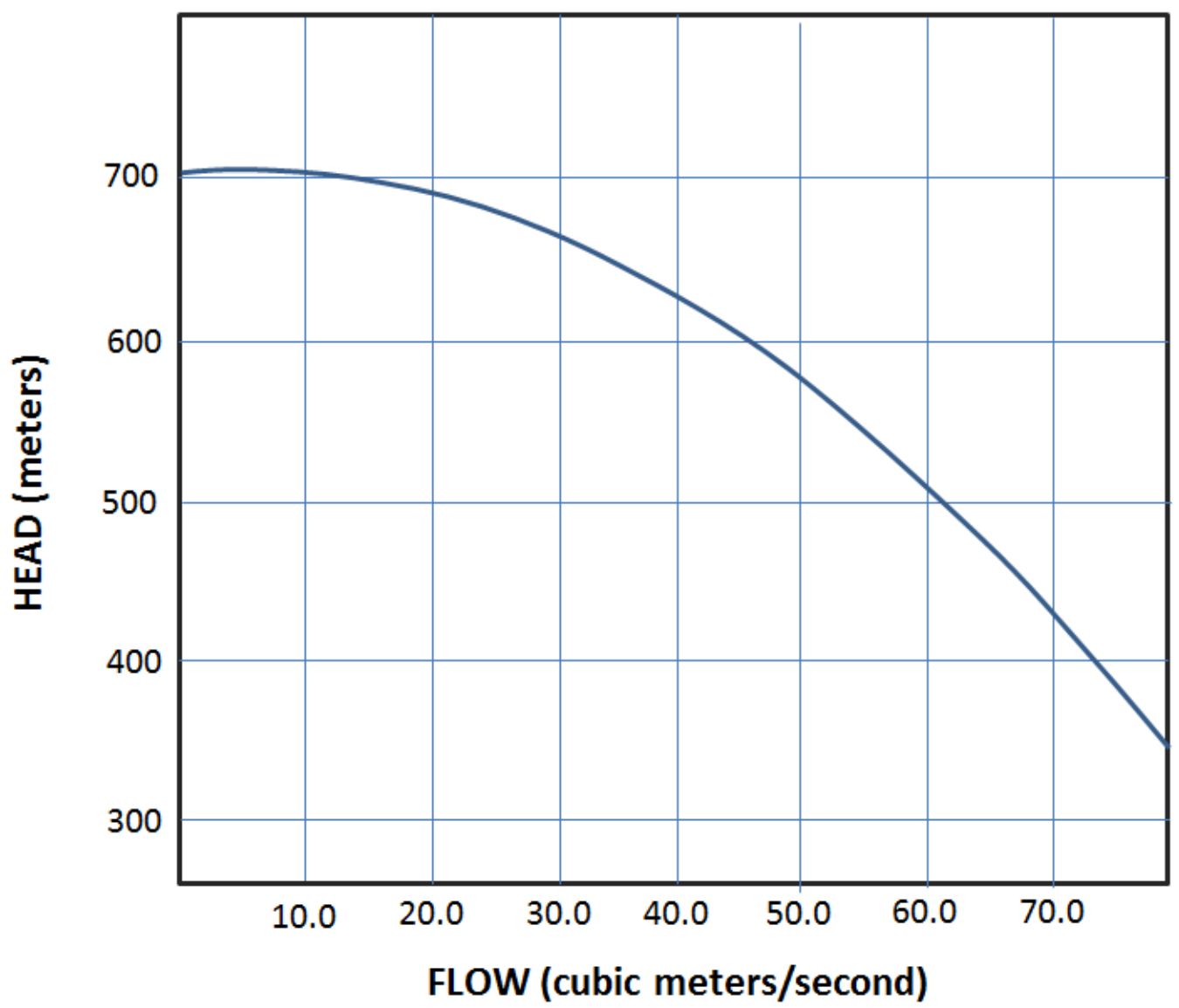

Figure 5-3 Pump Head Versus Water Flow

If speed deviations during transient conditions are noticeable, the flow, head, and power of the pump should be adjusted. The model allows adjustment per affinity laws proportionally to the speed, to the square of speed, and to the cube of speed, respectively, for flow, head, and power.

Mechanical power is calculated as the product of flow and head divided by efficiency. If sufficient data are available, look-up tables of flow versus gate position and of mechanical power versus flow can be represented in the model.

An example of the pump model is shown in the block diagram of Figure 5-4. 


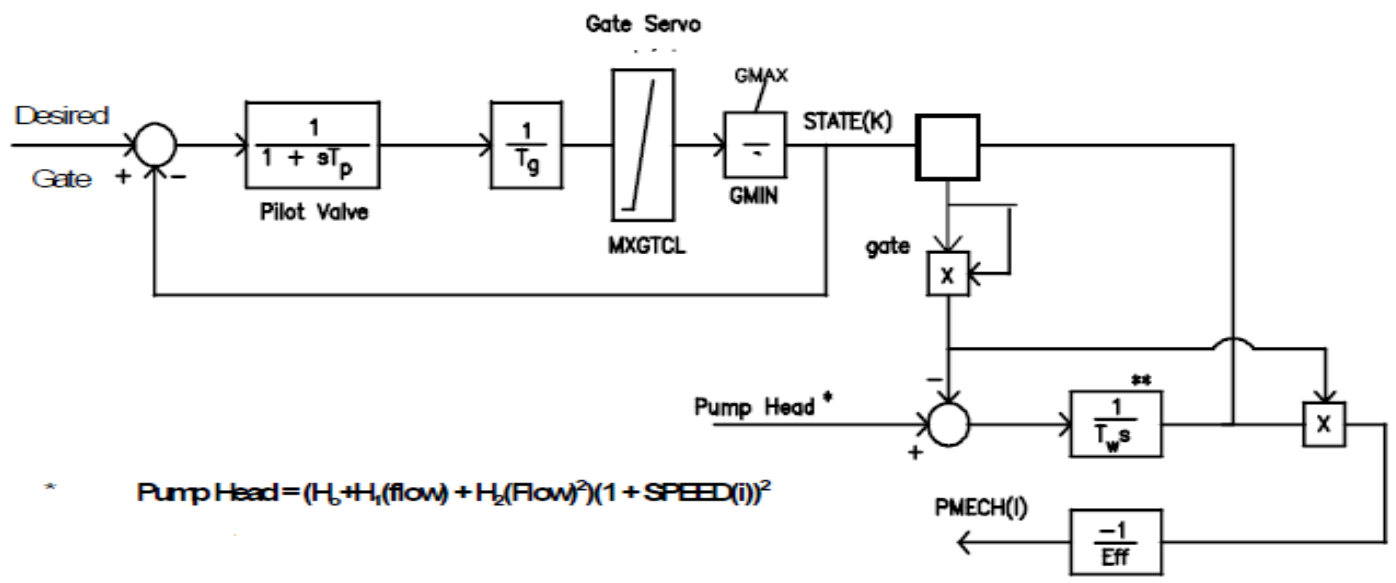

Figure 5-4 Block Diagram of Pump Model

The models and parameters for both the generating mode and the pumping mode of operation should be thoroughly tested. Such tests can be used to demonstrate some of the characteristics of the model that was just described. Regarding operation as a generator, one concern is the tuning of the speed governor. Usually, during this test (by simulation - not a field test), the plant is isolated and carrying a local load. During the governor test, the load is dropped by $5 \%$ to $10 \%$, and mechanical power and speed responses are monitored. The plots in Figure 5-5 illustrate the governor test for a hydro plant with three units sharing the same conduit for the conditions where one, two, and three units are online. The difference in response is due to the difference in flows depending on the number of units that are committed, resulting in a change in the hydraulic characteristics. Similar tests can be performed for an increase in load. 


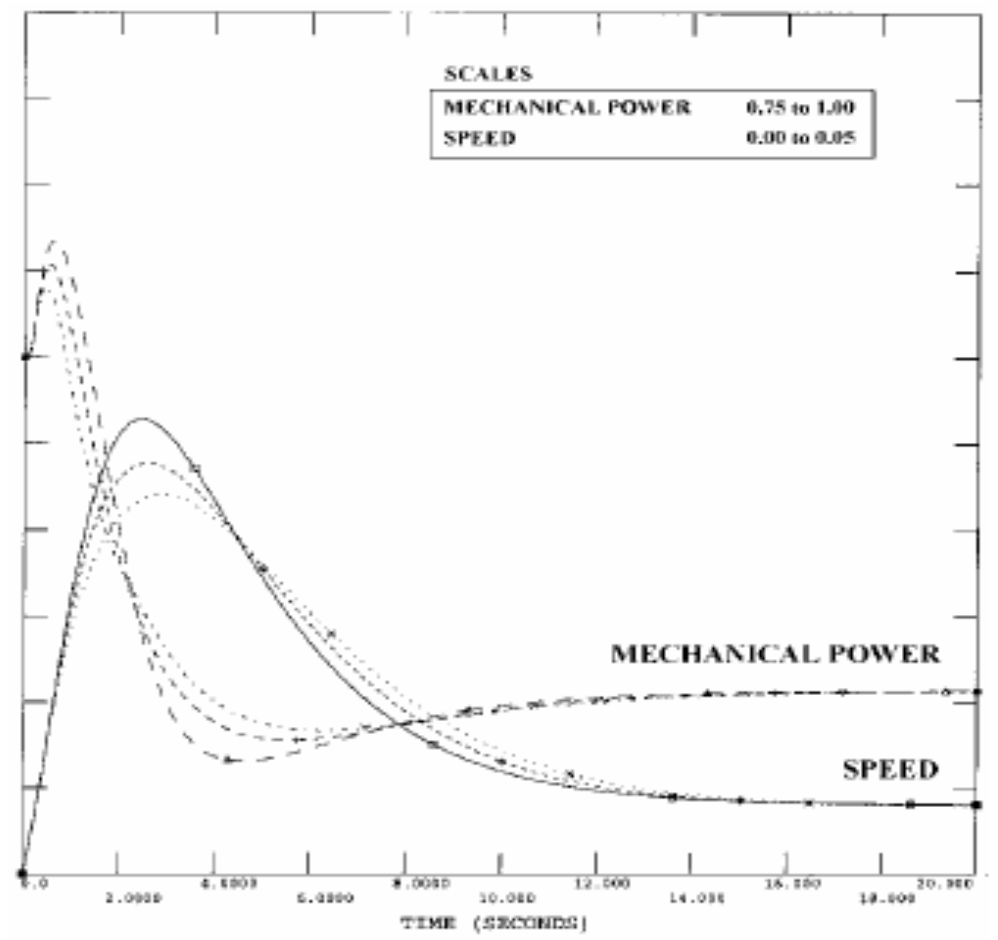

Figure 5-5 Comparison Plot for Different Plant Configuration for a 10\% Step Change in Load

In the pumping mode of operation, the features of the CPSH plant mentioned above (i.e., three units sharing a common tunnel) also result in some peculiarities. The initial plant conditions for the test illustrated in Figures 5-6 and 5-7 were that one unit (Pump 1) was online at partial load and the second unit was also online as a synchronous condenser. During the simulation, the gates for the second unit were opened with a ramp that reached the fully opened position in 10 seconds. Pump 1 experienced a drop in mechanical power and flow during the ramping of the gates of Pump 2. The initial surge in the drop in flow and power for Pump 1 was due to the initial increase in the flow of Pump 2. Because of inertial effects, there was no immediate change in flow in the common tunnel. The sudden drop in flow in Pump 1 produced a higher pumped head, which partially restored the flow. The flow in the common tunnel increased due to the increased pump pressure from both units. After the gates for Pump 2 stopped moving, the flows, gate positions, heads, and powers settled at steady-state values.

This illustrates that the models for the pumped storage unit can be used to represent a wide variety of operating conditions. 


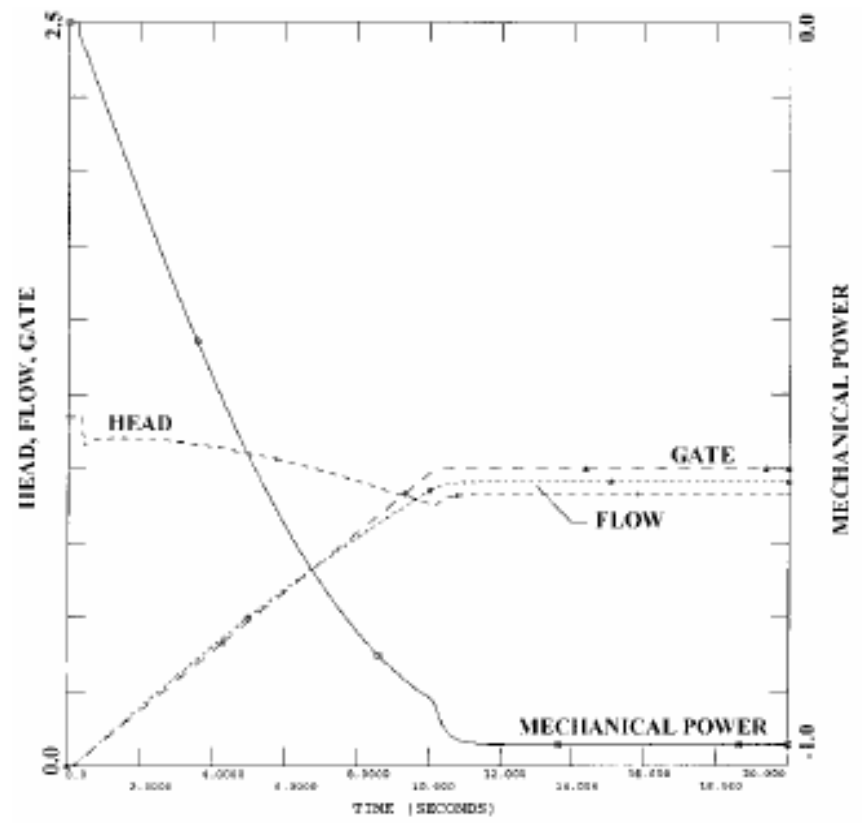

Figure 5-6 Response of Pump 2 during Startup of Pump 2

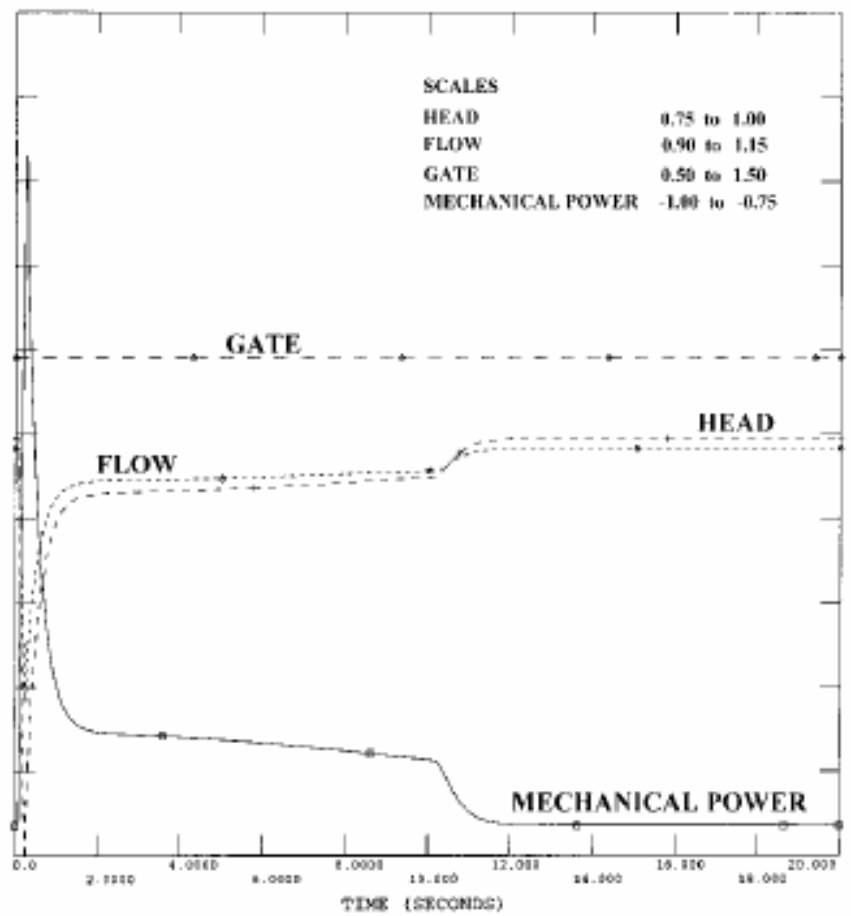

Figure 5-7 Response of Pump 1 during Startup of Pump 2 
This page intentionally left blank 


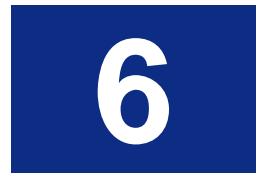

\section{Bibliography}

1. Agnew, P.W., "The Governing of Francis Turbines," Water Power, April 1974, pages 119-127.

2. IEEE Committee Report, "Dynamic Models for Steam and Hydro Turbines in Power System Studies," IEEE Transactions on Power Apparatus and Systems, Volume PAS-92, Issue 6, 1973, pages 1904-1915.

3. Hagihara, S., Yokota, H., Goda, K., and Isaobe, K., "Stability of a Hydraulic Turbine Generating Unit Controlled by PID Governor," Transactions on Power Apparatus and Systems, Volume 97, No. 6, Nov./Dec. 1979, pages 2294-2298.

4. Hannett, L.N., Feltes, J.W., Fardanesh, B., and Crean, W., "Modeling and Control Tuning of a Hydro Station with Units Sharing a Common Penstock Section," IEEE Transactions on Power Systems, Volume 14, Issue 4, 1999, pages 1407-1414.

5. Hannett, L.N., Lam, B.P., Prabhakara, F.S., Qiu Guofu, Ding Mincheng, and Bian Beilei, "Modeling of a Pumped Storage Hydro Plant for Power System Stability Studies," Proceedings of the International Conference on Power System Technology, POWERCON '98, 1998, Volume 2, pages 1300-1304.

6. IEEE Working Group Report, "Hydraulic Turbine and Turbine Control Models for System Dynamic Studies," IEEE Transactions on Power Systems, Volume 7, Issue 1, 1992, pages 167-179.

7. IEEE Guide for the Application of Turbine Governing Systems for Hydroelectric Generating Units, IEEE Std 1207-2011 (Revision to IEEE Std 1207-2004), June 20, 2011.

8. Kosterev, D., "Hydro Turbine-Governor Model Validation in the Pacific North West," IEEE Transactions on Power Systems, Volume 19, No. 2, May 2004, pages 11441149.

9. Kundur, P. Power System Stability and Control, McGraw-Hill Companies, Incorporated,1994.

10. Oldenburger, R., and Donelson, J., "Dynamic Response of a Hydroelectric Plant," Transactions AIEE, Volume 81, Part III, 1962, pages 403-418. 
11. Ramey, D.G., and Skooglund, J.W., "Detailed Hydrogovernor Representation for System Stability Studies," IEEE Transactions on Power Apparatus and Systems, Volume PAS-89, Issue 1, 1970, pages 106-112.

12. Sanathanan, C.K., "A Frequency Domain Based Method for Tuning Hydro Governors," IEEE Transactions on Energy Conversion, Volume 3, No. 1, March 1988, pages 14-17.

13. Schleif, F.R., and Wilbor, A.B., "The Coordination of Hydraulic Turbine Governors for Power System Operation," Transactions on Power Apparatus and Systems, Volume 85, July 1966, pages 750-758.

14. Strah, B., Kuljaca, O., and Vukic, Z., "Speed and Active Power Control of a Hydro Turbine Unit," IEEE Transactions on Energy Conversion, Volume 20, No. 2, June 2005, pages 424-434.

15. U.S. Army Corp of Engineers, Engineering and Design - Hydropower, Engineering Manual EM-1110-2-1701, December 1985.

16. U.S. Bureau of Reclamation, Selecting Hydraulic Reaction Turbines, Engineering Monograph EM20, 1976.

17. Undrill, J.M., and Woodward, J.L., "Nonlinear Hydro Governing Model and Improved Calculation for Determining Temporary Droop," IEEE Transactions on Power Apparatus and Systems, Volume 86, No. 4, 1967, pages 443-453.

18. Vournas, C.D., and Papaioannou, G., "Modeling and Stability of a Hydro Plant with Surge Tanks," IEEE Transactions on Energy Conversion, Volume 10, No. 2, June 1995, pages 368-375.

19. Woodward, J.L., "Hydraulic - Turbine Transfer Function for Use in Governing Studies," Proceedings IEEE, Volume 115, March 1968, pages 424-426. 
- 


\section{Argonne}

\section{Decision and Information Sciences}

Argonne National Laboratory

9700 South Cass Avenue, Bldg. 221

Argonne, IL 60439-4844

www.anl.gov 